\title{
Transport Membrane Condenser for Water and Energy Recovery from Power Plant Flue Gas
}

\author{
FINAL TECHNICAL REPORT
}

October 1, 2008 to March 31, 2012

by

Dexin Wang

Report Issued June 2012

DOE Award Number DE-NT0005350

Gas Technology Institute

1700 S Mount Prospect Rd

Des Plaines, IL 60016 


\section{Disclaimer}

"This report was prepared as an account of work sponsored by an agency of the United States Government. Neither the United States Government nor any agency thereof, nor any of their employees, makes any warranty, express or implied, or assumes any legal liability or responsibility for the accuracy, completeness, or usefulness of any information, apparatus, product, or process disclosed, or represents that its use would not infringe privately owned rights, Reference herein to any specific commercial product, process, or service by trade name, trademark, manufacturer, or otherwise does not necessarily constitute or imply its endorsement, recommendation, or favoring by the United States Government or any agency thereof, The views and opinions of authors expressed herein do not necessarily state or reflect those of United States Government or any agency thereof." 


\section{ACKNOWLEDGEMENTS}

In addition to the U.S. Department of Energy, the authors of this report are extremely grateful to Illinois Clean Coal Institute for supporting this project.

The authors are grateful to Dr. Paul Liu, and Dr. Richard Ciora, Jr. from Media and Process Technology Inc.; and Dr. Zhanhua Ma and Dr. Heyang Wang from SmartBurn LLC for supporting this project.

The authors are also grateful to the members of Gas Technology Institute project team, which includes Mr. Walter Kunc, Dr. John Wagner and Dr. Ainan Bao. 


\begin{abstract}
The new waste heat and water recovery technology based on a nanoporous ceramic membrane vapor separation mechanism has been developed for power plant flue gas application. The recovered water vapor and its latent heat from the flue gas can increase the power plant boiler efficiency and reduce water consumption. This report describes the development of the Transport Membrane Condenser (TMC) technology in details for power plant flue gas application. The two-stage TMC design can achieve maximum heat and water recovery based on practical power plant flue gas and cooling water stream conditions. And the report includes:
\end{abstract}

- Two-stage TMC water and heat recovery system design based on potential host power plant coal fired flue gas conditions.

- Membrane performance optimization process based on the flue gas conditions, heat sink conditions, and water and heat transport rate requirement.

- Pilot-Scale Unit design, fabrication and performance validation test results. Laboratory test results showed the TMC system can exact significant amount of vapor and heat from the flue gases. The recovered water has been tested and proved of good quality, and the impact of $\mathrm{SO}_{2}$ in the flue gas on the membrane has been evaluated.

- The TMC pilot-scale system has been field tested with a slip stream of flue gas in a power plant to prove its long term real world operation performance.

- A TMC scale-up design approach has been investigated and an economic analysis of applying the technology has been performed. 


\section{Table of Content}

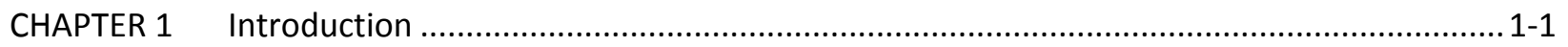

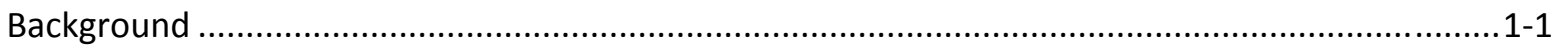

TMC Technology Concept and Development History ................................................................. 1-3

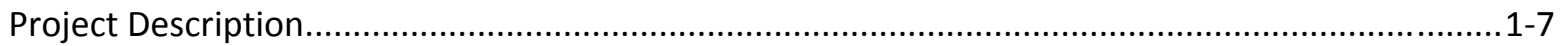

CHAPTER 2 Coal Power Plant Flue Gas Evaluation and TMC Concept Design ...................................2-1

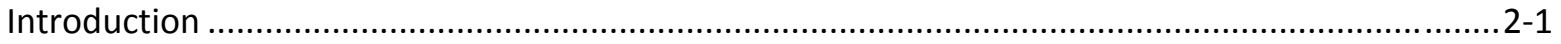

Power Plant Flue Gas Condition Analysis.................................................................................. 2-1

A Two-stage TMC Concept Design for Power Plant Water/Steam Cycle..........................................2-6

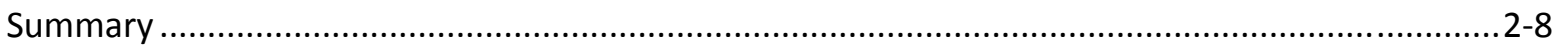

CHAPTER 3 TMC Membrane Performance Evaluation and Selection................................................ 3-1

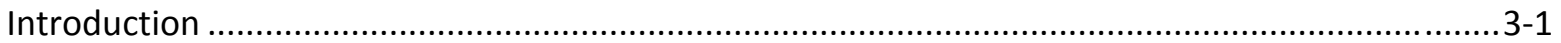

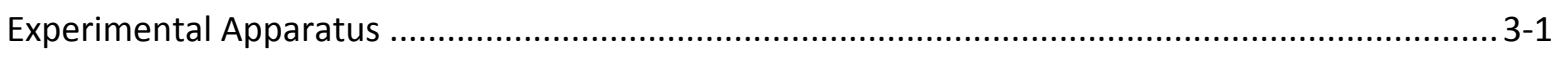

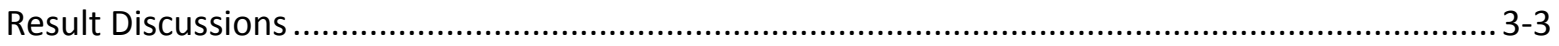

CHAPTER 4 Pilot-Scale TMC Design, Fabrication and Performance Test ............................................ 4-1

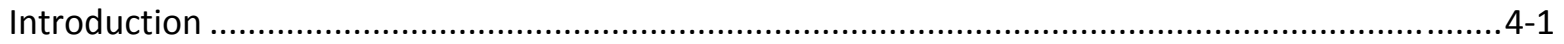

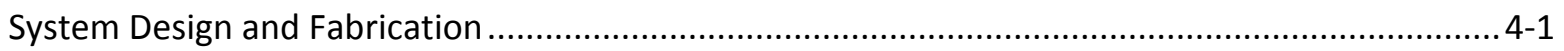

Pilot-Scale Unit Performance Test ........................................................................................... 4-4

CHAPTER 5 Pilot-Scale TMC Field Testing at a Power Plant............................................................. 5-1

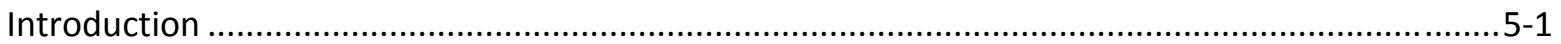

TMC Field Test System Setup ........................................................................................... $5-1$

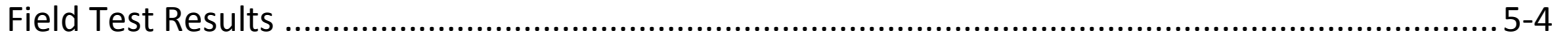

Summary

CHAPTER 6 TMC Waste heat and Water Recovery System Scale-Up Design Investigation .................6-1

Scale up investigation for a 550MW power plant ....................................................................... $6-1$

CHAPTER 7 Technology Application and Commercialization.......................................................... $7-1$

TMC technology application and economic analysis ................................................................ 7-2

TMC technology commercialization path ........................................................................ $7-6$ 


\section{LIST OF FIGURES}

Figure 1-1: TMC concept schematic. $1-5$

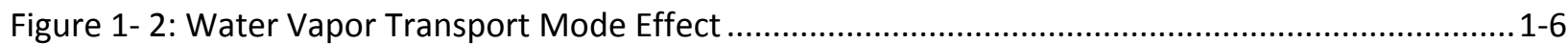

Figure 1- 3: Photomicrograph of TMC Membrane Cross-Section...................................................... 1-6

Figure 1-4: New Membrane Module (left),Version 1.0 and 2.0 TMC Design (middle), and an installed unit

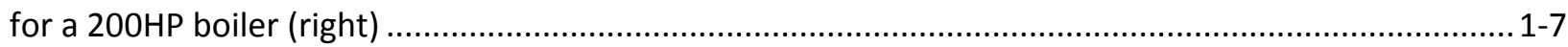

Figure 2-1: Typical fly ash particle size distribution from a plant using western Elk Coal .......................2-6

Figure 2-2: Power Plant Flue Gas Heat and Water Recovery with a Two-Stage TMC ............................2-8

Figure 3-1: Lab TMC module performance test setup ..................................................................... 3-2

Figure 3-2: Lab size TMC module with Garolite material and new adhesive ....................................... 3-2

Figures 3-3 Water transport rate vs. inlet flue gas temperature............................................................ 3-4

Figures 3-4 Water transport rate vs. water inlet temperature and water flow rate.............................3-4

Figures 3-5 Water transport rate under different vacuums ................................................................. 3-5

Figure 3-6: TMC/Stage 1 different membrane pore size effect on water transfer..................................3-6

Figure 3-7: TMC/Stage 1 different membrane pore size effect on heat transfer .................................... 3-6

Figure 3-8: High moisture flue gas effect on water transport .........................................................

Figure 3-9: High moisture flue gas effect on heat transfer ..............................................................

Figure 3-10: Different membrane pore size effect on water transport.................................................. 3-8

Figure 3-11: Different membrane pore size effect on heat recovery ................................................. $3-9$

Figure 3-12: Photograph of the membranes following fouling test. ................................................. 3-11

Figure 3-13: Photograph of black debris on the membranes following fouling test...............................3-12

Figure 4-1: TMC test setup layout drawing (boiler and economizer are not shown) ...............................4-2

Figure 4-2: Long TMC module designed and made for utility boiler application .....................................4-2

Figure 4-3: pilot-scale TMC unit test system with the boiler on the right side ...................................... 4-3

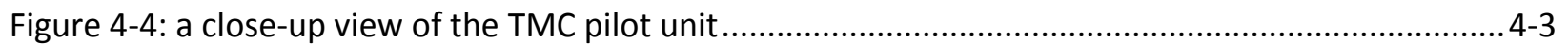

Figure 4-5: Different pore size membrane modules used for different TMC test settings ...................... 4-6

Figure 4-6: Stage 1 water average temperature effect for different TMC settings...............................4-7

Figure 4-7: Stage 2 water average temperature effect for different TMC settings................................. 4-7

Figure 4-8: Stage 1 water inlet temperature effect for different TMC settings .................................... 4-8

Figure 4-9: Stage 1 water average temperature effect for different TMC settings................................ 4-9

Figure 4-10: Stage 2 water average temperature effect for different TMC settings.............................. 4-9

Figure 4-11: Stage 1 water flow rate effect ..................................................................................... 4-11

Figure 4-12: Stage 1 water inlet temperature effect .................................................................. 4-11

Figure 4-13: Stage 2 water flow rate effect .............................................................................. 4-12

Figure 4-14: Stage 2 water inlet temperature effect .................................................................... 4-12

Figure 4-15: Flue gas inlet temperature effect. ......................................................................... 4-13

Figure 4-16: Flue gas inlet moisture content effect.......................................................................... 4-13



Figure 4-18: Stage 2 average temperature effect............................................................................. $4-14$

Figure 4-19: Stage 1 heat transfer coefficient vs. flow rate................................................................ 4-15

Figure 4-20: Stage 2 heat transfer coefficient vs. flow rate................................................................ 4-15 
Figure 4-21: Stage 1 water flow rate effect on heat recovery.

Figure 4-22: Stage 1 water inlet temperature effect on heat recovery.

Figure 4-23: Stage 2 water flow rate effect on heat recovery .............................................................. 17

Figure 4-24: Stage 2 water inlet temperature effect on heat recovery............................................... 17

Figure 4-25: Flue gas inlet temperature effect on heat recovery....................................................... 18

Figure 4-26: Flue gas inlet moisture content effect on heat recovery .................................................... 18

Figure 4-27: Stage 1 water average temperature effect for heat recovery .......................................... 4-19

Figure 4-28: Stage 2 water average temperature effect for heat recovery ..................................... 4-19

Figure 4-29: Stage 1 water average temperature effect before and after SO2 injection....................... 4-22

Figure 4-30: Stage 2 water average temperature effect before and after SO2 injection....................... 4-22

Figure 4-31: Stage 1 water average temperature effect before and after SO2 injection at high moisture content

Figure 4-32: Stage 2 water average temperature effect before and after SO2 injection at high moisture content

Figure 5-2: picture of the test system installation location before installation .......................................5-3

Figure 5-3: Pilot unit in the field: left shows in installation, right shows in testing with a tent ................5-4

Figure 5-4: Flue gas pressure drop through the pilot unit for the whole long term test period..............5-5

Figure 5-5: The pilot unit overall water recovery rate for the long term test period..............................5-6

Figure 5-6: the pilot unit overall heat recovery rate for the long term test period ..................................5-6

Figure 5-7: Water transport rates at the beginning and at the end of the long term field test................5-7

Figure 5-7: Laboratory test and field test TMC performance comparison .......................................... 5-8

Figure 6-1: TMC module arrangement in one of the $550 \mathrm{MW}$ unit flue gas ductwork ...........................6-2

Figure 6-2: Power Plant Flue Gas Water Recovery with a Two-Stage TMC .......................................... 6-3

Figure 7-1: Water usage in a coal fired power plant (source: NETL) ................................................... 7-3 


\section{LIST OF TABLES}

Table 2-1: Typical flue gas composition for a FGD unit ...................................................................... 2-3

Table 2-2:Typical coal power plant operation information .................................................................. $2-4$

Table 2-3: Condensate and cooling water streams for several coal power plants...................................2-5

Table 3-1: membrane transport rate changes after 100 hour fouling test with natural gas flue ............3-10

Table 3-2: membrane transport rate changes after 100 hour test with 200ppm SO2 flue gas ..............3-12

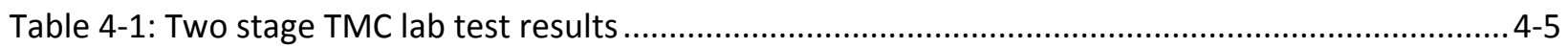

Table 4-1: Water Quality Testing without SO2 ................................................................................ 4-21

Table 4-2: Water Quality Testing with 250ppm SO2 ….................................................................. 4-21

Table 5-1: Host site flue gas components by measurement .............................................................. $5-4$

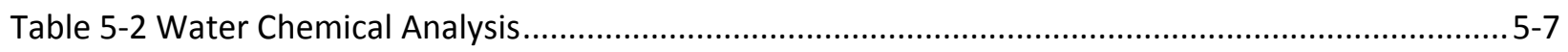

Table 6-1: A 550 MW boiler operating condition .......................................................................... 6-1

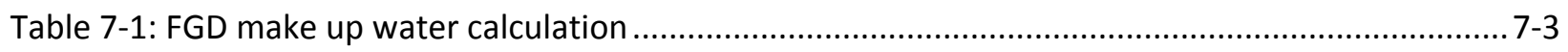

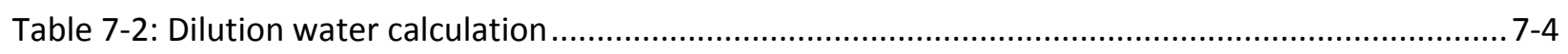

Table 7-3: TMC system cost benefit analysis ................................................................................. $7-5$ 


\section{EXECUTIVE SUMMARY}

An innovative waste heat and water recovery technology based on a nanoporous ceramic membrane vapor separation mechanism has been developed, to exact the water vapor and its latent heat from low temperature high moisture content waste gas streams. And this Transport Membrane Condenser (TMC) technology was further developed into a two stage design for coal fired power plant applications. The new design can achieve maximum heat and water recovery, based on practical power plant flue gas and cooling water conditions. The recovered high-quality water and heat can be used to preheat and replace part of the power plant boiler makeup water and other plant water usage; as a result, the TMC technology can increase the boiler efficiency and decrease the plant water consumption. .

This report, the final technical report for DOE project DE-NT0005350, describes the technology development of the TMC system for water and waste heat recovery from power plant flue gases. In particular, this report includes power plant flue gas data evaluation and the two stage TMC system design process; the membrane performance optimization process based on information from potential host power plants; pilot-scale unit design, fabrication and performance validation test in a laboratory environment; long term pilot-scale TMC unit performance testing for a power plant flue gas slip stream; and the TMC system scale-up design and TMC technology potential commercialization paths.

Two-stage TMC system engineering design: Based on power plant data collected and analyzed, the project team designed and evaluated the TMC system with two separate cooling water streams to enhance the water and heat recovery. The first-stage TMC inlet water will be obtained from steam condensate from the condenser, and its outlet water with recovered water vapor and associated latent heat from flue gas will go to the deaerator for boiler water makeup. The second-stage TMC inlet water will be part of the condenser cooling water stream, the outlet water from this TMC stage will then be routed to go back to the cooling water stream with extra recovered water from the flue gas.

Membrane performance optimization: Based on power plant flue gas and cooling water conditions, membrane performance modeling and optimization work has been carried out. The water and heat transport rate requirement and membrane fouling prevention requirement have been used to determine the membrane and substrate material and structure. Laboratory testing results showed that the membrane selection and optimization, especially on the membrane pore size and porosity, can help both stages of the TMC unit to achieve required water and heat transfer rates, and reduce the membrane fouling effect.

Pilot-scale unit design, fabrication, and performance validation testing: A pilot-scale TMC unit has been designed, fabricated, and assembled at Gas Technology Institute (GTI) 
Combustion Laboratory. A test setup was also configured at GTI for the TMC laboratory testing, which includes a 3-million-But/hr natural gas-fired boiler and gas component simulation system to match coal-fired flue gas components. The performance validation testing results showed the TMC system, at the specific parametric ranges based on potential host power plant conditions, can recover a significant amount of water and heat. The water quality testing, high vapor concentration flue gas testing and flue gas spiked with $\mathrm{SO}_{2}$ testing also validated the TMC system performance at various conditions.

Pilot-scale unit field long term testing: The pilot-scale unit with full instrumentation and control was installed at a host power plant at Baltimore, MD. A slip stream of the coal-fired flue gas was used for the continuous five-week testing. The results demonstrated the TMC water and heat recovery system can achieve stable and reliable performance under a real world operating conditions.

Scale-up Design and TMC Technology Commercialization Path: A system scale-up evaluation has been carried out for a typical $550 \mathrm{MW}$ power plant, with potential integration strategy into the plant water loop. The TMC technology application in a power plant and its potential economic impact has been analyzed, and the technology preliminary commercialization path has been outlined. 


\section{CHAPTER 1 \\ Introduction}

\section{Background}

As fresh water is becoming a less abundant natural resource, retrieving water from different waste water sources, such as industrial waste water, brackish water, produced water, as well as sea water, becomes a promising choice to produce fresh water. But these processes are typically energy intensive, no matter it is a thermal process or a membrane separation process, therefore they are still not cost competitive for wide commercial use. On the other hand, there is another waste water source that was not given enough attention, the water vapor contained in many waste gas streams, which is present in many industrial and power generation processes. Minimum external energy source will be needed to recover these water because they themselves are already at high energy status. Also, the water vapor latent heat of these waste gas streams, is substantial compared with the sensible heat associated with the temperatures of these streams; these vapor can release significant amount of heat when turned to liquid phase. As a result, recovery of these waste water vapors can also greatly improve the overall industrial process thermal efficiency.

For instance, a large portion of energy consumed today comes from hydrocarbon fuel combustion, and one of the major combustion products of this combustion is water vapor [1]. For a coal-fired power plant boiler equipped with a wet Flue Gas Desulfurization (FGD) unit, flue gas exits at 160 to $180^{\circ} \mathrm{F}$ with nearly $100 \%$ relative humidity, contains about $40 \%$ in volume of water vapor. For a coal-fired power plant boiler with a dry FGD, the flue gas moisture content is still comparable with the industrial gas-fired flue gas, with a dew point at 130 to $140^{\circ} \mathrm{F}$, or about $20 \%$ in volume of water vapor in the flue gas stream. If 40 to $60 \%$ of this water vapor and its latent heat could be recovered and reused, the plant thermal efficiency can be significantly improved besides the water recovery benefit.

Until now, there has been no practical commercial technology available for recovering waste heat and water vapor from the power plant flue gases. Condensing flue gas moisture by simply removing heat in a heat exchanger presents the problem of a large surface area 
requirement for the low-temperature flue gas, and also raises the issue of equipment corrosion by the acidic condensate. The recovered water needs further treatment before it can be used for any other processes, due to the high acidity and other contaminates that may present in the water.

Gas Technology Institute (GTI) has developed a new technology based on a nanoporous ceramic separation membrane to extract a portion of the water vapor and its latent heat from flue gases and return the recovered water and heat to the steam cycle. This is achieved through the use of its patented Transport Membrane Condenser (TMC). Water vapor condenses and passes through the membrane, which has the permeate side in direct contact with a low-temperature water stream. Contaminants such as $\mathrm{CO}_{2}, \mathrm{O}_{2}, \mathrm{NOx}$, and $\mathrm{SO}_{2}$ are inhibited from passing through the membrane by its high selectivity. The recovered water is of high quality and mineral free, therefore can be used as supplemental makeup water for other processes. The TMC has been developed and proven at industrial demonstration scale for gasfired package boilers and commercial laundry application, and already commercialized. The TMC technology was developed by GTI as a key component for high-efficiency Super Boiler program, which was sponsored by the United States Department of Energy (DOE) and other industrial sponsors started in 2000.

This project aimed at developing a new two-stage TMC design for recovering water vapor and its latent heat from power plant flue gases. The new two-stage TMC seeks to achieve maximum heat and water recovery. The recovered high-purity water and heat can be used directly to replace power plant boiler makeup water to improve its efficiency, and any remaining recovered water can be used for FGD water makeup or other plant uses. The TMC technology will be particularly beneficial to coal-fired power plants that use high-moisture coals and/or FGD for flue gas cleanup. The TMC can be used to process high-moisture flue gas from the FGD to recover its water vapor and latent heat to increase boiler efficiency and decrease its water consumption.

The economic benefits of water vapor removal from flue gas are substantial. GTI calculates a reduction in the flue gas dew point from $140^{\circ} \mathrm{F}$ down to $100^{\circ} \mathrm{F}$, which corresponds to recovering $84 \mathrm{lb} / \mathrm{h}$ water per 1 million Btu/h firing rate. For the year 2000, the net U.S. 
electric power generation was 3,802 billion kWh, of which coal-fired generation was 1,966 billion kWh, and natural gas-fired generation was another 613 billion kWh. [2] Because this water recovery technology could be used for both coal- and gas-fired power plants, up to 2,579 billion kWh of capacity could be impacted by this technology. Assuming 35\% baseline fuel-toelectricity efficiency, the total firing rate is estimated at 25 trillion Btu/h. The corresponding total water saving, if this technology were applied to all U.S. power generation, would be 8.3 billion tons per year. At a typical treated water price of $\$ 0.52 /$ ton [3], the total annual U.S. cost saving in water alone would be $\$ 4.3$ billion/year. Additionally, the use of TMC can increase boiler thermal efficiency by $0.1-0.2 \%$ as described above by recovering the water vapor latent heat. This efficiency increase would increase power output by 3.0 billion kWh nationwide.

\section{TMC Technology Concept and Development History}

Membrane separation technology has been used commercially for many years for gas separation and liquid filtration, and features low energy cost and high separation ratio compared with competing separation methods. There are two kinds of membranes, porous and non-porous. For porous membranes, the pore size is normally in the sub-micron (nanoporous) range, and varies for different applications. To achieve a good separation ratio with a porous membrane for gaseous species, including the separation of water vapor from flue gas, the typical pore size must be less than $50 \mathrm{~nm}$. Water vapor transport through a porous ceramic membrane must follow some combination of the following four modes: Knudsen diffusion, surface diffusion, capillary condensation, and molecular sieving.

For water vapor, molecular sieving mode can only occur when the pore size of membrane is smaller than $1 \mathrm{~nm}$. The pore size used in the TMC is $4 \mathrm{~nm}$ and larger, so this mode does not apply. This operating mode can achieve high separation ratio, but the permeate flux is too low for bulk separation applications. For the Knudsen and surface diffusion modes, water vapor passes through the membrane pores essentially in the gas phase, as can many other gas components, but the water vapor molecules transport faster because of their lower molecular weight. Water vapor separation ratio in these modes is not high. The permeate flux is also too low at the water vapor partial pressure difference presented in the flue gas. 
But when one of the gas components is a condensable vapor and the pores are small, capillary condensation can occur. In this case, the condensate can block gas phase diffusion through the pores, allowing only the condensed phase to pass through. The Kelvin equation predicts that condensation can occur in small pores even though the partial pressure of that component is below its vapor pressure. In most cases, capillary condensation begins to occur at $50-80 \%$ of the saturation vapor pressure-which in the case of water is equal to relative humidity-because of the surface tension in the pores. As a result, the pores can be completely filled with condensed water. The flux of other components in the flue gas through the membrane will be very small, limited by their solubility in water and by the limited mobility of solvated molecules. Thus, a very high separation ratio can be achieved for water vapor. Also, under the same pressure difference across the membrane, H2O mass transport rate in liquid phase can be as high as 40 times the rate in the gas phase. This is mainly due to the more than a thousand-fold difference of their densities, although viscosity change adversely affects liquid transport, but much less than the favorable effect of density. The above evidence proves that membrane water vapor separation in a capillary condensation mode can promote both a high transport rate and a high separation ratio.

GTI has investigated water vapor transport from flue gas using both non-porous and porous membranes. The conclusion was that a nanoporous ceramic membrane can achieve both high water vapor transport rate and high separation ratio when it works at favorable capillary condensation conditions. For flue gas from natural gas firing, the flue gas moisture content is typically at $18 \%$ in volume for the high hydrogen element content in the fuel. With coal firing, the moisture produced from combustion itself is usually lower for the lower hydrogen content of coal. But for high moisture content coals and plants equipped with FGDs, the flue gas humidity is comparable or much higher than the natural gas firing flue gas. This provides a favorable condition for extracting water vapor from their flue gases. In the TMC, water vapor from flue gas passes through a permselective membrane (Figure 1-1), and is condensed by direct contact with low-temperature water. In this way, the transported water is recovered along with virtually all of its latent heat. The conditioned flue gas leaves the TMC at a reduced temperature and relative humidity below saturation. 


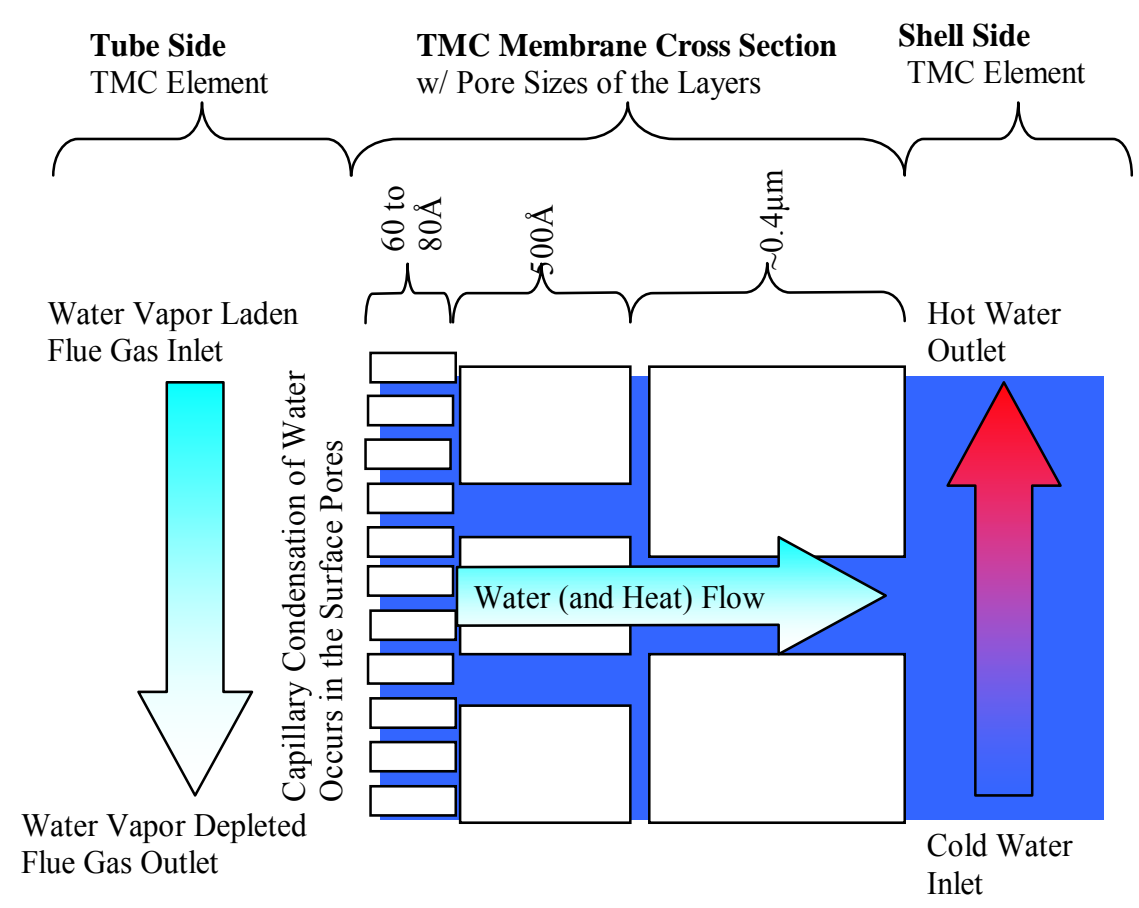

Figure 1-1: TMC concept schematic

GTI experimental data in Figure 1-2, shows that the water vapor transport rate in capillary condensation mode is more than five-fold higher than in its gas phase Knudsen diffusion mode. GTI has also done extensive studies on other factors that affect the ceramic membrane transport performance, including membrane pore size, permeate side vacuum, water inlet temperature, flow rate, flue gas inlet temperature, and flue gas humidity. These fundamental test data provide a solid foundation for the development of the TMC unit. Figure 1-3 shows the typical ceramic membrane structure and pore size distribution used for the TMC (refer back to Figure 1-1). It consists of a top layer with a pore size of 60 to $80 \AA$ ( 2 to $4 \mu \mathrm{m}$ thick), a $500 \AA ̊$ pore size intermediate layer (typically 20 to $50 \mu \mathrm{m}$ thick), and a $\sim 0.4 \mu \mathrm{m}$ pore size substrate ( $1 \mathrm{~mm}$ thick). This is called an "asymmetric" structure and is used for both polymeric and ceramic nanoporous separation membranes to achieve high separation ratio with minimal resistance to flux of the permeating species. 


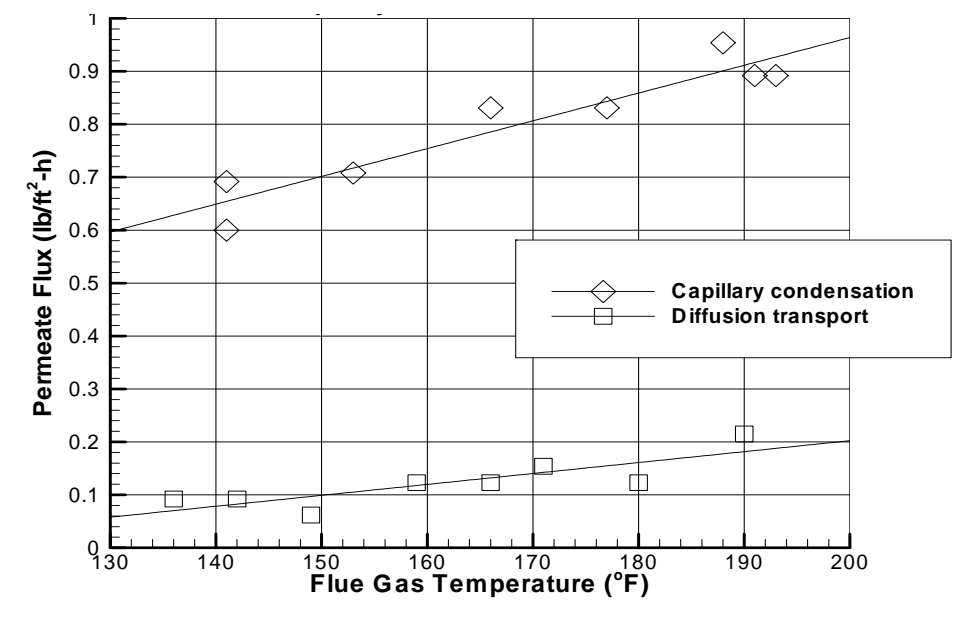

Figure 1- 2: Water Vapor Transport Mode Effect

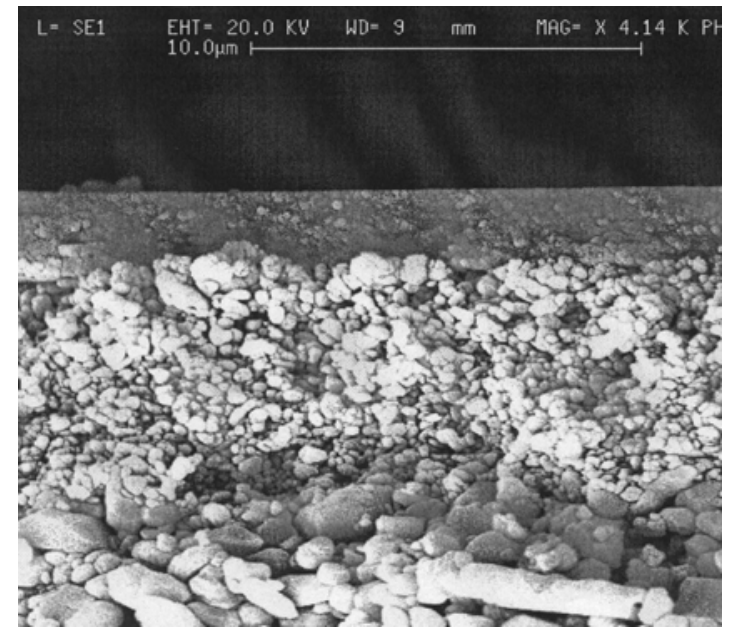

Figure 1- 3: Photomicrograph of TMC Membrane Cross-Section

GTI has already demonstrated the use of the TMC in four industrial gas-fired boilers for long-term operations, with the first unit being in continuous operation for nearly three years with no detectable performance degradation. The customer has confirmed $12 \%$ fuel saving and $20 \%$ makeup water saving. However, economic analysis showed that the earlier version of the TMC (version 1.0) was too expensive to manufacture, assemble, and maintain. As a result, GTI has developed a version 2.0 design of the TMC for industrial and commercial boilers with more cost-effective characteristics. With water flowing inside the tubes, the water side management allows a more flexible design, with the TMC to be designed with several passes (Figure 1-4 shows a three-pass design). Hot water can be pumped out from the lower section of the TMC instead of the upper section, which results in simplified water level controls. Another important advantage of the new design is that flue gas now flows upwards instead of 
downwards as in the previous TMC, allowing the unit to be mounted directly on top of a boiler stack without the lengthy ductwork needed to direct the flue gas downwards and then reverse direction to go upwards to the atmosphere. This greatly reduces the installation cost. Also shown in Figure 1-4 is the larger tube count of the new membrane module - a four-fold increase - which reduces manufacturing and assembly cost. An optimum spacing between tubes allows flue gas to flow through with a favorable tradeoff between turbulence and pressure drop. The tubes are protected from both sides by metal plates, which also reinforce the overall module structure strength. For a typical 300 HP industrial boiler, only 9 of these modules is needed instead of 94 modules in the original TMC design, which facilitates assembly and service. Figure 1-4 also shows the first Version 2.0 TMC unit installed on a 200HP natural gas fired boiler. The redesigned TMC is more efficient and cost-effective, and the modular design is more friendly for assembly and maintenance.
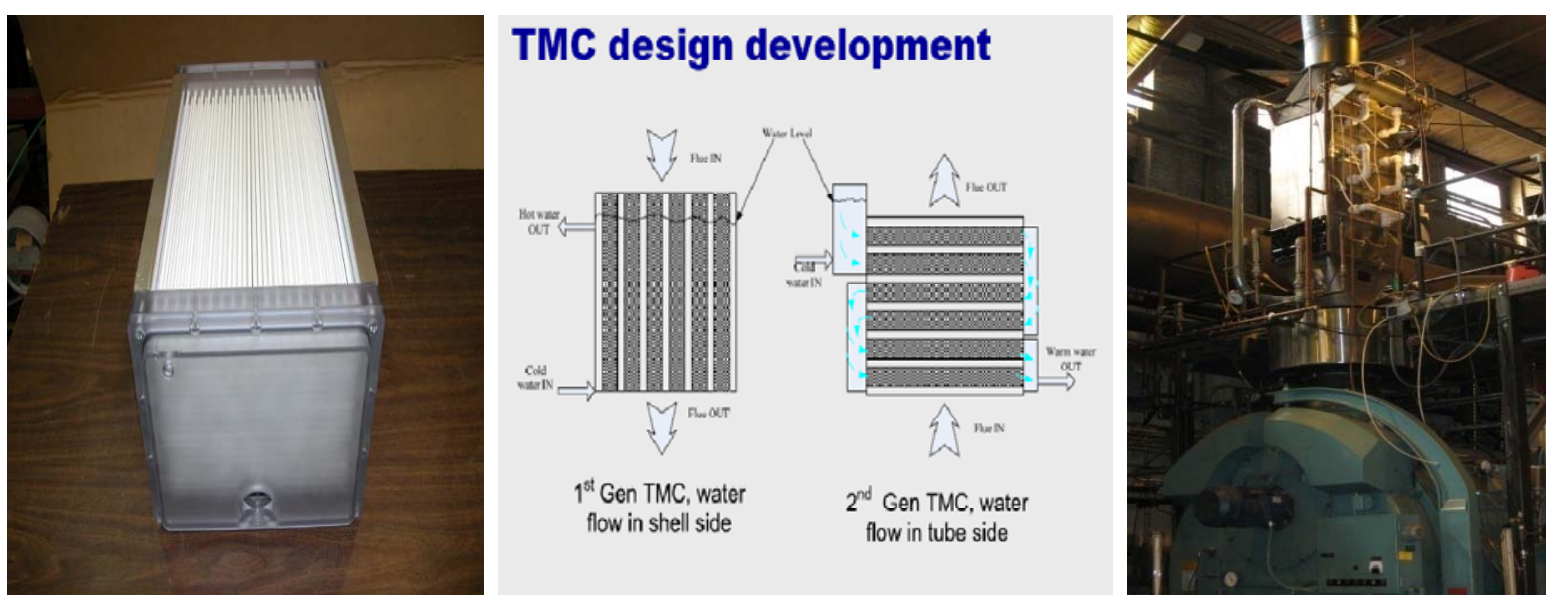

Figure 1-4: New Membrane Module (left),Version 1.0 and 2.0 TMC Design (middle), and an installed unit for a 200HP boiler (right)

\section{Project Description}

This report, the final technical report for DOE project DE-NT0005350, describes the technology development of the TMC system for water and waste heat recovery from power plant flue gases. In particular, this report includes power plant flue gas data evaluation and the two stage TMC system design process; the membrane performance optimization process based on information from potential host power plants; pilot-scale unit design, fabrication and performance validation test in a laboratory environment; long term pilot-scale TMC unit 
performance testing for a power plant flue gas slip stream; and the TMC system scale-up design and TMC technology potential commercialization paths.

Two-stage TMC system engineering design: Based on power plant data collected and analyzed, the project team designed and evaluated the TMC system with two separate cooling water streams to enhance the water and heat recovery. The first-stage TMC inlet water will be obtained from steam condensate from the condenser, and its outlet water with recovered water vapor and associated latent heat from flue gas will go to the deaerator for boiler water makeup. The second-stage TMC inlet water will be part of the condenser cooling water stream, the outlet water from this TMC stage will then be routed to go back to the cooling water stream with extra recovered water from the flue gas.

Membrane performance optimization: Based on power plant flue gas and cooling water conditions, membrane performance modeling and optimization work has been carried out. The water and heat transport rate requirement and membrane fouling prevention requirement have been used to determine the membrane and subtract material and structure. Laboratory testing results showed that membrane modification and optimization, especially the membrane pore size and porosity, can provide both stages with required water and heat transfer rates, and reduce the membrane fouling effect.

Pilot-scale unit design, fabrication, and performance validation testing: A pilot-scale TMC unit has been designed, fabricated, and assembled at Gas Technology Institute (GTI) Combustion Laboratory. A test setup was also configured at GTI for the TMC laboratory testing, which includes a 3-million-But/h natural gas-fired boiler and gas component simulation system to match coal-fired flue gas components. The performance validation testing results showed the TMC system, at the specific parametric ranges based on potential host power plant conditions, can recover significant water and heat. The water quality testing, high vapor concentration flue gas testing and flue gas spiked with SO2 testing also validated the TMC system performance at various conditions.

Pilot-scale unit field long term testing: The pilot-scale unit with full instrumentation and control was installed at a host power plant at Baltimore, MD. A slip stream of the coal-fired flue 
gas was used for the continuous five-week testing. The results demonstrated the TMC water and heat recovery system can achieve stable and reliable performance under a real world operating conditions.

Scale-up Design and TMC Technology Commercialization Path: A system scale-up evaluation has been carried out for a typical $550 \mathrm{MW}$ power plant, with potential integration strategy into the plant water loop. The TMC technology application in a power plant and its potential economic impact has been analyzed, and the technology preliminary commercialization path has been outlined.

\section{References:}

1. J. Boyen, Thermal Energy recovery, JOHN WILEY\&SONS, (1980)

2. Bend Research, Research on an Energy-Efficient Drying Process, DOE Final Report, DOE/ID/12293-1 (DE 86013369, Feb.25, (1986).

3. I. Rabovister, R. Knight, R. Remick, "Method and Apparatus for Selective Removal of a Condensable Component from a Process Stream with Latent Heat Recovery", U.S. Patent No. 6,517, 607 B2, Feb.11, 2003.

4. A. Bao, D. Wang, and C.X. Lin, "Nanoporous Membrane Tube Condensing Heat Transfer Enhancement Study", IMECE 2011-63530, Denver, CO, Nov. 11-17, 2011

5. K. Keizer, R. Uhlhorn, V. Zaspalis and A. Burggraaf, "Transport and Related (Gas and Vapor) Separation in Ceramic Membranes", Key Engineering materials, v.61\&62, p. 143154,1991

6. R. Knight, "Compact Package Boiler Combining Ultra-High-Efficient and Ultra-Low Emissions: Development and Demonstration", Natural Gas Technology Conference II, Buena Vista, FL, 2005

7. D. Wang, W. Liss, and A. Bao, "Water Reclamation from High Moisture Content Waste Heat Streams", IMECE 2011-63513, Denver, CO, Nov. 11-17, 2011

8. R. Knight, I. Rabovister, D. Wang, "Method and Apparatus for Enhanced Heat Recovery from Stream Generators and Water Heaters", U.S. Patent No. 7,066.396 B2, Jun.27,2006

9. D. Wang, R. Knight, D. Chojnacki, P. Molvie, B. Tynkov, and D. Willems, "Reduce Energy Cost with the Super Boiler", WEEC 2007, Atlanta, GA, August 15-16, 2007

10. D. Wang, R. Knight, D. Chojnacki, P. Molvie, B. Tynkov, and D. Willems, "Saving Energy with the High Efficiency Super Boiler", Journal of Energy Engineering, Vol. 105, No.3, pp.38-48, 2008. 


\section{CHAPTER 2 \\ Coal Power Plant Flue Gas Evaluation and TMC Concept Design}

\section{Introduction}

In this chapter, the two-stage TMC heat and water recovery concept has been developed, modeled, and evaluated by using analytical and numerical methods for coal-fired power plant application. Our power industry partner, SmartBurn LLC has provided detailed coal-fired power plant data on operations and flue gases, as well as cooling water conditions. Analysis based on these information was performed for a specific existing plant, and for a conceptual plant of typical capacity and flow characteristics. The two stage TMC design has been optimized so that the TMC/stage 1 can recover maximum heat and just enough water for the boiler makeup, and the TMC/stage2 can recover maximum amount of water.

\section{Power Plant Flue Gas Condition Analysis}

Detailed power plant related data was collected by SmartBurn. Data obtained includes flue gas parameters (flow rate, temperature, composition, pressure, etc. see Table 2-1 and 2-2) before and after a FGD unit, steam condensate and cooling water parameters (temperature and flow rate, Table 2-3), condensate and cooling water parameters (Table 2-4), potential demineralized water usage (boiler makeup, heating system losses, bearing cooling, FGD, etc) in a power plant, and fly ash data (particulate concentration and size, before and after an ESP, see Figure 2-1). The purpose of this exercise was to determine the amount of water vapor typically available from a flue gas stream and estimate a recoverable amount with the available cooling sources. Additionally, application of this recovered water in the power plant water circuits besides boiler makeup and cooling water makeup was also identified. This is because the recovered water is basically mineral free and of high quality, and we should find a better using place than cooling water makeup. Fly ash data is for identifying if there is any concern of these small particulates for membrane fouling. From Figure 2-1, you can see a fly ash particle size distribution, they are in the range of 1 to 10 microns after coming out of an ESP. For the TMC 
membrane pore size is 8 to 25 nanometer, the fly ash will not present any problem to block the membrane pores, they are simple too large for the pores.

More information about typical power plant operating data obtained is listed below to show the benefit analysis if this TMC technology is used for any specific boilers. Data was compiled from 3 power plants burning PRB coal on a KPPH basis, starting 1/1/09 and ending $8 / 11 / 09$. For all the three plants, daily make-up water quantity to the condenser was identified, and potential savings calculated based on this number and the current cost of producing demineralized water. For one plant the potential savings were calculated assuming the use of recovered water instead of city water to eliminate the need of an additive that is required to run the RRI/SNCR injection system with city water.

\section{A 220 MW T-Fired Boiler}

-Demineralized water cost $\$ 6.50 / \mathrm{Kgal}$

- Averaged 70,000 gallons of make-up water per day.

- Potential cost savings using recovered water instead of producing demineralized water for make-up is $\$ 130 \mathrm{~K}$ per year.

A 675 MW T-Fired Boiler

- Demineralized water cost $\$ 6.50 / \mathrm{Kgal}$

- Averaged 92,000 gallons of make-up water per day.

- Potential cost savings using recovered water instead of producing demineralized water for make-up is $\$ 210 \mathrm{~K}$ per year.

A 330 MW Cyclone-Fired Boiler

- Demineralized water cost $\$ 4.00 /$ Kgal.

- Averaged 70,000 gallons of make-up water per day.

- Potential cost savings using recovered water instead of producing demineralized water for make-up is $\$ 91 \mathrm{~K}$ per year.

- Urea additive \$70/Ton with an average of 9 tons/day being used.

- Additional savings on additive if using recovered water in place of city water is $\$ 180 \mathrm{k}$ per year. 
Table 2-1: Typical flue gas composition for a FGD unit

\begin{tabular}{|c|c|c|c|c|}
\hline Parameter & $\begin{array}{l}\text { Total Unit Inlet } \\
\text { Flue Gas }\end{array}$ & $\begin{array}{l}\text { Inlet Flue Gas } \\
\text { per Module }\end{array}$ & $\begin{array}{l}\text { Outlet Flue } \\
\text { Gas per } \\
\text { Module }\end{array}$ & $\begin{array}{l}\text { Total Unit } \\
\text { Outlet Flue } \\
\text { Gas }\end{array}$ \\
\hline Flow, acfm & 1520707 & 380177 & 330588 & 1322350 \\
\hline${\text { scfm }\left(68^{\circ} \text { F-14.7psia) }\right.}^{\circ}$ & 1047496 & 261874 & 291932 & 1167728 \\
\hline Temperature, $^{\circ} \mathrm{F}$ & 300 & 300 & 125 & 125 \\
\hline Pressure, inwg & 6.5 & 6.5 & 1 & 1 \\
\hline Pressure, psia & 14.57 & 14.57 & 14.38 & 14.38 \\
\hline Air, lb/hr & 3692128 & 923032 & 967328 & 3869310 \\
\hline CO2, lb/hr & 866542 & 216636 & 220892 & 883569 \\
\hline $\mathrm{H} 2 \mathrm{O}, \mathrm{lb} / \mathrm{hr}$ & 257312 & 64328 & 118621 & 474483 \\
\hline $\mathrm{SO} 2, \mathrm{lb} / \mathrm{hr}$ & 24770 & 6193 & 124 & 495 \\
\hline $\mathrm{Hcl}, \mathrm{lb} / \mathrm{hr}$ & 421 & 105 & 0 & 0 \\
\hline Fly Ash, lb/hr & 168 & 42 & 21 & 84 \\
\hline Total, lb/hr & 4841342 & 1210335 & 1306985 & 5227942 \\
\hline
\end{tabular}


Table 2-2:Typical coal power plant operation information

\begin{tabular}{|c|c|c|c|c|}
\hline Identifier & Data Unit 1 & Data Unit 2 & Average U1 \& U2 & Units \\
\hline Generator Load & 386.3 & 388.5 & 387.4 & GMW \\
\hline FD Fan Left Air Flow 1 & 61.7 & 52.5 & 57.1 & $\%$ \\
\hline FD Fan Left Air Flow 2 & 68.1 & 53.3 & 60.7 & $\%$ \\
\hline FD Fan Right Air Flow 1 & 57.4 & 55.4 & 56.4 & $\%$ \\
\hline FD Fan Right Air Flow 2 & 58.3 & 59.6 & 58.95 & $\%$ \\
\hline Total Air Flow Boiler Control Selected & 76.3 & 85 & 80.65 & $\%$ \\
\hline Boiler Outlet Flue Gas O2 Left & 2.1 & 3.4 & 2.75 & $\%$ \\
\hline Boiler Outlet Flue Gas O2 Right & 3.6 & 2.8 & 3.2 & $\%$ \\
\hline FD Fan Left Disch Pressure & 9 & 9 & 9 & inH2O \\
\hline FD Fan Right Disch Pressure & 9.09 & 8.9 & 8.995 & inH2O \\
\hline AH Left Diff Air Pressure & 2.4 & 2.3 & 2.35 & $\mathrm{inH} 2 \mathrm{O}$ \\
\hline AH Right Diff Air Pressure & 1.97 & 2.3 & 2.135 & in $\mathrm{H} 2 \mathrm{O}$ \\
\hline Windbox Left Pressure & 3.63 & 2.8 & 3.215 & in $\mathrm{H} 2 \mathrm{O}$ \\
\hline Windbox Right Pressure & 3.54 & 2.6 & 3.07 & inH2O \\
\hline Windbox/Furnace DP Left & 3.58 & 3.7 & 3.64 & inH2O \\
\hline Windbox/Furnace DP Right & 4.32 & 3.4 & 3.86 & inH2O \\
\hline Furnace Pressure Left & -0.44 & -0.56 & -0.5 & inH2O \\
\hline Furnace Pressure Right & -0.44 & -0.49 & -0.465 & inH2O \\
\hline Furnace Pressure & -0.1 & -0.55 & -0.325 & $\mathrm{inH} 2 \mathrm{O}$ \\
\hline Superheater Outlet Gas Pressure & -1.9 & -1.5 & -1.7 & $\mathrm{inH} 2 \mathrm{O}$ \\
\hline RH Outlet Gas Pressure & -0.58 & -0.68 & -0.63 & inH2O \\
\hline ECO Left Flue Gas Exit Pressure & -3 & -2.1 & -2.55 & inH2O \\
\hline ECO Right Flue Gas Exit Pressure & -3 & -2.7 & -2.85 & in $\mathrm{H} 2 \mathrm{O}$ \\
\hline Furnace/ECO DP Left & 2.7 & 2.3 & 2.5 & inH2O \\
\hline Furnace/ECO DP Right & 2.8 & 2.2 & 2.5 & inH2O \\
\hline AH Left Diff Gas Pressure & 3.3 & 3.8 & 3.55 & $\mathrm{inH} 2 \mathrm{O}$ \\
\hline AH Right Diff Gas Pressure & 3.2 & 5 & 4.1 & inH2O \\
\hline ESP Left DP & -0.33 & -0.35 & -0.34 & $\mathrm{inH} 2 \mathrm{O}$ \\
\hline ESP Right DP & -0.35 & -0.35 & -0.35 & inH2O \\
\hline ID Fan Left Suction Pressure & -10.1 & -11.3 & -10.7 & $\mathrm{inH} 2 \mathrm{O}$ \\
\hline ID Fan Right Suction Pressure & -10.1 & -11.3 & -10.7 & inH2O \\
\hline FD Fan Left Discharge Temperature & 21.6 & 21.7 & 21.65 & ${ }^{\circ} \mathrm{F}$ \\
\hline FD Fan Right Discharge Temperature & & 22.1 & 11.05 & ${ }^{\circ} \mathrm{F}$ \\
\hline AH Left Air Inlet Temperature & 110.3 & 94.1 & 102.2 & ${ }^{\circ} \mathrm{F}$ \\
\hline AH Right Air Inlet Temperature & 112.3 & 103.3 & 107.8 & ${ }^{\circ} \mathrm{F}$ \\
\hline AH Left Air Outlet Temperature & 556.5 & 571.4 & 563.95 & ${ }^{\circ} \mathrm{F}$ \\
\hline AH Right Air Outlet Temperature & 540.6 & 601.6 & 571.1 & ${ }^{\circ} \mathrm{F}$ \\
\hline AH Left Gas Inlet Temperature & 661.6 & 748.4 & 705 & ${ }^{\circ} \mathrm{F}$ \\
\hline AH Right Gas Inlet Temperature & 609.1 & 701.9 & 655.5 & ${ }^{\circ} \mathrm{F}$ \\
\hline AH Left Gas Outlet Temperature & 288.4 & 308.7 & 298.55 & ${ }^{\circ} \mathrm{F}$ \\
\hline AH Right Gas Outlet Temperature & 295 & 294.3 & 294.65 & ${ }^{\circ} \mathrm{F}$ \\
\hline ESP Left Gas Outlet Temperature & 305.4 & 302.3 & 303.85 & ${ }^{\circ} \mathrm{F}$ \\
\hline ESP Right Gas outlet Temperature & 302.4 & 314.2 & 308.3 & ${ }^{\circ} \mathrm{F}$ \\
\hline AH Left Avg. Cold end temperature & 199.3 & 201.4 & 200.35 & ${ }^{\circ} \mathrm{F}$ \\
\hline AH Right Avg. Cold End Temperature & 203.7 & 198.8 & 201.25 & ${ }^{\circ} \mathrm{F}$ \\
\hline Glyco Heater L Glycol Outlet T & 193.9 & 147.7 & 170.8 & ${ }^{\circ} \mathrm{F}$ \\
\hline Glyco Heater R Glycol Outlet T & 195.9 & 147.7 & 171.8 & ${ }^{\circ} \mathrm{F}$ \\
\hline
\end{tabular}

Flue gas temperature $200 \sim 400^{\circ} \mathrm{F}$, depends on the unit load and air heater 
Table 2-3: Condensate and cooling water streams for several coal power plants

\begin{tabular}{|c|c|c|c|c|}
\hline Condenser parameters: & Plant 1 & Plant 2 & Plant 3 & Plant 4 \\
\hline Gross Generation (MW) & 198.4 & 547 & 540 & 384 \\
\hline Back pressure (inHga) & 2.11 & 2.88 & 2.52 & 1.43 \\
\hline Circulating water flow (GPM) & 117,175 & 190,250 & 185,000 & 175,000 \\
\hline Cooling water in temp (F) & 61 & 75.2 & 75 & 54 \\
\hline Cooling water out temp (F) & 77 & 106 & 104 & 81.7 \\
\hline Steam Condensate temp (F), calculated from back \\
pressure & & & 109.4 & 87.8 \\
\hline Condenser inlet steam temp (F) & 102.2 & 115 & 105 & 90.2 \\
\hline Condenser outlet water temp (F) & 106.1 & 114.6 & 109 & 96.6 \\
\hline Sub Cooling (F) & 11.8 & 1.1 & 0 & -6.4 \\
\hline
\end{tabular}

Table 2-4: Typical Power Plant Water Consumptions

\begin{tabular}{|c|c|c|c|c|}
\hline \multirow[t]{2}{*}{ Water Usage in Power Plants } & Unit \# 1 & Unit \# 2 & Unit \# 3 & Unit \#4 \\
\hline & $\begin{array}{l}\text { T-Fired } 530 \\
\text { MW }\end{array}$ & $\begin{array}{l}\text { Cyclone } 330 \\
\text { MW }\end{array}$ & $\begin{array}{l}\text { Wall Fired } \\
400 \mathrm{MW}\end{array}$ & $\begin{array}{l}\text { T-Fired } 390 \\
\text { MW }\end{array}$ \\
\hline Make-Up Water & 44 kpph & $21.5 \mathrm{kpph}$ & $29.9 \mathrm{kpph}$ & $90 \mathrm{kpph}$ \\
\hline Water Cannon & NA & NA & & NA \\
\hline Water Lance & $\begin{array}{l}\text { RO or Serv. } \\
\text { Water }\end{array}$ & NA & NA & NA \\
\hline Sootblowing Steam Make-Up & $22 \mathrm{kpph}$ & NA & $11.9 \mathrm{kpph}$ & $\begin{array}{l}\text { incl. in } \\
\text { make-up }\end{array}$ \\
\hline RRI/SNCR & NA & $7.6 \mathrm{kpph}$ & NA & NA \\
\hline Water Storage & $\begin{array}{l}\text { boiler fill \& } \\
\text { emergency - } \\
4 x \text { boiler fill }\end{array}$ & $\begin{array}{l}\text { boiler fill \& } \\
\text { emergency - } \\
4 \text { x boiler fill }\end{array}$ & $\begin{array}{l}\text { boiler fill } \& \\
\text { emergency } \\
-4 \times \text { boiler } \\
\text { fill }\end{array}$ & $\begin{array}{l}\text { boiler fill } \& \\
\text { emergency } \\
-4 \times \text { boiler } \\
\text { fill }\end{array}$ \\
\hline Feed Water & closed loop & closed loop & $\begin{array}{l}\text { closed } \\
\text { loop }\end{array}$ & closed loop \\
\hline Bearing Cooling Water & closed loop & closed loop & $\begin{array}{l}\text { closed } \\
\text { loop }\end{array}$ & closed loop \\
\hline FGD water & $\mathrm{NA}$ & NA & NA & $257 \mathrm{kpph}$ \\
\hline $\begin{array}{l}\text { Condenser Circulating Water } \\
\text { Flow }\end{array}$ & NA & NA & $185 \mathrm{kpph}$ & $175 \mathrm{kpph}$ \\
\hline Service Water Flow & NA & NA & NA & NA \\
\hline
\end{tabular}

Notes:

1. If Sootblowing Steam is listed it is already accounted for in the Make-up water. It is just showing how much of the make-up is due to sootblower consumption.

2. Water Storage - is part of emergency and reserve for start-up activities. Drum blow downs are open for boiler water chemistry control.

3. Make-up water includes normal blow downs, leaks through safety or other valves, plant heating systems and other open-loop steam usages.

4. Service Water flows and usage is depending on plant specific layout and location. It's sources are river, lake, city, deep well water sources. 


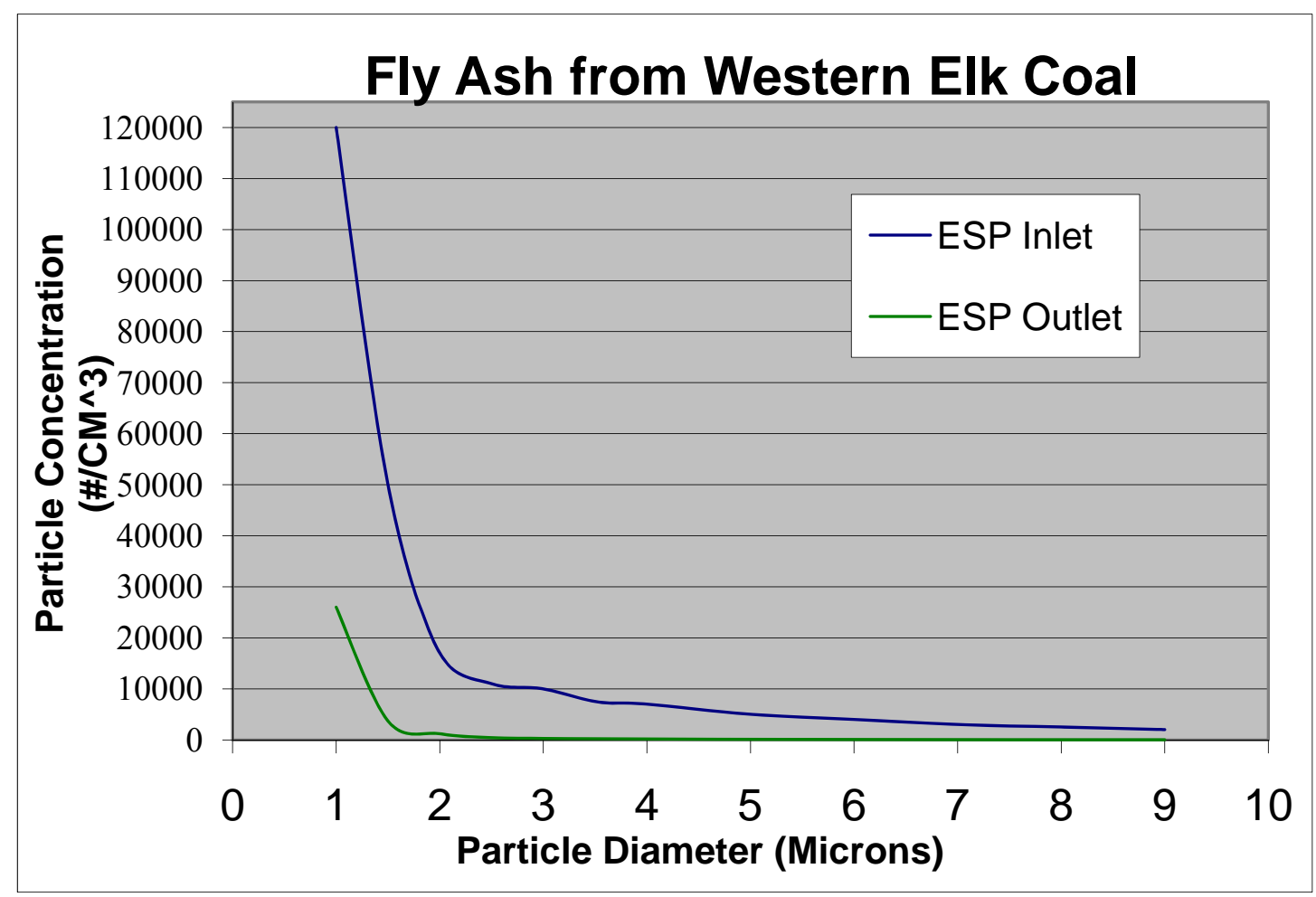

Figure 2-1: Typical fly ash particle size distribution from a plant using western Elk Coal

From the above collected data from several typical coal power plants and the analysis, we see great water saving potentials if the TMC technology can be successfully used to recover both waste heat and water vapor from the flue gases. As we have identified, there is plenty of moisture available from the flue gases, especially after a FGD unit. And there are also many potential places in a power plant besides boiler makeup, which may include FGD water, RRI/SNCR injection system, and other plant water users. The fly ash particles should not present a problem for the TMC membrane operation since its much larger size compared with the membrane pores. What we need to do is developing a TMC unit that can meet the specific need of a power plant, to achieve the best combination of efficiency improvement and water recovery.

\section{A Two-stage TMC Concept Design for Power Plant Water/Steam Cycle}

Based on the above information and our previous project modeling and analysis work, a two-stage TMC concept was developed for power plant applications. For power plants, there 
are two water streams can be used as TMC cooling sources: the turbine steam condensate and the condenser cooling water. Besides the lower temperature turbine steam condensate, the cooling water is typically 25 times of the boiler feed water flow rate, and can provide a much larger driving force for the TMC. With the two streams of cooling water, up to $90 \%$ moisture removal from the coal-fired power plant flue gas is possible.

Figure 2-2 shows a schematic for the two-stage TMC concept and how to integrate the TMC water recovery unit in a typical power generation boiler steam turbine loop. For the twostage TMC unit to maximize its function for recovering both water and heat, two separate cooling water streams are used. On the water side, the first-stage TMC inlet water will be obtained from steam condensate from the condenser, and its outlet water with recovered water vapor and associated latent heat from flue gas will go to the deaerator for boiler water makeup. This water is at a higher temperature $\left(130^{\circ} \mathrm{F}\right.$ to $160^{\circ} \mathrm{F}$ depending on incoming flue condition) than a regular makeup water, thus the overall boiler efficiency can be expected to increase about $0.5 \%$. Recovered water quantity was more than sufficient for boiler makeup (typically less than 1\% steaming rate) and the excess mineral free water can be used to makeup heating system losses, bearing cooling losses, in addition to being a part of FGD water supply. The second-stage TMC inlet water will be part of the condenser cooling water stream. The outlet water from this TMC stage will then be routed to go back to the cooling water stream with extra recovered water from the flue gas. On the flue gas side, the TMC is situated between the FGD unit and the stack. 


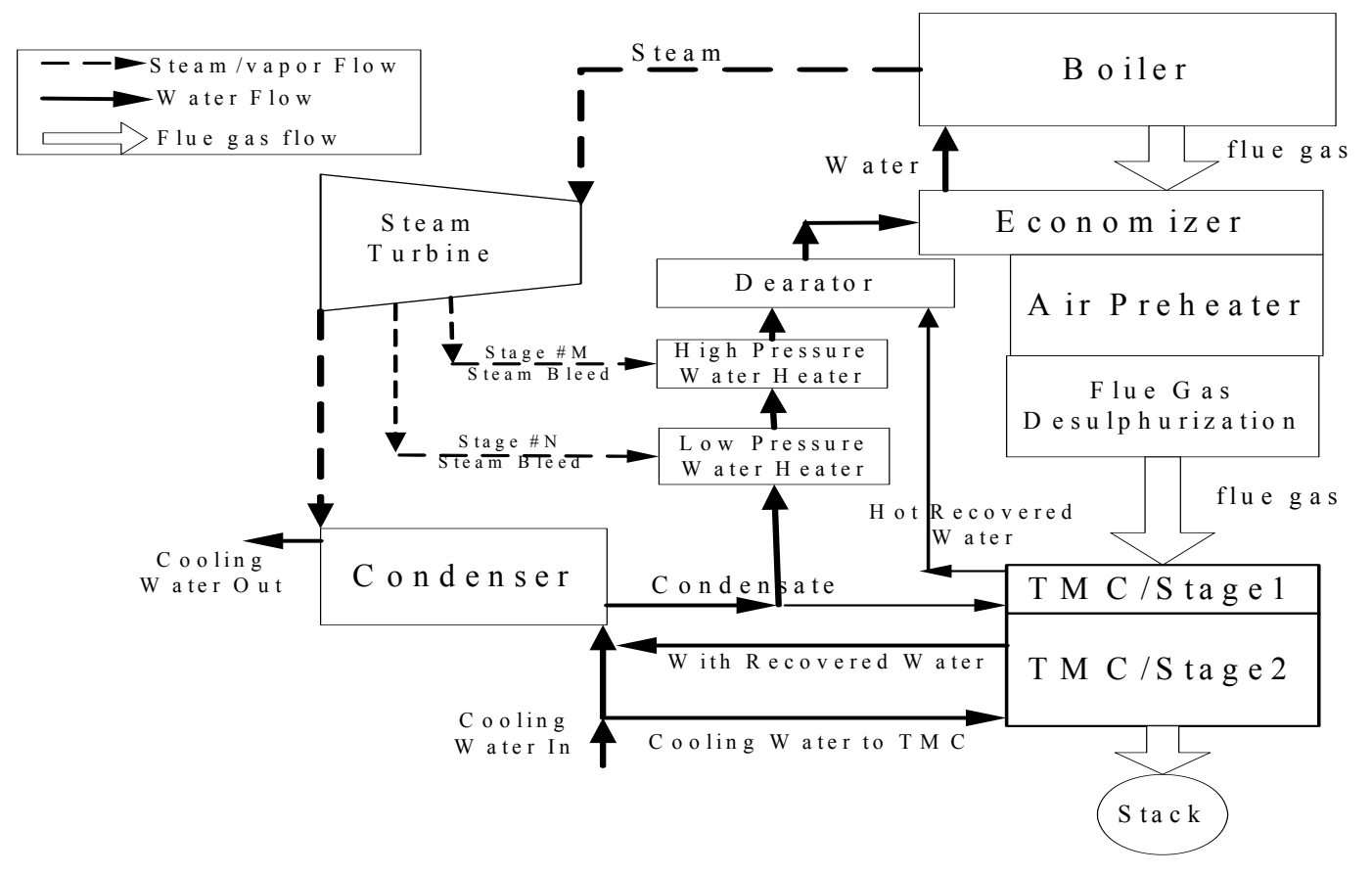

Figure 2-2: Power Plant Flue Gas Heat and Water Recovery with a Two-Stage TMC

\section{Summary}

The two-stage TMC concept design for a power plant flue gas stream was evaluated after analysis of collected data from typical power plants. Two separate cooling water streams are used for the two-stage TMC concept. TMC/stage1 utilizes the turbine condensate as cooling stream to recover both water and heat from the incoming hot flue gas stream, and sends the hot water to the deaerator as boiler makeup water. TMC/stage2 uses part of the condenser cooling water stream to recover a large amount of water and part of the heat from the flue gas stream coming out of TMC/stage1. This heat could be extracted later for coal drying or other heating purpose before the water stream joins the main cooling water stream. The large amount of recovered water can be used as cooling water makeup, which has additional benefits of reducing blow down losses for its low mineral contents. 


\section{CHAPTER 3 \\ TMC Membrane Performance Evaluation and Selection}

\section{Introduction}

For this two stage TMC design for coal power plant flue gas application, the project team investigated different membrane pore sizes to achieve optimized membrane heat transfer/water transport performance for TMC/stage 1 and TMC/stage 2. Also membrane fouling potentials for coal-fired flue gas has been studied. In addition to the current 8-nm membrane pore size that is used for both heat and water recovery application for most industrial boiler applications, two additional pore sizes were studied, namely $15 \mathrm{~nm}$ and $25 \mathrm{~nm}$ pore sizes, for maximizing water and heat transportation. Membrane coating method and membrane module construction method have also been investigated to lower the TMC cost.

\section{Experimental Apparatus}

The GTI laboratory TMC test setup was modified for current project membrane module performance test, which was aimed to select the appropriate membranes for the two-stage TMC unit. As shown in Figure 3-1, the test setup consists of a gas burner with a 200,000 Btu/hr firing capacity, two heat exchangers to cool the flue gas down for TMC test section inlet, and the TMC test section itself. A new water pump and a new water flow meter have been acquired and installed to accommodate the large water flow rate requirement special for this project. A portable automatic data acquisition box was built for this testing, and also for future field testing at host power plant.

TMC membrane modules were built with seventy eight $18^{\prime \prime}$ - long membrane tubes for TMC performance evaluation. The first module was built with our TMC typical membrane pore size $(8 \mathrm{~nm})$ tubes, which were used for most industrial TMC unit and can get the best water recovery quality and adequate water and heat recovery to the make-up water loop. One laboratory module built for this project is shown in Figure 3-2. 


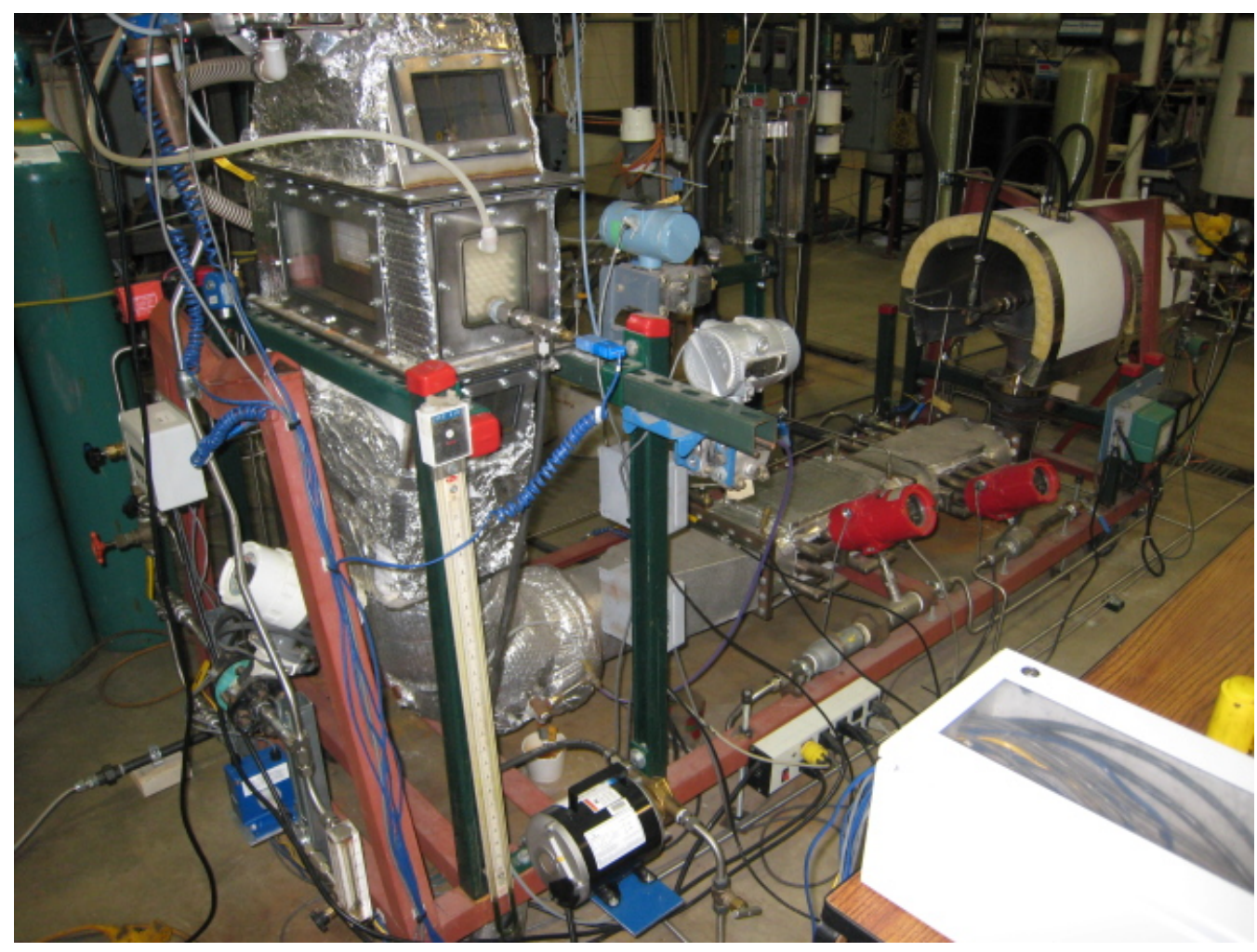

Figure 3-1: Lab TMC module performance test setup
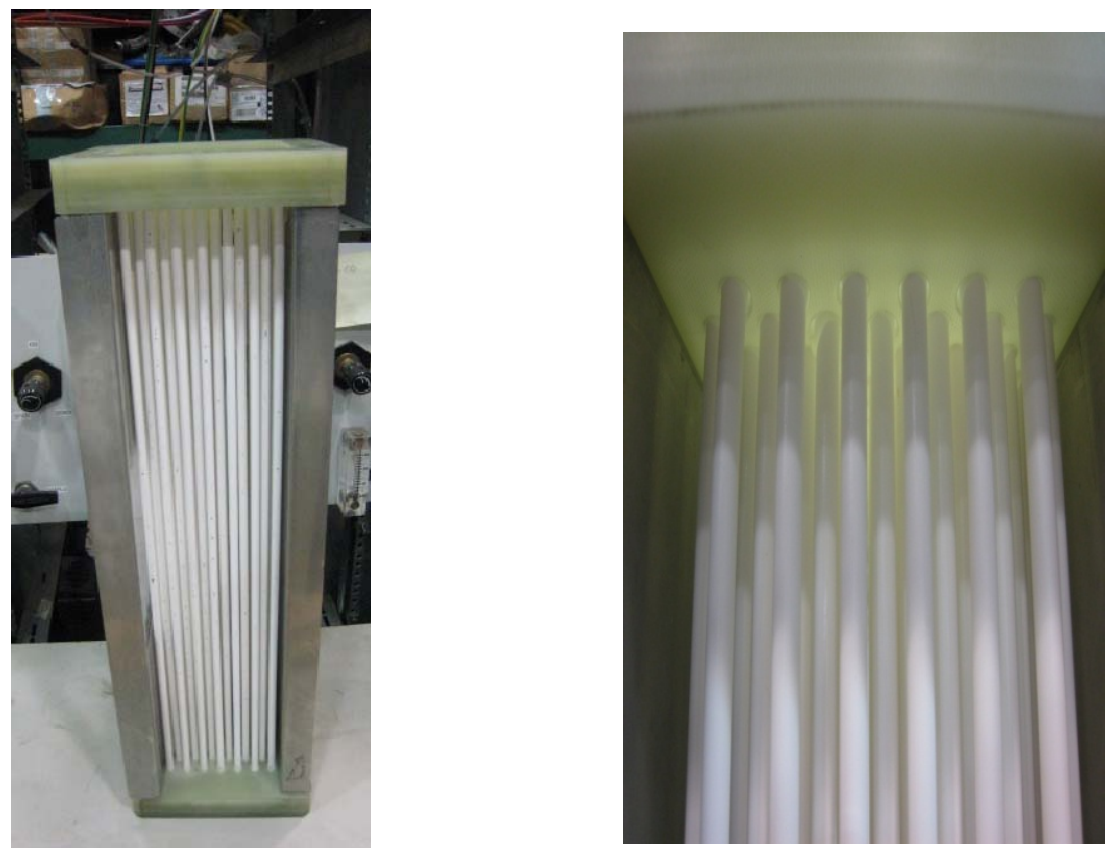

Figure 3-2: Lab size TMC module with Garolite material and new adhesive 


\section{Result Discussions}

Membrane module building method was evaluated by using different adhesives, different assembly part materials, and finally a two-part epoxy based adhesive and a glass-filled epoxy based assembly part material were selected for their great bonding strength at this temperature and humidity condition. Practical TMC membrane modules can be built with this method quick and economically.

$\underline{\text { TMC stage } 1 \text { membrane module (pore size } 8.5 \text { and } 15 \mathrm{~nm} \text { ) test results }}$

The stage 1 membrane module test was designed to find out if these membrane sizes were adequate for TMC/stage 1 application. The first stage TMC uses a portion of the turbine steam condensate stream (typical temperature $90-110^{\circ} \mathrm{F}$ ) as cooling water to recover a portion of the heat and water from the flue gas. After passing through the TMC, the water temperature will be raised by 20 to $50^{\circ} \mathrm{F}$ depending on the water flow rate, and the recovered water can be added into this water stream. The increased amount of hot water from the TMC can replace essentially all the cold makeup water for the boiler feed water stream to improve the boiler efficiency.

A range of parameters have been tested, and listed as following: flue gas inlet temperatures, $200^{\circ} \mathrm{F}, 180^{\circ} \mathrm{F}$, and $160^{\circ} \mathrm{F}$; TMC water inlet temperatures, $90^{\circ} \mathrm{F}, 100^{\circ} \mathrm{F}$, and $110^{\circ} \mathrm{F}$; TMC cooling water flow rates, 0.2 GPM, 0.33 GPM, and 0.5 GPM; and water side vacuum is -6.0" $\mathrm{Hg}$ for most of the cases except for the vacuum effect test. From the data we concluded, the lower the flue gas inlet temperature, the higher water vapor transport rate, as shown in Figure 3-3. At $160^{\circ} \mathrm{F}$ inlet flue gas condition, there are some pre-condensation for the flue gas, so the inlet flue gas dew point to the TMC module is lower, which results in lower transport rate. As a result, the water vapor transport rates are close for the two cases of flue gas inlet temperature $160^{\circ} \mathrm{F}$ and $180^{\circ} \mathrm{F}$. The water transport rate vs. water flow rate and water inlet temperature is shown in Figures 3-4. Higher water flow rate and lower water inlet temperature resulted in higher water transport rate.

For this small lab test module with only $7818^{\prime \prime}$ - long membrane tubes, up to $5.7 \mathrm{lb} / \mathrm{hr}$ of water can be recovered for the above test condition. Based on this number, we can figure out 
the membrane surface area needed for the TMC/stage 1 to recover enough makeup for a typical power plant boiler.

After this first stage TMC, the flue gas relative humidity $(\mathrm{RH})$ increases significantly, and it provides a good inlet condition for the TMC/stage 2 inlet. For example, the $\mathrm{RH}$ at $200^{\circ} \mathrm{F}$ inlet flue gas condition increase from $20 \%$ to about $60 \%$, and at $160^{\circ} \mathrm{F}, \mathrm{RH}$ increase from $50 \%$ to $80 \%$. From our past study we know, the higher the inlet flue $\mathrm{RH}$, the higher TMC performance we can expect.
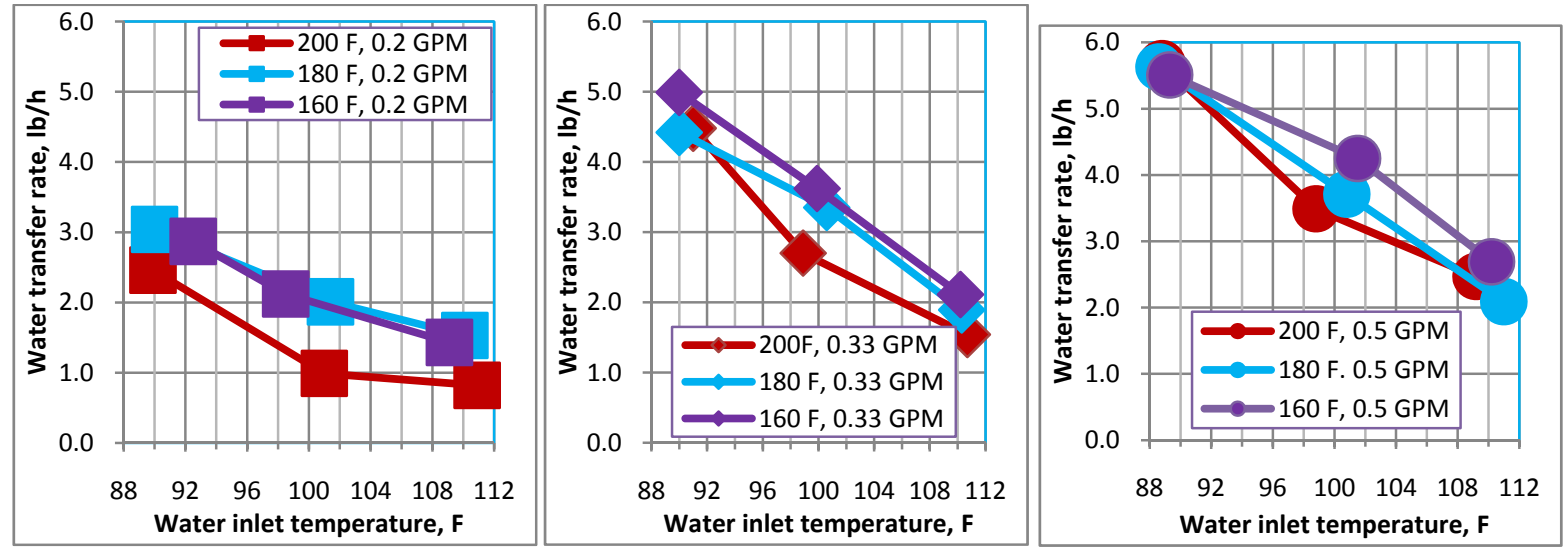

Figures 3-3 Water transport rate vs. inlet flue gas temperature
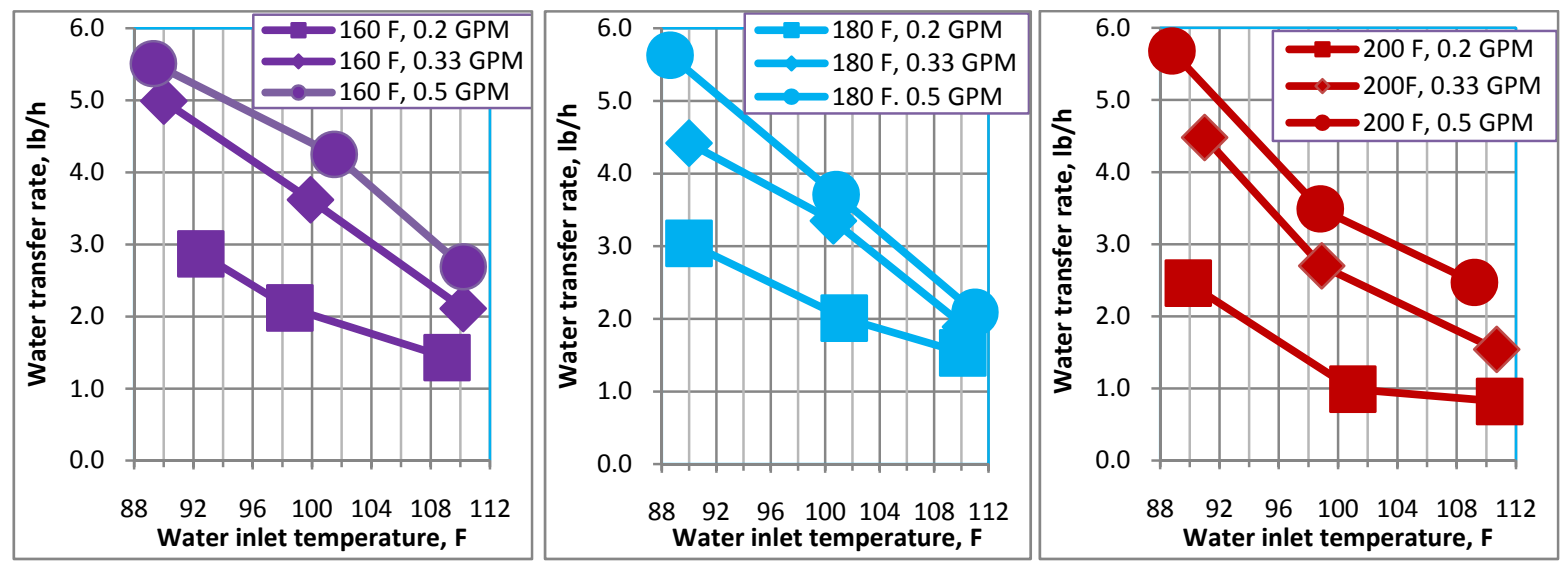

Figures 3-4 Water transport rate vs. water inlet temperature and water flow rate.

Based on inlet flue gas conditions (inlet temperature and dew point), we can control the water flow rate and water inlet temperature to achieve the required water conditions (makeup water flow rate and temperature). For most conditions, the current 8-nm membrane pore size is appropriate for TMC/stage 1. 
For some high water transport rate cases (low water inlet temperature and high water rate), there are water droplets occurs on the membrane surface at the tube water inlet side, which means the membrane can not transport all the water condensed. Larger membrane pore size module performance should be also investigated.

The different vacuum effect results are shown in Figure 3-5. The water transport rates are not affected by the vacuum change $\left(-5.9^{\prime \prime} \mathrm{Hg}\right.$ to $\left.-12.2^{\prime \prime} \mathrm{Hg}\right)$. This is mainly because that for the $8 \mathrm{~nm}$ membrane pore size membrane, heat transfer between the flue gas and cooling water is playing the bottle neck role not the pressure difference across the membrane.

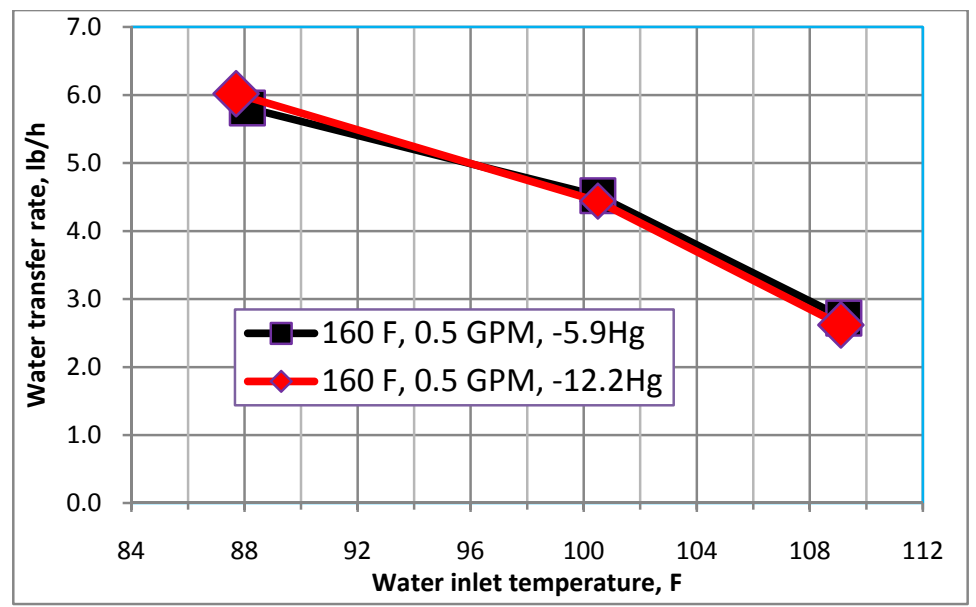

Figures 3-5 Water transport rate under different vacuums

For typical natural gas flue conditions, the current $8.5 \mathrm{~nm}$ membrane pore size is appropriate for TMC/stage 1. Figure 3-6 and Figure 3-7 show that different membrane pore sizes do not have much impact on the TMC water and heat transfer performance. 




Figure 3-6: TMC/Stage 1 different membrane pore size effect on water transfer

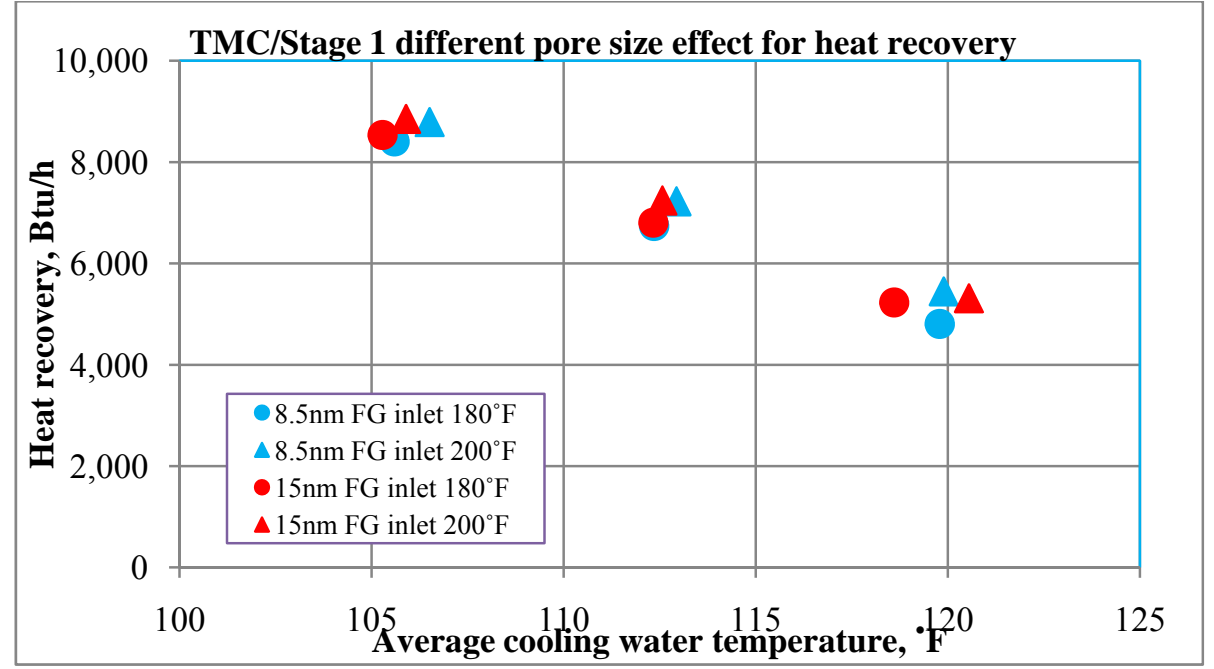

Figure 3-7: TMC/Stage 1 different membrane pore size effect on heat transfer $\underline{\text { TMC membrane module (pore size } 15 \mathrm{~nm} \text { ) high moisture test results }}$

The TMC module was tested for high moisture flue gas to study its performance at elevated moisture content conditions. By injecting water into the natural gas flue gas stream, the flue gas dew points were increased from $134^{\circ} \mathrm{F}$ to $150^{\circ} \mathrm{F}$, with a corresponding moisture volume increase from $16.8 \%$ to $25.3 \%$. Figure $3-8$ and Figure $3-9$ show the results and they indicate that both the moisture transport rate and heat recovery are more than doubled, which proves the TMC can be more effective when being used for high moisture waste heat exhausts. 
These test results confirmed the theoretical analysis that high moisture content flue gas can provide high vapor transport driving force and create a higher water transfer rate.

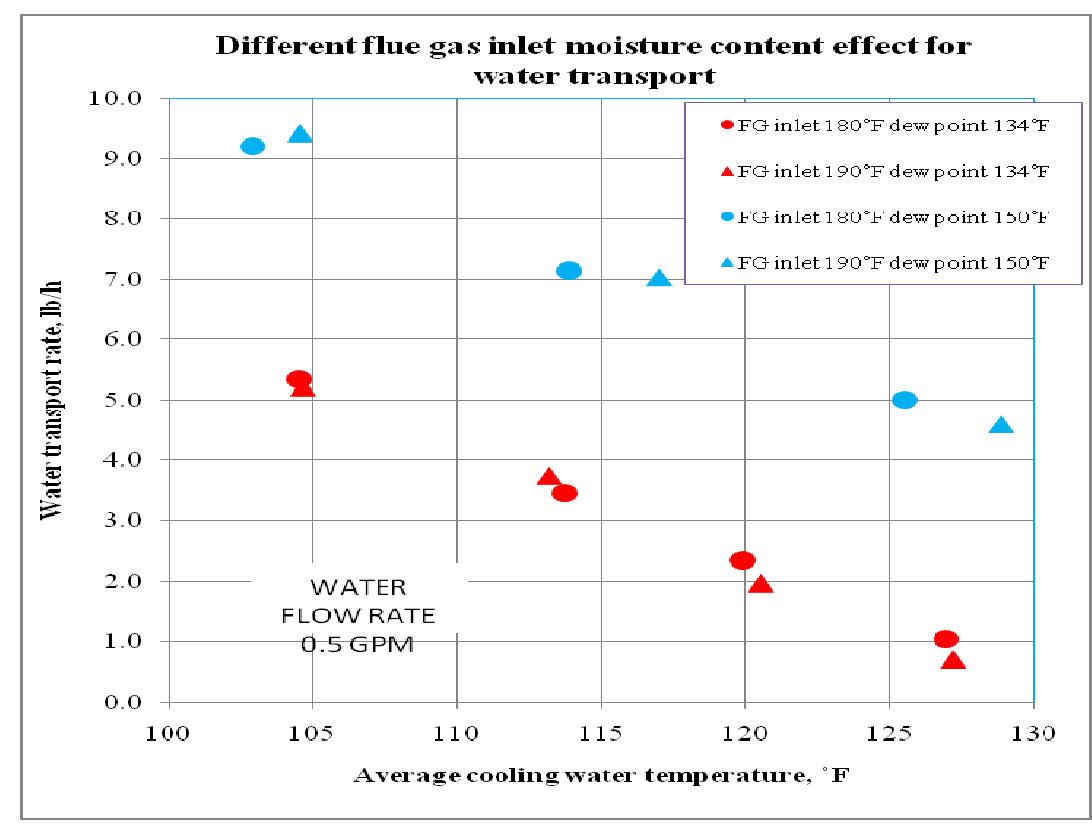

Figure 3-8: High moisture flue gas effect on water transport

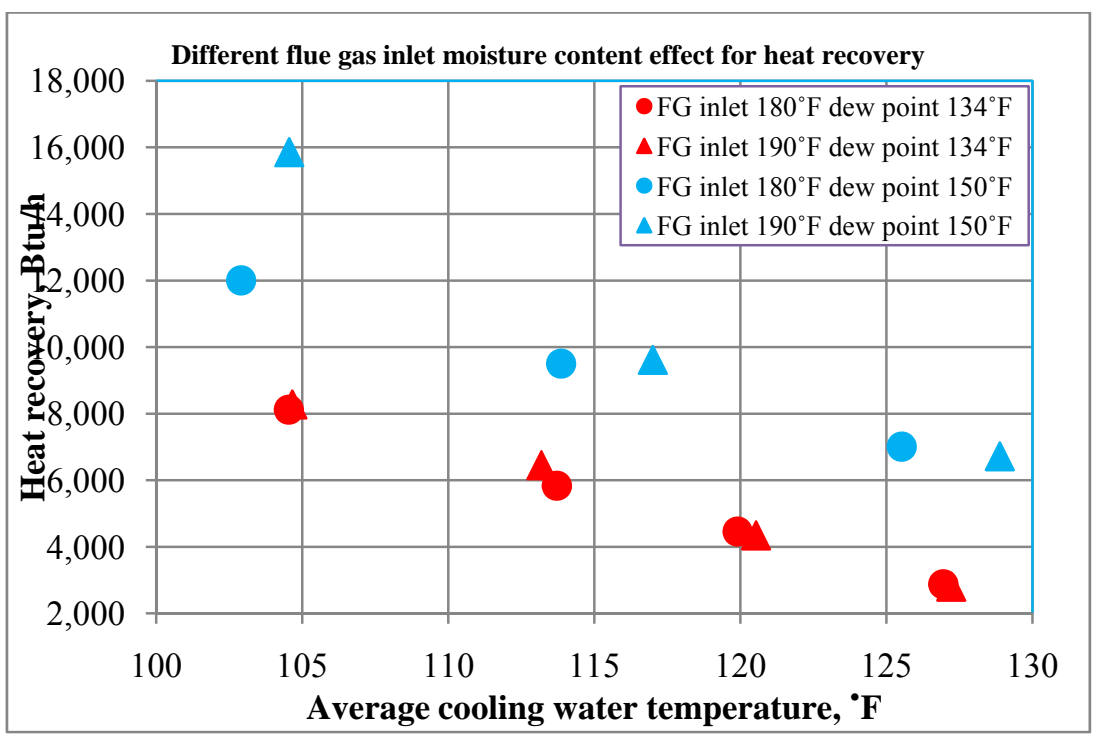

Figure 3-9: High moisture flue gas effect on heat transfer

$\underline{\mathrm{TMC} / \text { stage } 1 \text { result summary }}$

Two membrane pore sizes ( $8 \mathrm{~nm}$ and $15 \mathrm{~nm}$ ) were investigated for their water and heat transport performance at different flue gas conditions (temperature, moisture contents), different cooling water conditions (flow rate, inlet temperature) and different membrane 
permeate side vacuums. A larger pore size is favored for high moisture content conditions where high water transport rate is needed, but a smaller pore size is favored for most of the cases of TMC/stage1 flue gas condition so as to create a better capillary condensation effect.

$\underline{\text { TMC stage } 2 \text { membrane module (pore size } 15 \text { and } 25 \mathrm{~nm} \text { ) test results }}$

This test was designed to investigate the adequacy of membrane sizes for a TMC/stage 2 application. The TMC/stage 2 receives low temperature flue gas from TMC/stage 1 with a low moisture content. However since the flue gas is at a high relative humidity condition it is favorable to recover a large portion of the water. Figure 3-10 and Figure 3-11 show data plots for different flue gas inlet temperatures and different averaged cooling water temperatures (water flow rate is already considered in this parameter). Under these testing conditions, no performance difference on water and heat transfer for the two membrane pore sizes were noted. Therefore a $15 \mathrm{~nm}$ pore size membrane is suggested for a TMC/stage 2 application since the smaller pore size is more favorable for contaminant rejection and encourages earlier capillary condensation.

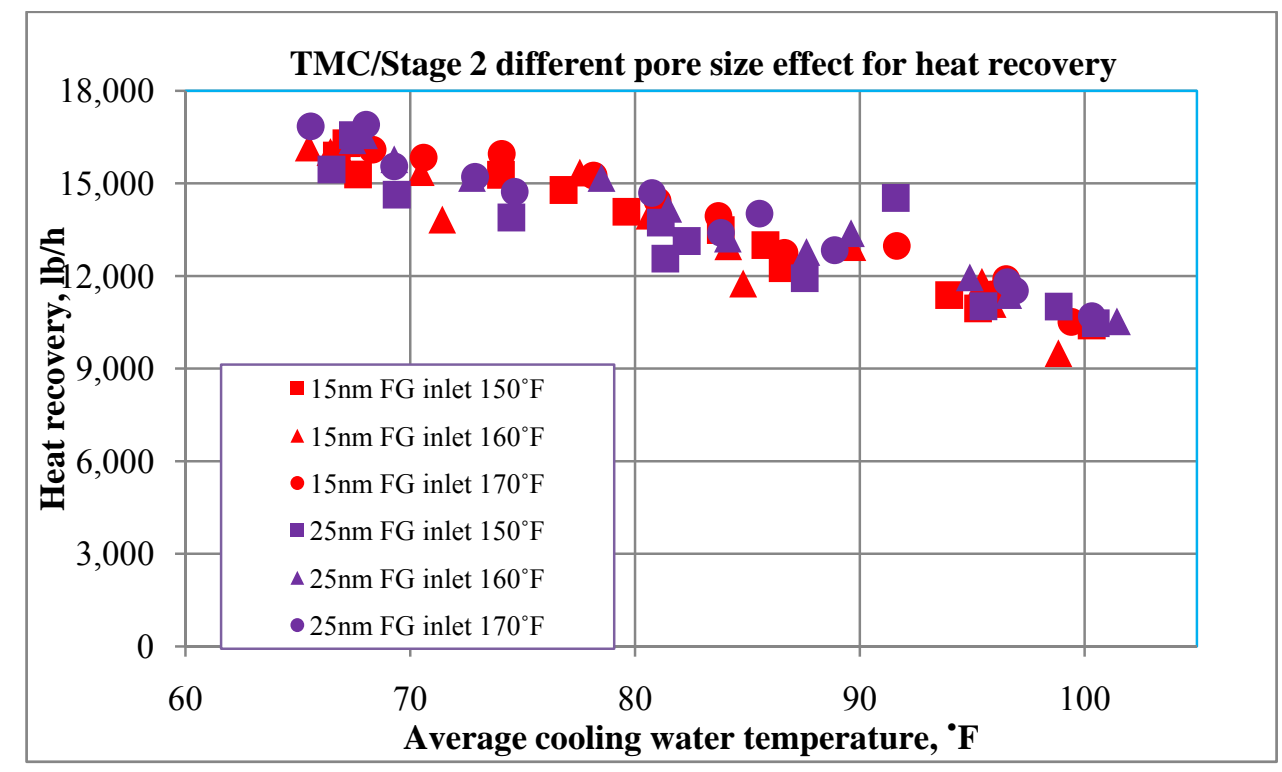

Figure 3-10: Different membrane pore size effect on water transport 


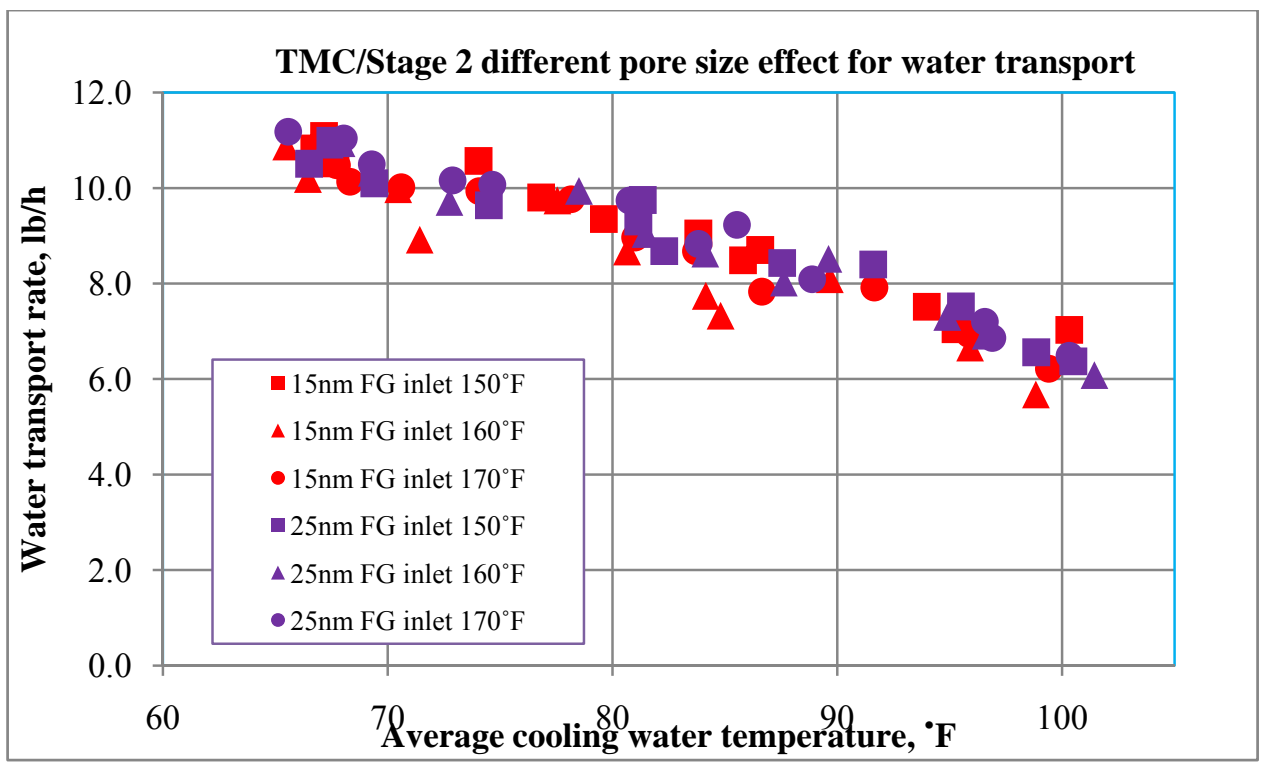

Figure 3-11: Different membrane pore size effect on heat recovery

\section{$\underline{\mathrm{TMC} / \text { stage } 2 \text { result summary }}$}

Two membrane pore sizes (15nm and $25 \mathrm{~nm}$ ) were investigated for their water and heat transport performance at different flue gas conditions (temperature, moisture contents), different cooling water conditions (flow rate, inlet temperature), and different membrane permeate side vacuums. The $15 \mathrm{~nm}$ pore size was selected for stage 2 TMC design.

More membrane development work

Improving membrane surface area per unit volume and increasing the membrane tube length are critical factors in the development of a two-stage TMC unit. For increasing the membrane surface area, the membrane was affixed to the outer surface of a substrate tube instead of the traditional inside surface coating. This increased the membrane surface area by $57 \%$ for a tube with an ID $3.5 \mathrm{~mm}$ and OD $5.5 \mathrm{~mm}$. The ceramic membrane is typically coated on a porous ceramic substrate, which has good anti-corrosion performance, but it is limited to a length of 1 meter. A sintered metal substrate made from Stainless Steel 434 and a high chrome content for corrosion resistant was also studied. It was tested over 7,000 hours in a 600 ppm sulfurous acid environment with no weight loss due to corrosion. A ceramic membrane separation layer was then successfully coated on the metal substrate's outer surface for further protection. Membrane fouling tests were done at a natural gas burnt flue gas environment for 100 hours and water transport flux noted before and after the fouling testing showed less than 
$1.6 \%$ in transport flux loss. The flux loss trend for membrane tends to become constant after 50 hours depending on the feed side stream conditions. A membrane fouling test with $200 \mathrm{ppm}$ $\mathrm{SO}_{2}$ added into a natural flue gas was also used to test the TMC membrane module for 100 hours. Initial data obtained shows some flux losses and further detailed measurements are required. Membrane surface chemical modifications with an inorganic coating of $\mathrm{ZrO}_{2}(\mathrm{rather}$ than a standard $\mathrm{Al}_{2} \mathrm{O}_{3}$ coating) and an organic ligand modifier yielding a sulfonic acid pendant group were studied to avoid surface deposition buildup. Both of these modifications have shown higher resistance to membrane fouling due to adsorption of chemical species over alumina based membrane systems.

Table 3-1: membrane transport rate changes after 100 hour fouling test with natural gas flue

\begin{tabular}{|c|c|c|c|c|}
\hline \multirow{2}{*}{$\begin{array}{c}\text { Membrane } \\
\text { ID } \\
{[-]}\end{array}$} & \multicolumn{3}{|c|}{ Membrane Permeance } & \multirow{2}{*}{$\begin{array}{c}\text { Batch } \\
\text { Reference } \\
\text { ID }\end{array}$} \\
\hline & $\begin{array}{l}\text { Before } \\
{[\operatorname{lmhb}]}\end{array}$ & $\begin{array}{c}\text { After } \\
{[\operatorname{lmhb}]}\end{array}$ & $\begin{array}{c}\text { Change } \\
{[\operatorname{lmhb}]}\end{array}$ & \\
\hline$\# 10$ & 34.3 & 33.2 & -1.1 & Batch\#1 \\
\hline \#11 & 36.2 & 35.6 & -0.6 & Batch\#1 \\
\hline \#12 & 31.9 & 32.9 & 1.0 & Batch\#1 \\
\hline \#13 & 38.3 & 38.1 & -0.2 & Batch\# 1 \\
\hline$\# 14$ & 40.4 & 40.1 & -0.3 & Batch\#1 \\
\hline$\# 15$ & 38.3 & 37.1 & -1.2 & Batch\#1 \\
\hline \#16 & 39.1 & 38.9 & -0.2 & Batch\#1 \\
\hline$\# 17$ & 37.5 & 35.3 & -2.2 & Batch\#1 \\
\hline average & 37.0 & 36.4 & -0.6 & \\
\hline
\end{tabular}

*Imhb: liter $/ \mathrm{m}^{2} /$ hour/bar

$\underline{\text { TMC membrane fouling prevention }}$

We have done the membrane fouling test at GTI, as well as at our membrane partner, Media \& Process Technology (MPT) facility. At GTI, we used natural gas combustion flue gas as the baseline testing for 100 hours, then add into the flue gas stream $\mathrm{SO}_{2}$ to reach a concentration of about $300 \mathrm{ppm}$ to simulate the high end $\mathrm{SO}_{2}$ concentration for a power plant flue gas. At MPT, we have built an oil burner test setup, which can generate soot particles, tars, and other contaminates to accelerate the membrane fouling process to see its impact on the membrane at TMC application. A batch of 8 membranes fouled at the GTI testing facility in the presence of natural gas based combustion flue gas were tested for water permeance and comparison against clean membrane results. For the water transport flux testing, the 
permeance results were obtained using distilled water pretreated with a $100 \AA$ pore size membrane. The tests were conducted at room temperature $\left(\sim 22^{\circ} \mathrm{C}\right)$ at $10 \mathrm{psig}$. The data in Table 3-1 shows the permeance and the change in permeance following the TMC testing. A negative value for the change in permeance indicates a decrease in permeance following exposure to the flue gas. In all but one of the cases, the membrane permeance decreased slightly, indicating a general but relatively small amount of membrane fouling. A slight decay in membrane permeance is to be expected under general use conditions. It should be noted that the error in the measurement in the water testing unit is on the order of 0.2 to 0.4 liter/m2/hr/bar, so that many of the observed changes in membrane permeance are within the error limit. Hence, overall, under the gas conditions studied, very little impact on membrane permeance is noted.

Visual inspection of the tubes revealed the deposition of a small amount of black debris on the surface of the membranes consistent with the general trend in the permeance results. The photographs of the membrane elements following the fouling test are shown in Figure 3-12 and Figure 3-13. It is clear that the debris is concentrated at one end of the elements and can be seen on all of the membranes in the bundle. These are the soot particles generated by occasional rich combustion, and it can be easily wiped off from the membrane surface. Because the soot particles are of the size in microns, much larger than the nano-scale membrane pores, also plenty of space between these particles, no obstruction for vapor flowing through. This was confirmed by the minimum permeate rate loss.

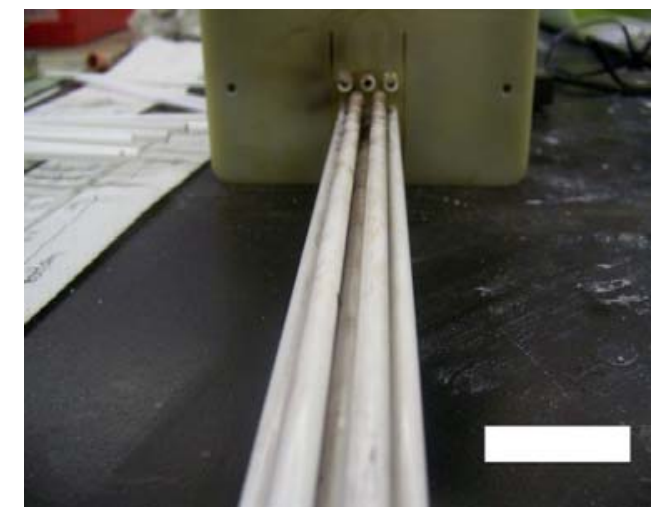

Figure 3-12: Photograph of the membranes following fouling test. 


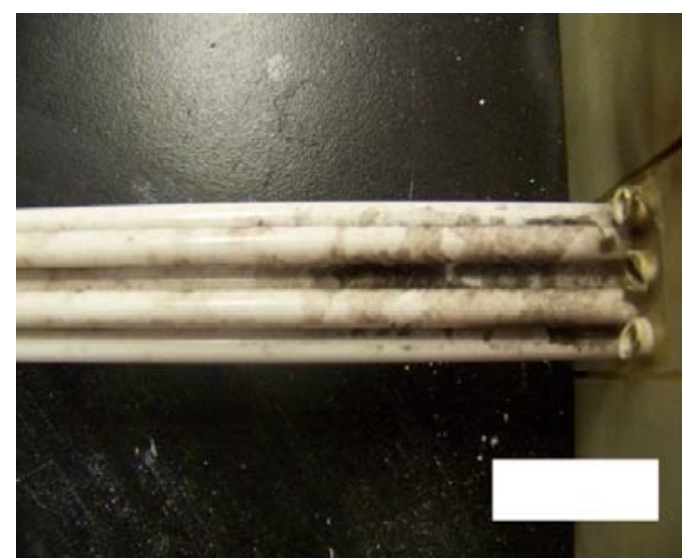

Figure 3-13: Photograph of black debris on the membranes following fouling test.

The results in Table 3-2 with 200ppm SO 2 show permeance increasing by up to $50 \%$. SEM photomicrographs of the Batch \#2 membrane surfaces showed no evidence of "catastrophic" membrane damage, specifically, cracking, pinholing, delamination, etc. Further, cross sections of the surface layer did not appear to show any irregular features and were generally consistent with the virgin membranes. Hence, the increase in Batch \#2 membrane permeance in Table 3-2 is likely due to membrane pore growth as a result of exposure of the membrane surface to low $\mathrm{pH}$ due to the $\mathrm{SO}_{2}$ presence at high temperature moisture condition. At the moment it is not known if the current pore growth represents a new equilibrium or if pore size enlargement will continue with additional exposure to $\mathrm{SO}_{2}$ laden combustion gas.

Table 3-2: membrane transport rate changes after 100 hour test with 200ppm $\mathrm{SO}_{2}$ flue gas

\begin{tabular}{|c|c|c|c|c|}
\hline \multirow{2}{*}{$\begin{array}{c}\text { Membrane } \\
\text { ID } \\
\text { [-] }\end{array}$} & \multicolumn{3}{|c|}{ Membrane Permeance } & \multirow{2}{*}{$\begin{array}{c}\text { Batch } \\
\text { Reference } \\
\text { ID }\end{array}$} \\
\hline & $\begin{array}{l}\text { Before } \\
\text { [lmbb] }\end{array}$ & $\begin{array}{c}\text { After } \\
\text { [lmhb] }\end{array}$ & $\begin{array}{l}\text { Change } \\
\text { [lmhb] }\end{array}$ & \\
\hline$\# 18$ & 40.7 & 50.1 & 9.4 & Batch\#2 \\
\hline$\# 19$ & 35.4 & 54.3 & 18.9 & Batch\#2 \\
\hline$\# 20$ & 40.2 & 57.6 & 17.4 & Batch\#2 \\
\hline$\# 21$ & 39.6 & 62.6 & 23.0 & Batch $\# 2$ \\
\hline$\# 22$ & 36.4 & 62.8 & 26.4 & Batch\#2 \\
\hline$\# 23$ & 35.4 & 51.8 & 16.4 & Batch\#2 \\
\hline$\# 24$ & 40.7 & 57.7 & 17.0 & Batch\#2 \\
\hline$\# 25$ & 32.1 & 51.8 & 19.7 & Batch\#2 \\
\hline average & 37.6 & 56.1 & 18.5 & \\
\hline
\end{tabular}




\section{CHAPTER 4 \\ Pilot-Scale TMC Design, Fabrication and Performance Test}

\section{Introduction}

A pilot-scale test system for the TMC technology to be applied for coal-fired power plant flue gases was designed, fabricated, and assembled. The team then performed comprehensive testing for the 3-million-Btu/h capacity pilot-scale TMC unit with flue gas from a boiler in GTI's combustion laboratory. Steam was also added to the flue gas as required to simulate the moisture level corresponding to wet or dry FGD exhaust streams. The two separate TMC cooling water stream flow rates were adjusted to match in proportion with real power plant operating conditions, and optimized within a certain range to achieve different objectives of the TMC two stage designs. Recovered water quality was analyzed from the two outlet water streams. Both water and energy recovery from the TMC unit have been quantified and analyzed for the laboratory performance testing.

\section{System Design and Fabrication}

The TMC module design, TMC chamber design, and the overall test system design were carried out for a 3-million-Btu/h capacity pilot-scale TMC unit at GTI. The test system layout arrangement is as shown in Figure 4-1. Figure 4-2 shows one of the long membrane modules we specifically designed and made for the power plant application, which is 34" long compared with 18" long module that was typically used for industrial boilers. Figure 4-3 shows the test system installed in GTI boiler room, and Figure 4-4 is a close up view of the TMC unit. The whole system is configured with necessary pumps, valves, controls, flue gas ductwork, water piping, instrumentation, and data acquisition system. In addition, a boiler and related supporting equipment are an integrate part of the test system, to provide flue gases with different constituents for the TMC testing. 


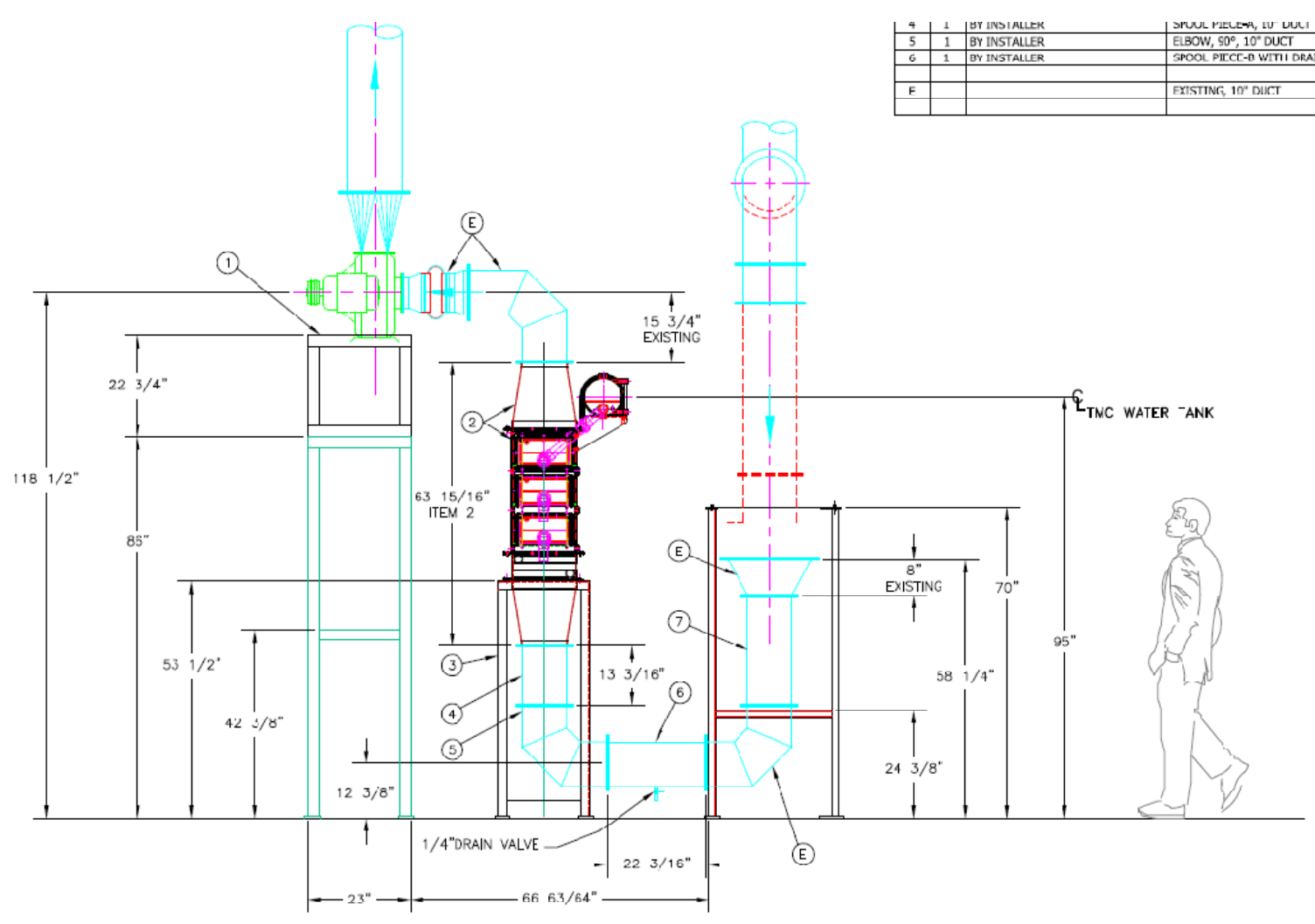

Figure 4-1: TMC test setup layout drawing (boiler and economizer are not shown)



Figure 4-2: Long TMC module designed and made for utility boiler application 


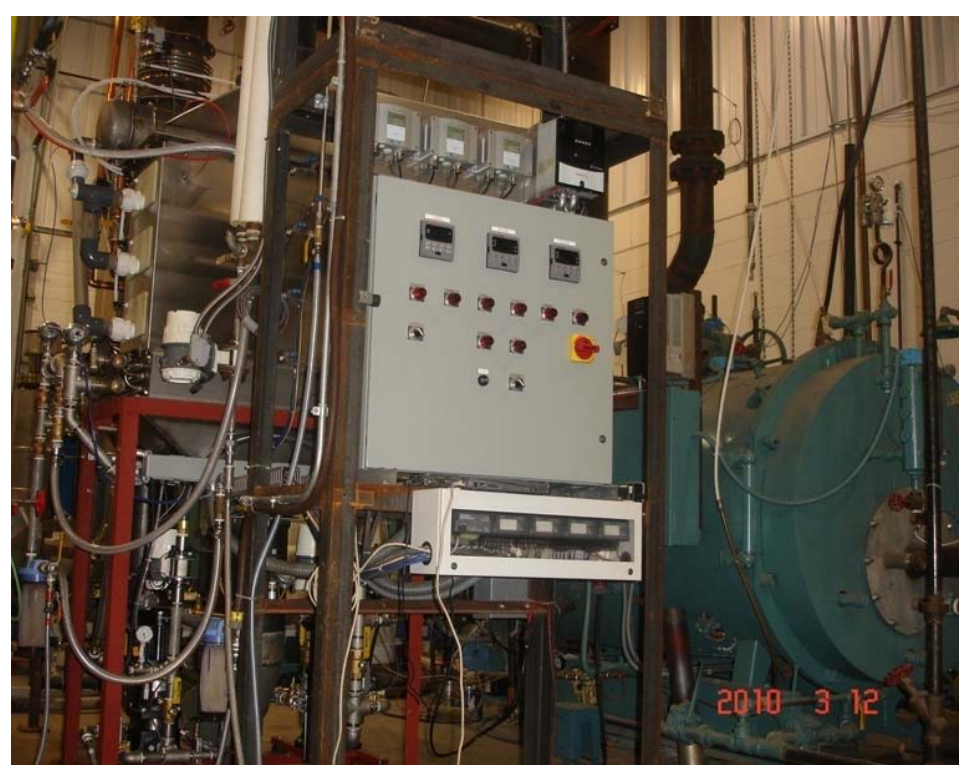

Figure 4-3: pilot-scale TMC unit test system with the boiler on the right side

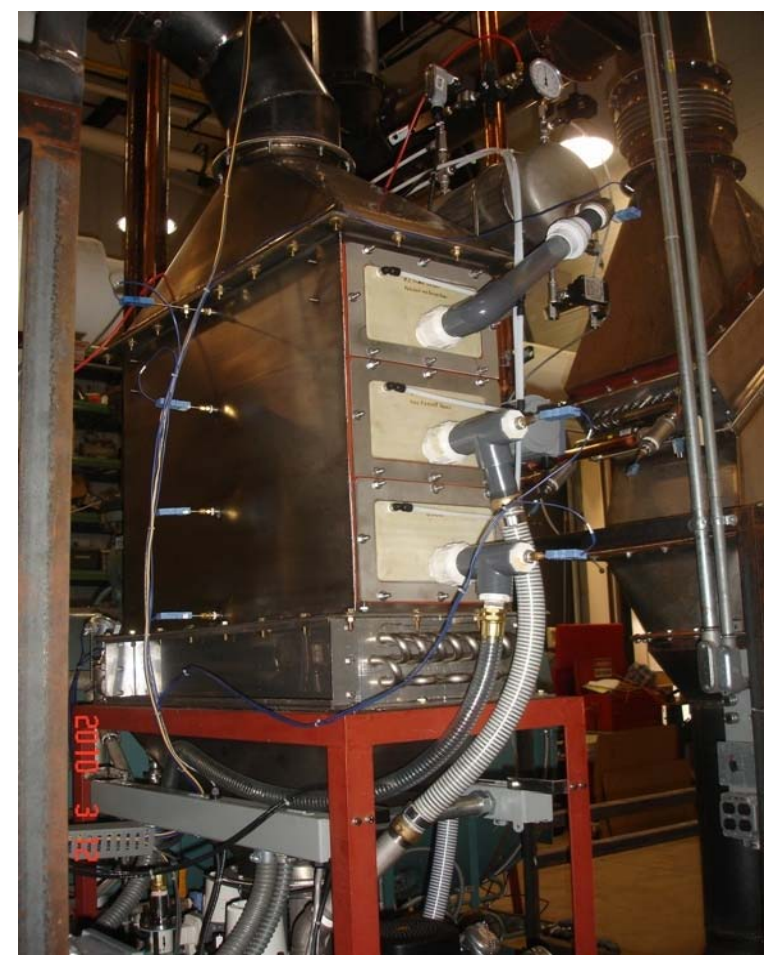

Figure 4-4: a close-up view of the TMC pilot unit

As shown in Figure 4-3 and Figure 4-4, the pilot TMC system was installed with control and instrumentations. A data acquisition system is also designed and implemented for this test setup to collect all important data into a computer. The whole test system also includes a boiler 
to supply flue gas to the TMC system, and a water softener to supply high quality water to TMC to simulate steam condensate.

\section{Pilot-Scale Unit Performance Test}

After installation and shakedown, we were able to perform several test runs to prove the TMC preliminary performance. Table 4-1 lists the 6 cases we have tested with detailed parameters. Good performance has been achieved. Both stage 1 and stage 2 of the TMC unit can realize high water vapor transfer rates, and the total vapor transport is $65 \%$ of the total moisture in the flue gas. Along with the water vapor transportation, significant waste heat was also transferred to the water side. The TMC/stage 1 water was heated up to $116^{\circ} \mathrm{F}$, which can contribute to higher boiler efficiency if it is used for boiler makeup water as designed. Then we proceed to more specific testing as will be discussed next. 
Table 4-1: Two stage TMC lab test results

\begin{tabular}{|c|c|c|c|c|c|c|c|}
\hline 4 & & 1 & 2 & 3 & 4 & 5 & 6 \\
\hline Natural gas flow rate & SCFH & 2250 & 2250 & 2250 & 2250 & 2250 & 2250 \\
\hline $\mathrm{O} 2$ at stack (dry) & $\%$ & 5.11 & 5.11 & 5.11 & 5.29 & 5.29 & 5.29 \\
\hline Flue inlet $T$ to $L P E$ & & 206.33 & 204.31 & 196.84 & 189.97 & 183.43 & 185.17 \\
\hline Flue inlet $T$ & ${ }^{\circ} \mathrm{F}$ & 146.98 & 149.04 & 143.79 & 143.45 & 137.50 & 147.43 \\
\hline Flue inlet Humidity & $\%$ & 100.00 & 98.00 & 97.77 & 98.70 & 100.00 & 100.00 \\
\hline Flue inlet dew point & ${ }^{\circ} \mathrm{F}$ & 130.91 & 131.11 & 129.67 & 129.29 & 130.27 & 131.97 \\
\hline Flue inlet vapor wt\% & $\%$ & 10.23 & 10.29 & 9.88 & 9.78 & 10.05 & 10.55 \\
\hline Flue stage 1 outlet $T$ & ${ }^{\circ} \mathrm{F}$ & 124.71 & 127.31 & 123.26 & 122.73 & 123.84 & 128.58 \\
\hline Flue stage 1 outlet Humidity & $\%$ & 99.4 & 100.1 & 100.1 & 93.2 & 99.1 & 91.7 \\
\hline Flue stage 1 outlet dew point & ${ }^{\circ} \mathrm{F}$ & 122.0 & 124.9 & 121.0 & 121.7 & 123.1 & 126.2 \\
\hline Flue stage 1 outlet vapor wt\% & $\%$ & 7.9 & 8.6 & 7.7 & 7.9 & 8.2 & 9.0 \\
\hline Flue stage 2 outlet $T$ & ${ }^{\circ} \mathrm{F}$ & 95.6 & 97.2 & 93.6 & 96.1 & 96.3 & 97.8 \\
\hline Flue stage 2 outlet Humidity & ${ }^{\circ} \mathrm{F}$ & 99.9 & 99.8 & 99.5 & 99.9 & 100.0 & 99.7 \\
\hline Flue outlet dew point & ${ }^{\circ} \mathrm{F}$ & 93.4 & 94.6 & 92.0 & 95.6 & 95.2 & 96.5 \\
\hline Flue stage 2 outlet vapor wt\% & $\%$ & 3.3 & 3.5 & 3.2 & 3.6 & 3.5 & 3.7 \\
\hline Overall Flue pressure drop & & 0.8 & 0.9 & 0.9 & 0.5 & 0.5 & 0.5 \\
\hline Stage 1 water FR & gpm & 5.8 & 7.0 & 6.6 & 7.0 & 6.7 & 4.3 \\
\hline Stage 1 water inlet $\mathrm{T}$ & ${ }^{\circ} \mathrm{F}$ & 84.0 & 95.0 & 81.7 & 93.0 & 91.6 & 100.9 \\
\hline Stage 1 water outlet $T$ & ${ }^{\circ} \mathrm{F}$ & 105.1 & 109.4 & 101.6 & 107.2 & 107.6 & 119.0 \\
\hline Stage 2 water FR & gpm & 10.8 & 10.0 & 9.9 & 13.8 & 13.9 & 10.0 \\
\hline Stage 2 water inlet $T$ & ${ }^{\circ} \mathrm{F}$ & 75.3 & 71.7 & 69.3 & 80.4 & 79.9 & 70.9 \\
\hline Stage 2 water outlet $T$ & ${ }^{\circ} \mathrm{F}$ & 93.2 & 93.3 & 88.9 & 93.9 & 94.1 & 95.6 \\
\hline \multicolumn{8}{|l|}{ Calculated Parameters } \\
\hline Stage 1 water transferred & $\mathrm{lb} / \mathrm{h}$ & 50.7 & 36.7 & 47.6 & 42.4 & 41.0 & 35.3 \\
\hline Stage 2 water transferred & $\mathrm{lb} / \mathrm{h}$ & 100.7 & 113.1 & 99.2 & 94.8 & 103.3 & 116.7 \\
\hline Total water transferred & $\mathrm{lb} / \mathrm{h}$ & 151.3 & 149.8 & 146.8 & 137.2 & 144.3 & 152.0 \\
\hline Total water transferred & $\%$ & 67.3 & 66.2 & 67.6 & 63.3 & 64.7 & 65.0 \\
\hline Stage 1 Water enthalpy change & Btu/h & 61067 & 50207 & 65841 & 49403 & 53556 & 38427 \\
\hline Stage 1 Flue enthalpy change & Btu/h & 77295 & 61653 & 70822 & 65302 & 60388 & 59299 \\
\hline Stage 2 Water enthalpy change & Btu/h & 96245 & 107595 & 96251 & 92367 & 98127 & 122864 \\
\hline Stage 2 Flue enthalpy change & Btu/h & 131059 & 144153 & 128139 & 121781 & 131873 & 149068 \\
\hline
\end{tabular}




\section{$\underline{\text { Two stage TMC pore size effect comparison }}$}

To further verify membrane pore size effect, we have arranged the following tests for this pilot-scale unit. Overall, there are three TMC modules in this two-stage TMC pilot unit, one for TMC/stage 1 (bottom), and two for TMC/stage 2 (middle and top). Three different TMC settings have been tested to compare the TMC water transport and heat recovery performance for different TMC membrane pore size effect. Figure 4-5 shows the detailed different pore size TMC module arrangement for the three settings.

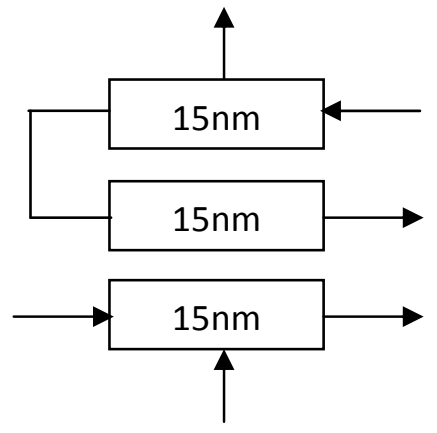

TMC Setting A

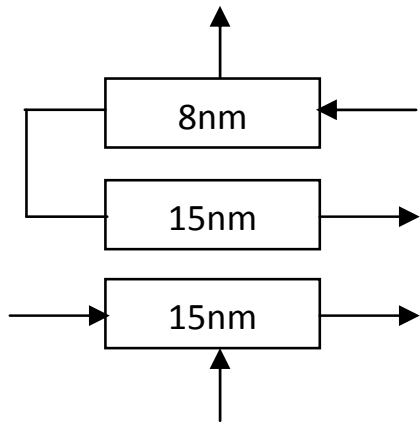

TMC Setting B

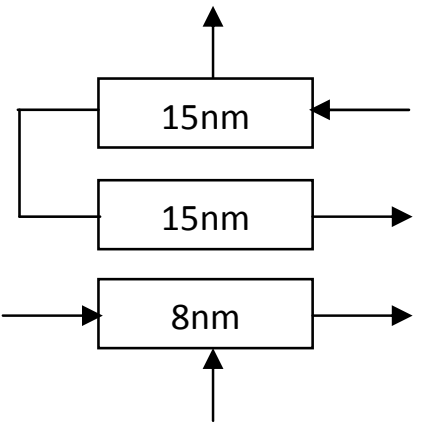

TMC Setting C

Figure 4-5: Different pore size membrane modules used for different TMC test settings

For TMC setting A, a series of tests have been done to test the TMC water transport and heat recovery performance at different flue gas and water conditions. For TMC settings B and C, some TMC parameters have been changed to compare the heat and water recovery performance with setting $A$. The testing facility has the capacity with flue gas inlet temperature $150-190^{\circ} \mathrm{F}$, and inlet dew point $130-155^{\circ} \mathrm{F}$; stage 1 soften water flow rate $4-14 \mathrm{GPM}$, and inlet temperature $80-110^{\circ} \mathrm{F}$, to simulate steam condensate; and stage 2 city water flow rate 414GPM, with inlet temperature $65-100^{\circ} \mathrm{F}$, to simulate circulating cooling water.

Figure 4-6 and Figure 4-7 show the two-stage TMC water transfer rates for stage 1, stage 2, and overall TMC unit at different stage 1 and stage 2 cooling water average temperatures. The water average temperature is defined as $T_{\text {avg }}=\left(T_{\text {in }}+T_{\text {out }}\right) / 2$, and it is a parameter considering both water inlet temperature and flow rate effect (Tout is related with the water flow rate). Also, we compared the water transfer rates at different stage 1 water inlet temperatures and flow rates, stage 2 water inlet temperatures and flow rates. For example, Figure 4-8 shows the water transfer rates at different stage 1 water inlet temperatures for 
these three TMC settings. All the results show, for different TMC settings, at lower inlet flue gas moisture content (inlet dew point $132^{\circ} \mathrm{F}$ ), there is no significant difference for water transfer rates in the two stages. The larger membrane pore size TMC module does not increase the water transfer rate, which means neither of the membrane modules has reached their water transport limits. This also demonstrates that for this flue gas moisture content and cooling condition, the smaller membrane pore size module TMC arrangement (all with 8nm membrane pore size) is enough to recover the water and heat from flue gas successfully.

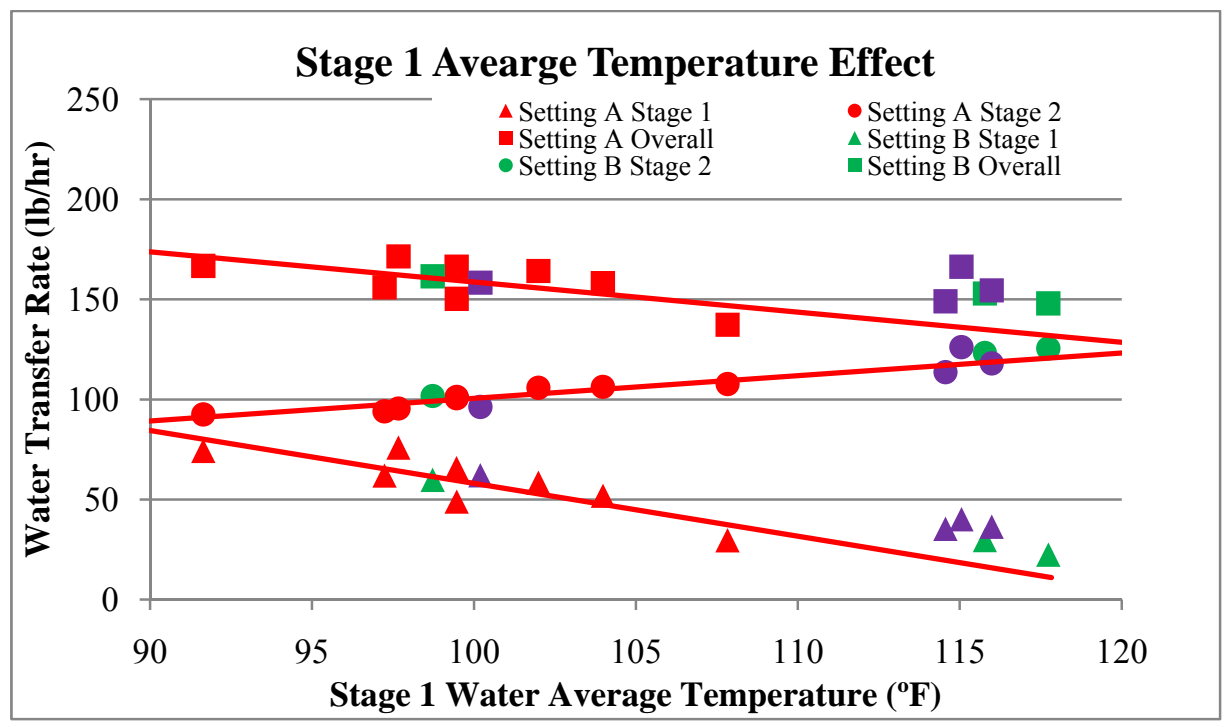

Figure 4-6: Stage 1 water average temperature effect for different TMC settings

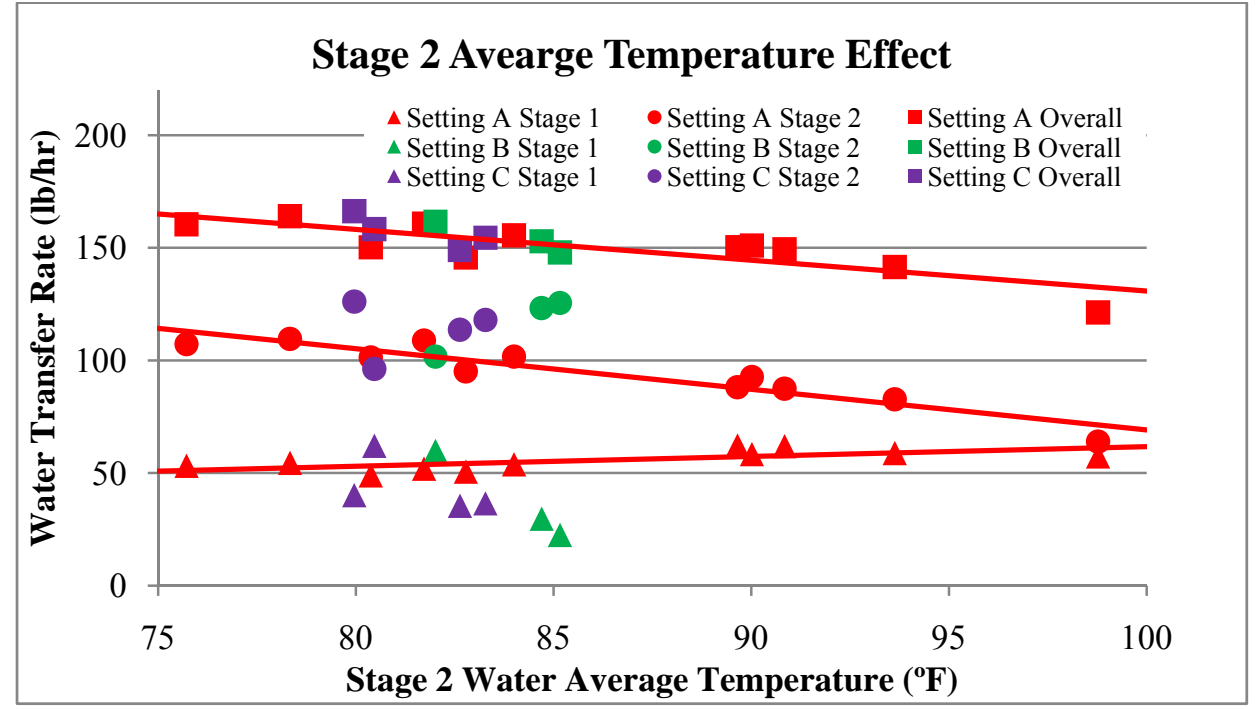

Figure 4-7: Stage 2 water average temperature effect for different TMC settings 


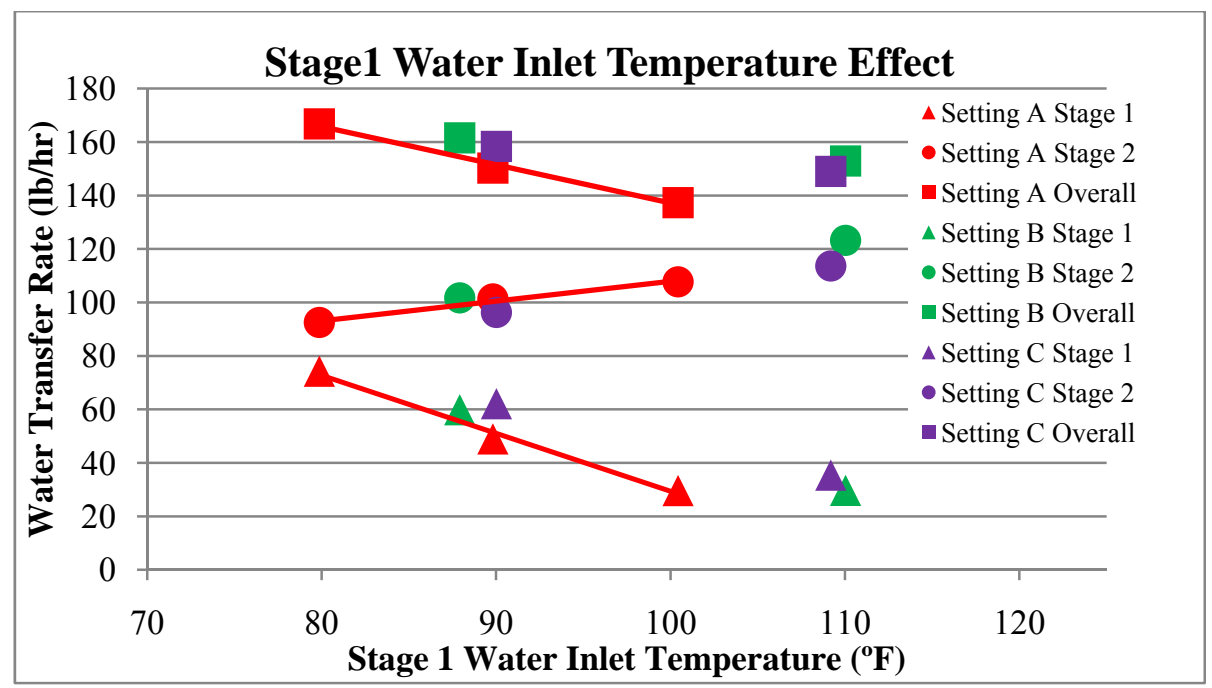

Figure 4-8: Stage 1 water inlet temperature effect for different TMC settings

Figure 4-9 and Figure 4-10 show the two-stage TMC water transfer rates for stage 1, stage 2, and overall TMC unit at different stage 1 and stage 2 averaged cooling water temperatures for higher inlet flue gas dew point $152^{\circ} \mathrm{F}$. Both plots show at the same stage 1 and stage 2 averaged cooling water temperatures, stage 1 water transfer rates are the same for the three different TMC settings. Even at the higher flue gas inlet moisture content conditions, the smaller membrane pore size module can still transfer most condensate and has similar performance with larger membrane module. At lower stage 2 average cooling water temperature, as shown in Figure 4-10, the stage 2 water transfer rates are $15-20 \%$ lower for settings $B$ and $C$ than setting $A$. And for setting $B$ and $C$, the stage 2 water transfer rate did not increase when stage 2 water average temperature decreases. It indicates the water condensate rate is higher than stage 2 water transfer limit for the smaller pore size module. Also, there were a lot of condensate flowing out from the drain port at the bottom of the TMC housing for the high flue gas moisture content tests for TMC setting $B$ and $C$. Therefore for higher moisture content flue gas, the $15 \mathrm{~nm}$ membrane pore size should be used for all the TMC modules to achieve the highest water transport rate for both stage 1 and stage 2 . 


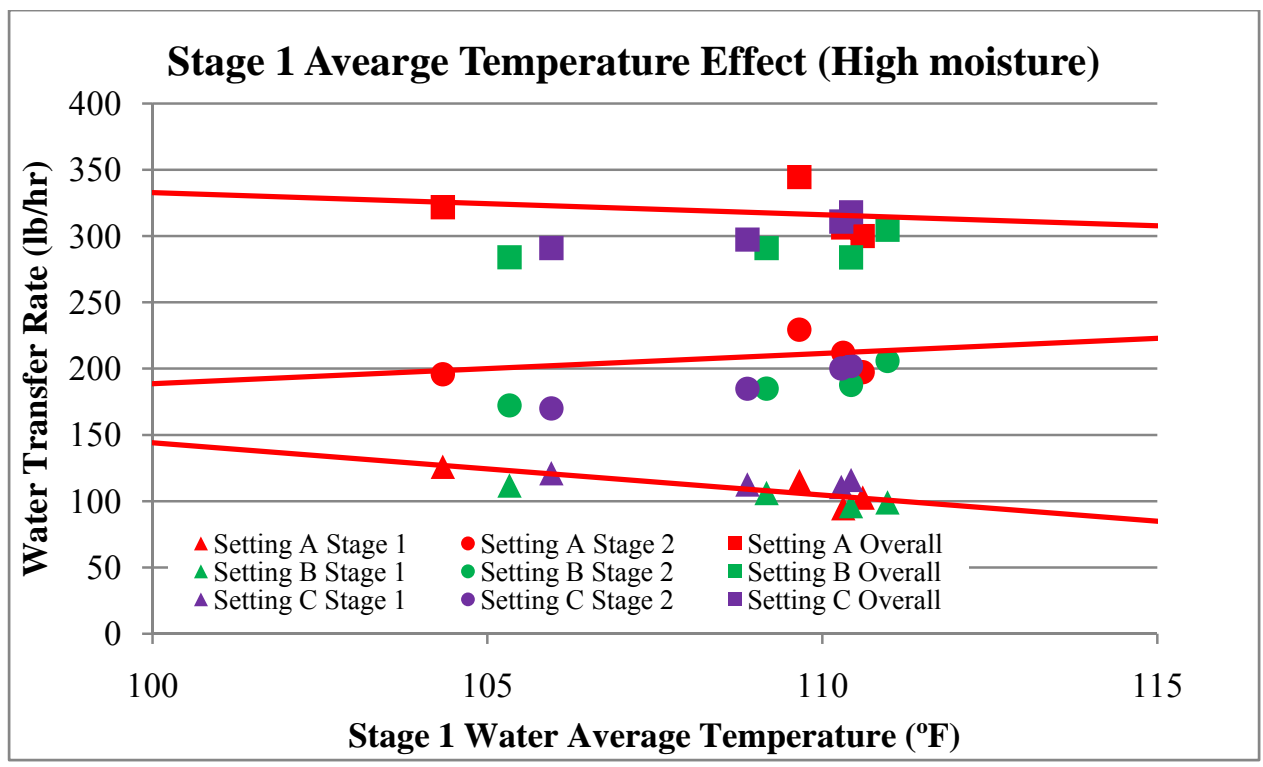

Figure 4-9: Stage 1 water average temperature effect for different TMC settings

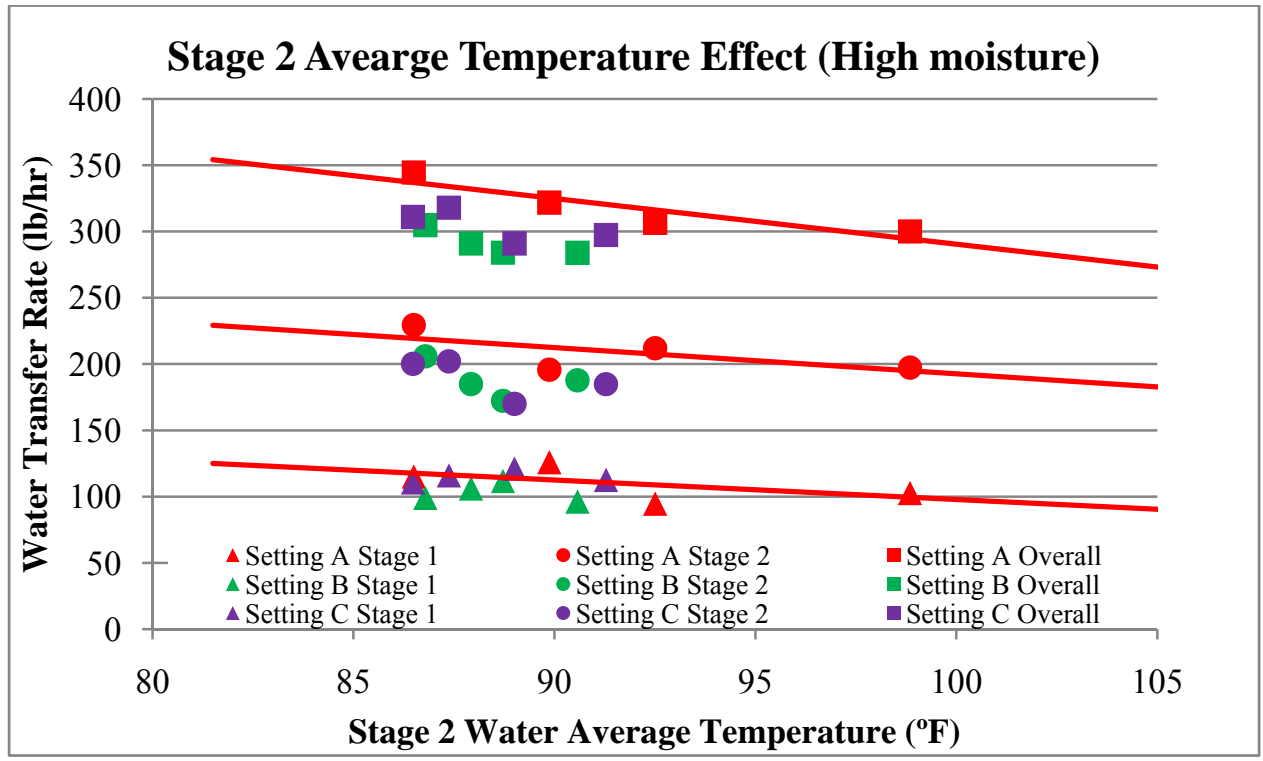

Figure 4-10: Stage 2 water average temperature effect for different TMC settings

\section{Pilot-Scale Unit Performance Testing}

After the above TMC membrane pore size effect testing, the team have carried out a series of testing to verify the TMC water transport and heat recovery performance at different flue gas and water conditions.

Flue gas and cooling water inlet parameters have been varied to test the TMC performance. We setup the flue gas inlet temperature $150^{\circ} \mathrm{F}$, dew point $133^{\circ} \mathrm{F}$ (corresponding 
to stack $\mathrm{O}_{2}$ around $5 \%$ ), stage 1 flow rate $7 \mathrm{GPM}$ and inlet temperature $80^{\circ} \mathrm{F}$, stage 2 flow rate 10GPM and inlet temperature $70^{\circ} \mathrm{F}$, as the baseline condition, and the flue gas volume flow rate to TMC is $30,000 \mathrm{SCFH}$.

Figures 4-11 and 4-12 show the water transfer rates (stage 1, stage 2, and overall) at different stage 1 water flow rates and water inlet temperatures. Higher flow rate or lower inlet temperature increased the stage 1 water transfer rate; at the same time, the flue gas carries less moisture to TMC stage 2, and stage 2 water transfer rate therefore decreased. The overall water transfer rate change with Stage 1 water flow rate is not that significant due to the balance effect of stage 2 . On the other hand, the Stage 1 water temperature effect is stronger than the water flow rate effect. Therefore, the overall TMC water transport rate will be affected more by the steam condensate temperature instead of its flow rate to the TMC as the cooling source for Stage 1.

Figures 4-13 and 4-14 show the water transfer rates (stage 1, stage 2, and overall) at different stage 2 water flow rates and water inlet temperatures. The different inlet parameters do not affect the TMC stage 1 performance, and the overall water transfer rate change is exactly the same as stage 2 transfer rate change. Figures 4-14 shows when the circulating cooling water temperature changes from $65^{\circ} \mathrm{F}$ to $90^{\circ} \mathrm{F}$, the TMC stage 2 and overall transfer rate will decrease $50 \%$ and $30 \%$, respectively. The stage 2 inlet temperature will be a key parameter for the TMC water recovery performance.

Figure 4-15 shows the TMC water transfer rates at different flue gas inlet temperatures. The results proved that the flue gas inlet temperature has minimum effect on the TMC performance at current range $150^{\circ} \mathrm{F}$ to $190^{\circ} \mathrm{F}$, because sensible heat transfer rate is much less than latent heat for the overall process. Figure 4-16 shows the water transfer rates for different flue gas inlet dew points, from $129^{\circ} \mathrm{F}$ to $155^{\circ} \mathrm{F}$. The higher moisture concentration in flue gas increased the TMC performance significantly, overall water transfer rate $150 \mathrm{lb} / \mathrm{hr}$ for flue gas dew point at $130^{\circ} \mathrm{F}$, and $300 \mathrm{lb} / \mathrm{hr}$ for flue gas dew point at $155^{\circ} \mathrm{F}$. The tests also indicate that for higher moisture content cases, some of the condensed water vapor was not able to be transferred into TMC water side, for the membrane already reached its transport limit at this 
condition. As an evidence, there were some droplets observed attached to the membrane tube surfaces or falling down.



Figure 4-11: Stage 1 water flow rate effect

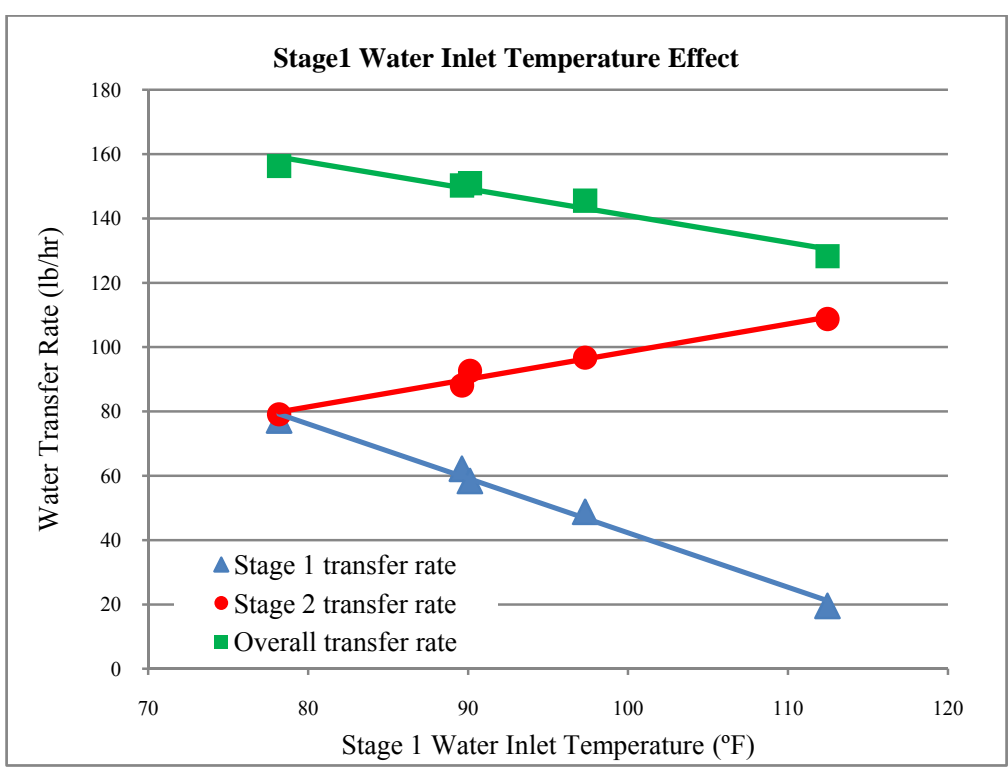

Figure 4-12: Stage 1 water inlet temperature effect 


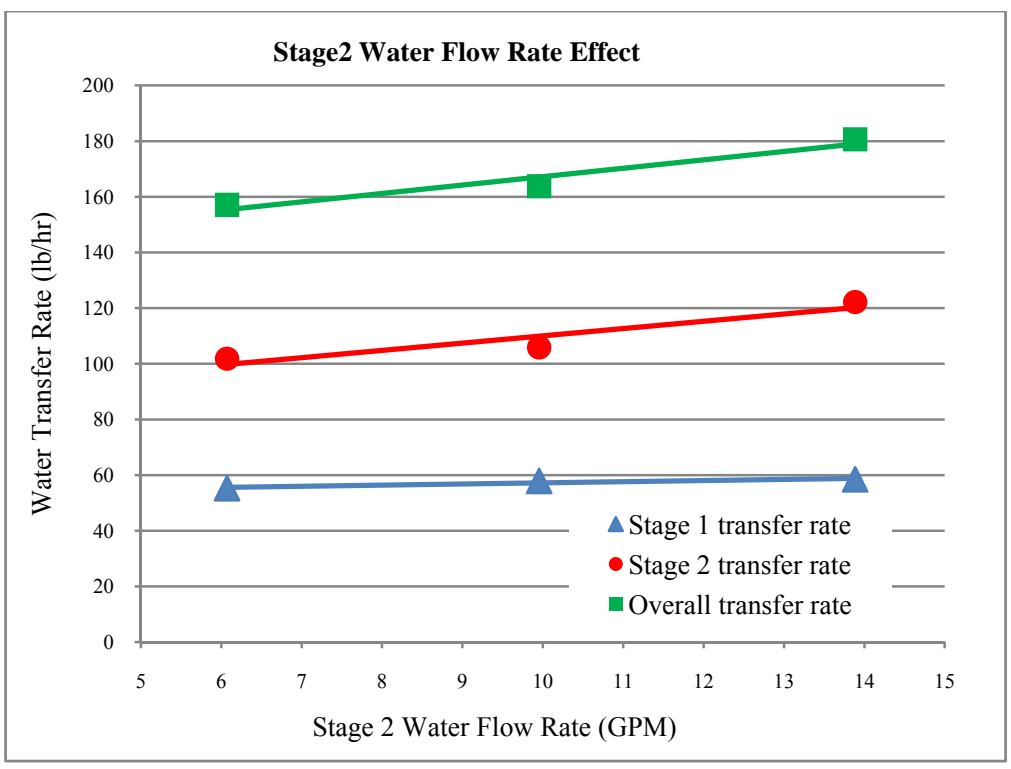

Figure 4-13: Stage 2 water flow rate effect

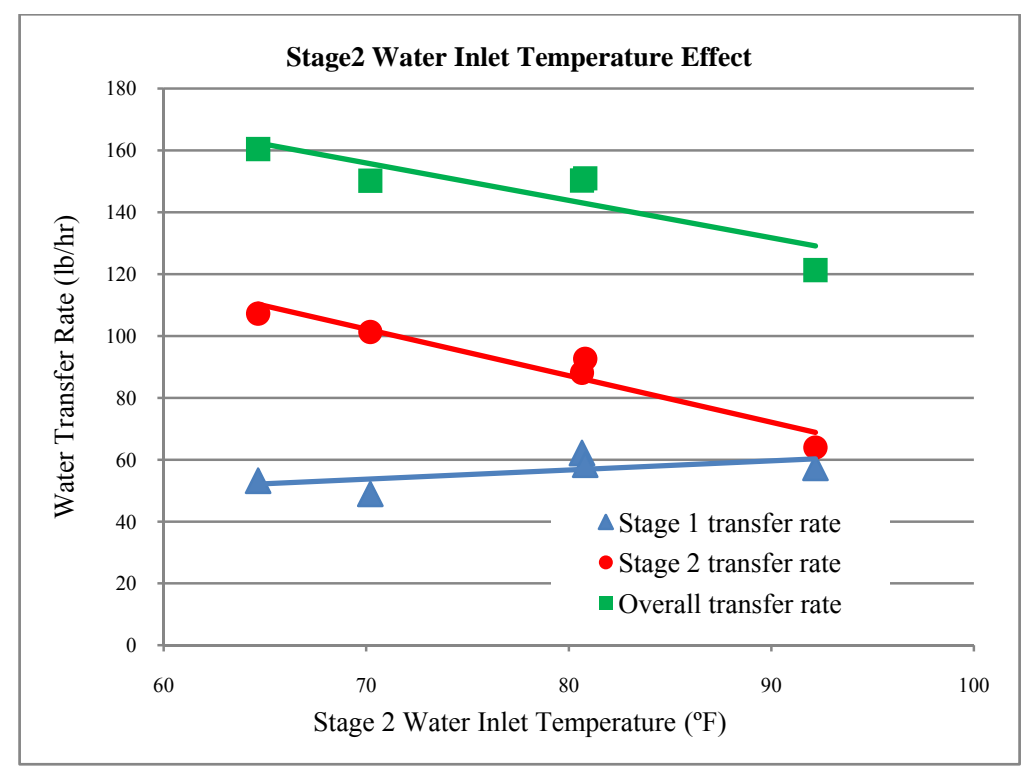

Figure 4-14: Stage 2 water inlet temperature effect 


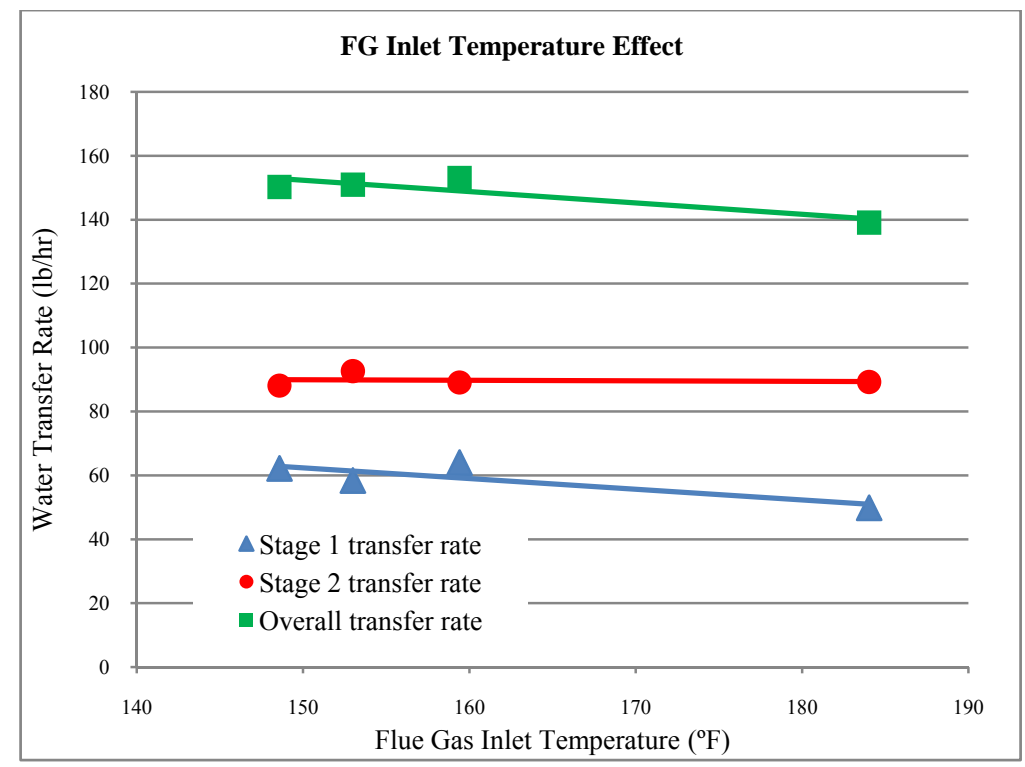

Figure 4-15: Flue gas inlet temperature effect.

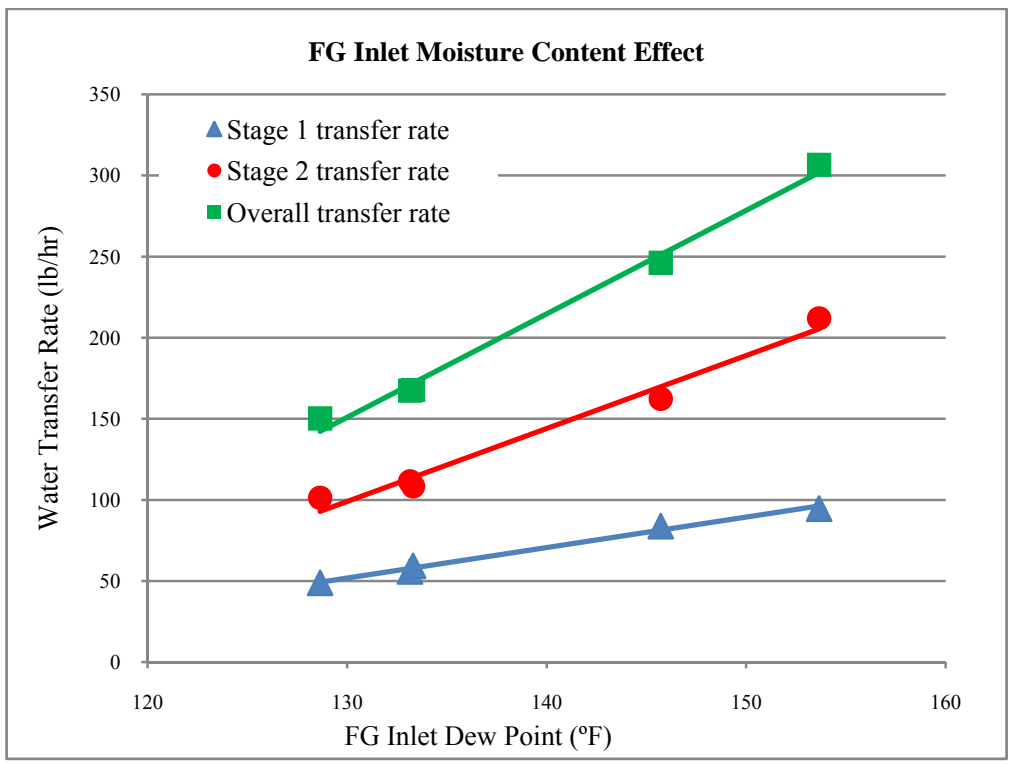

Figure 4-16: Flue gas inlet moisture content effect

Figures 4-17 and 4-18 show the water transfer rates at different stage 1 and stage 2 water average temperatures. The average temperature of stage 2 affects the overall TMC performance stronger than that of stage 1, mainly because TMC/stage 2 is more sensitive to the water temperature change. Figures 4-19 and 4-20 show the heat transfer coefficient for stage 1 and stage 2 at different TMC water transfer rate. The latent heat from the water vapor 
condensation is very important to the heat transfer coefficient, much higher heat transfer coefficients have been achieved at higher water transfer rate (same as condensation rate).



Figure 4-17: Stage 1 average temperature effect

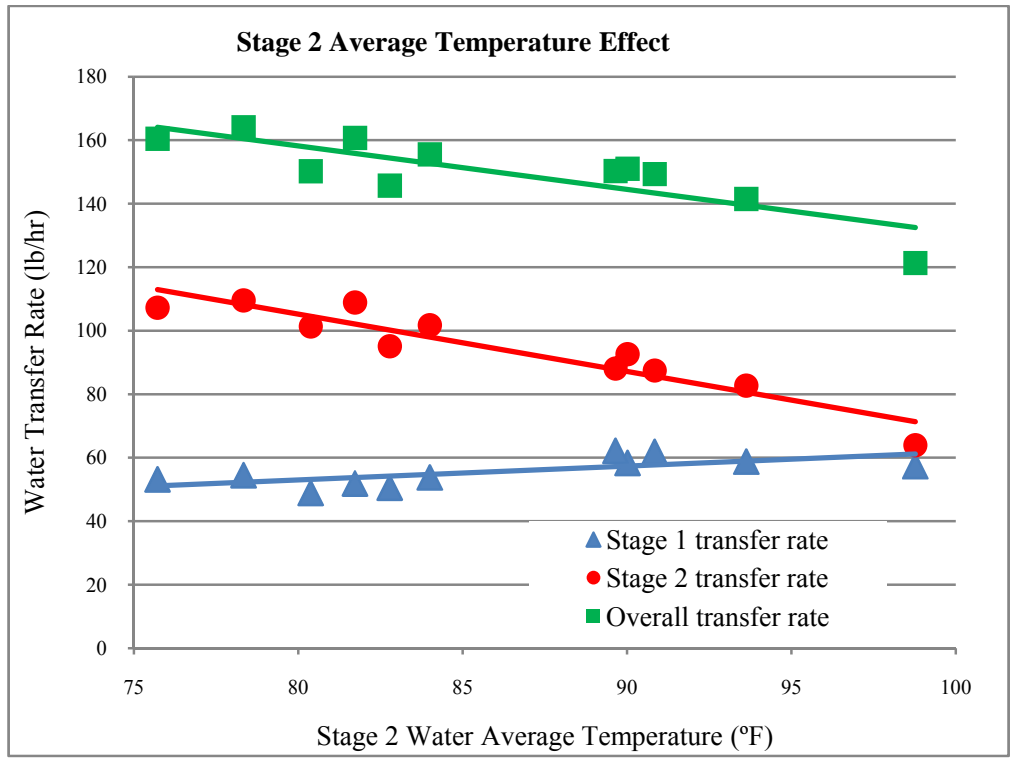

Figure 4-18: Stage 2 average temperature effect 


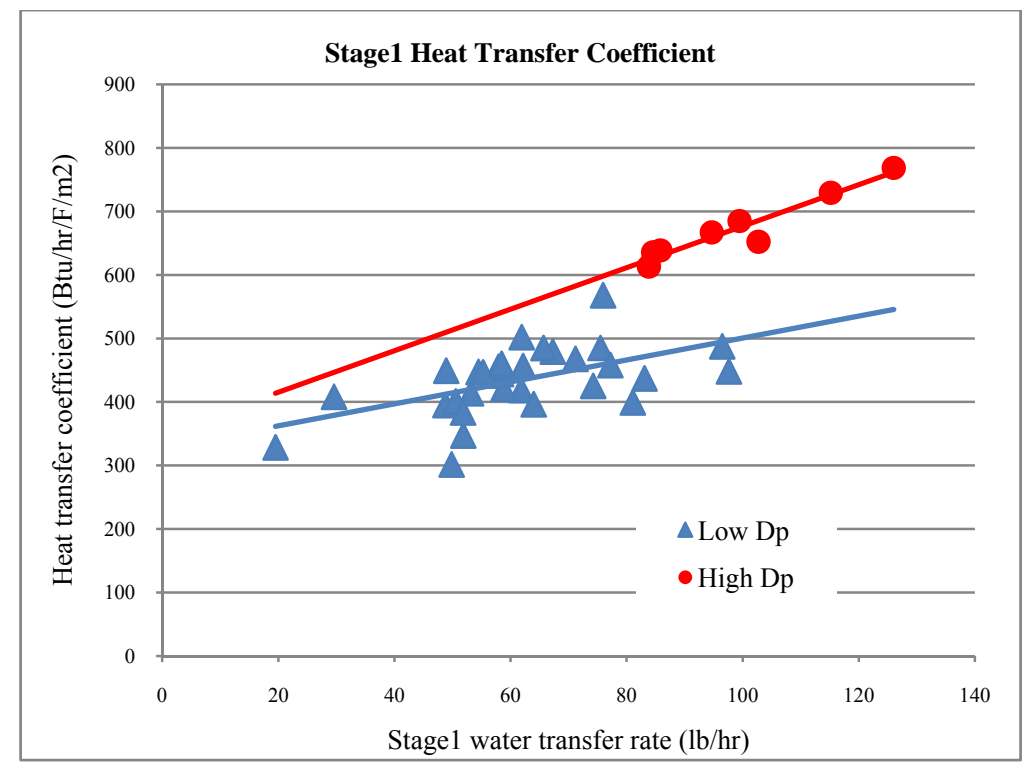

Figure 4-19: Stage 1 heat transfer coefficient vs. flow rate



Figure 4-20: Stage 2 heat transfer coefficient vs. flow rate

The heat recovery results for different water and flue gas inlet conditions are shown in Figures 4-21 to 4-28. The overall water side enthalpy changes include both sensible heat and latent heat recovery from the boiler flue gas. For TMC stage 1, sensible heat transfer is $20-45 \%$ of the overall heat recovery. For TMC stage 2, sensible heat transfer is only $14-21 \%$ of the overall heat recovery. Higher water flow rate or lower water inlet temperature increases the water enthalpy change, which is the total amount of the TMC heat recovery. Higher flue gas inlet temperature increases sensible heat transfer due to the larger temperature difference 
between the flue gas side and water side; however, it will increase water side average temperature and decrease the water vapor condensation rate thus less latent heat transfer can occur. The flue gas inlet temperature effect for overall heat transfer is very small.

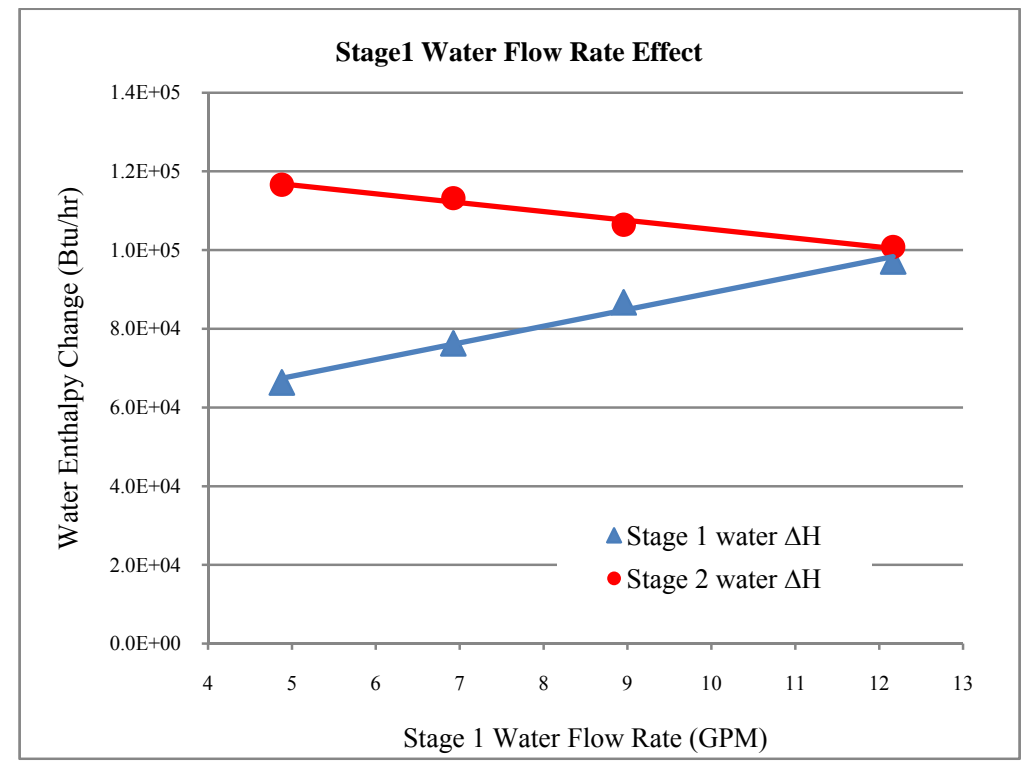

Figure 4-21: Stage 1 water flow rate effect on heat recovery

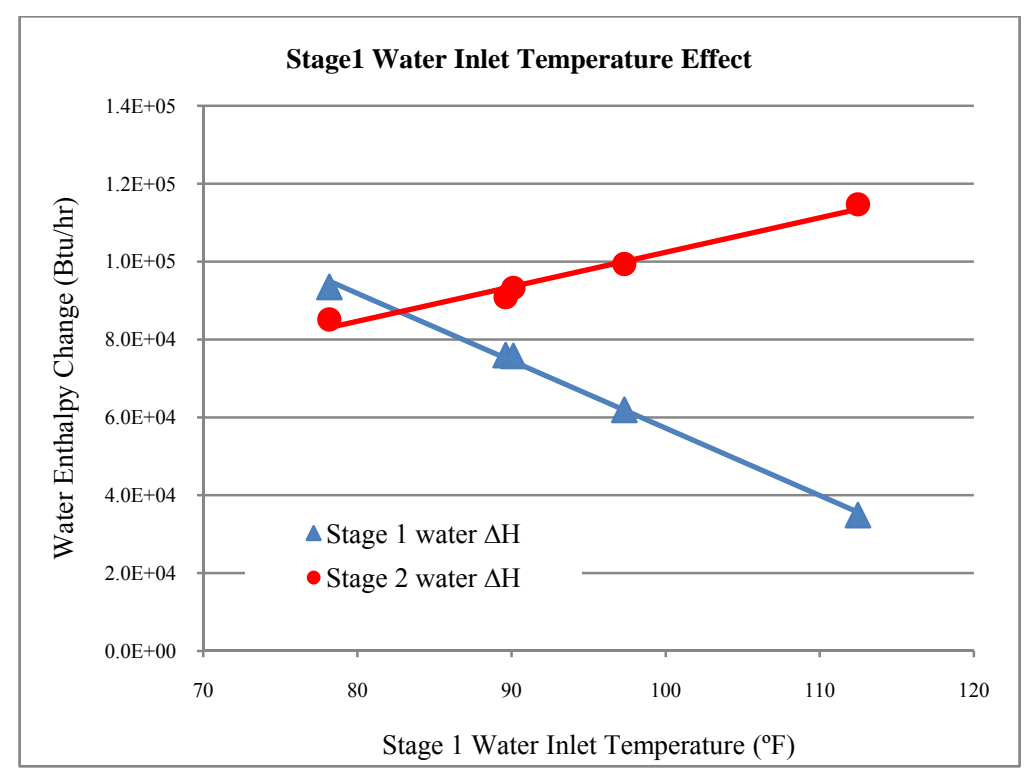

Figure 4-22: Stage 1 water inlet temperature effect on heat recovery 


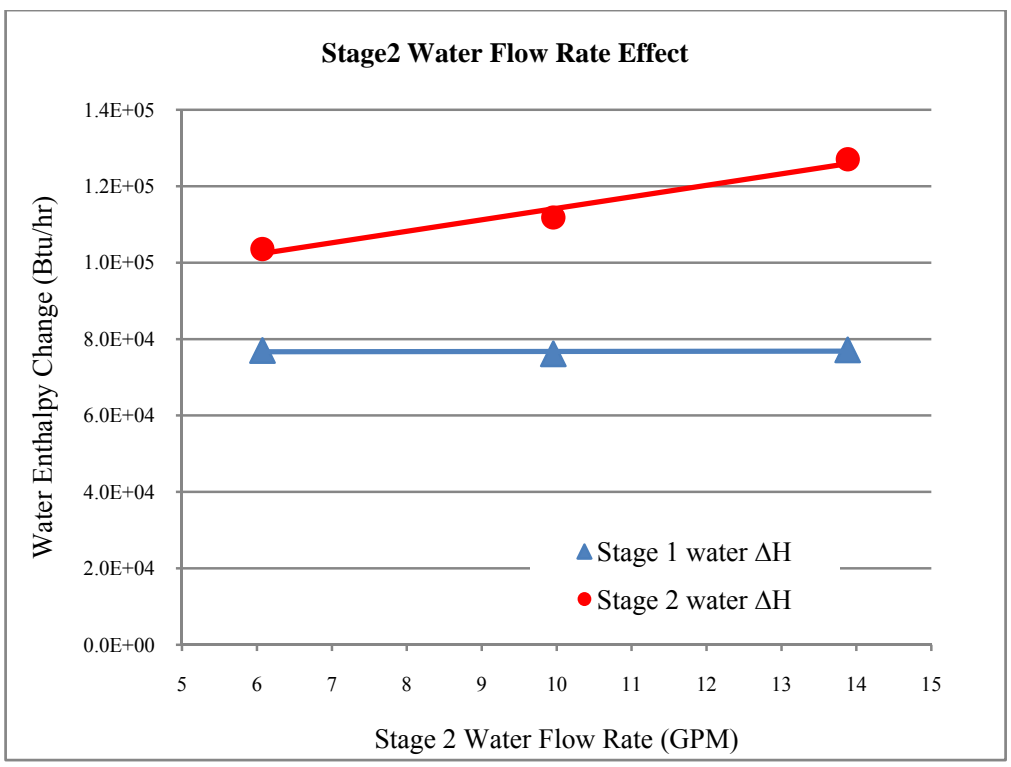

Figure 4-23: Stage 2 water flow rate effect on heat recovery

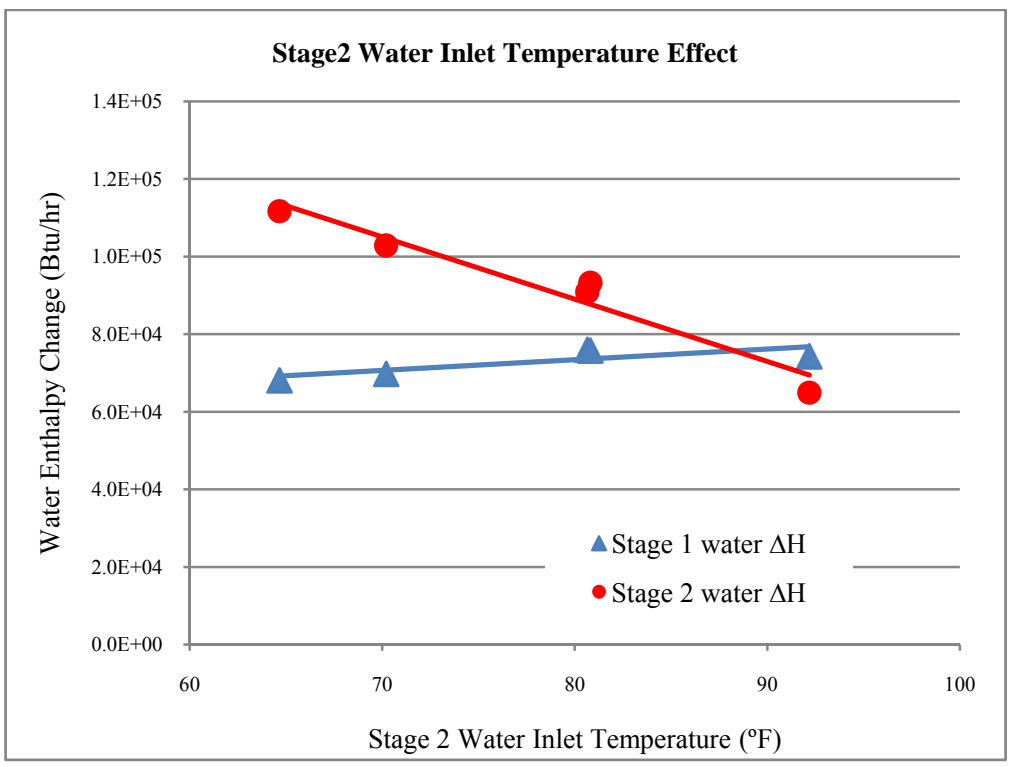

Figure 4-24: Stage 2 water inlet temperature effect on heat recovery 


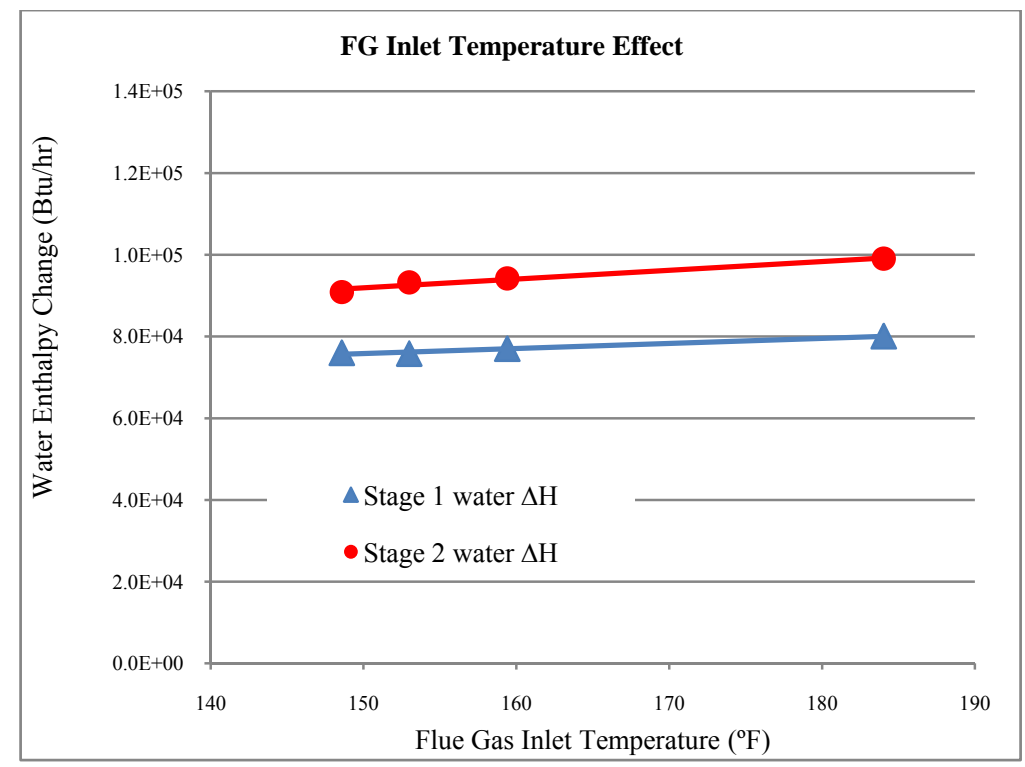

Figure 4-25: Flue gas inlet temperature effect on heat recovery

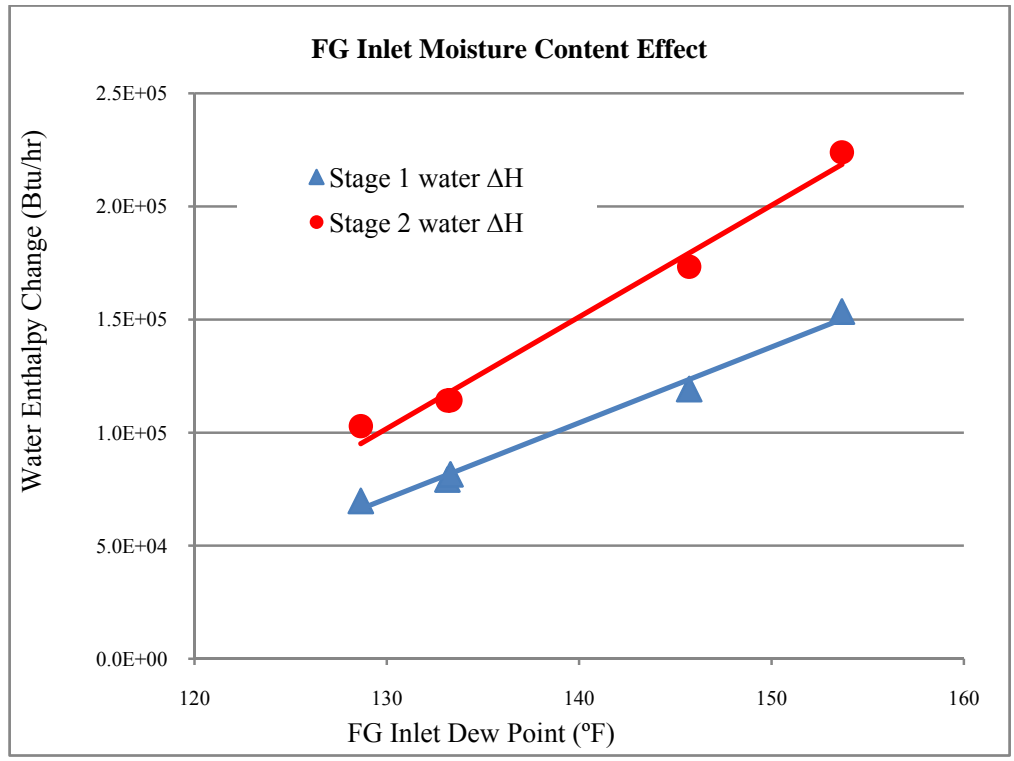

Figure 4-26: Flue gas inlet moisture content effect on heat recovery 


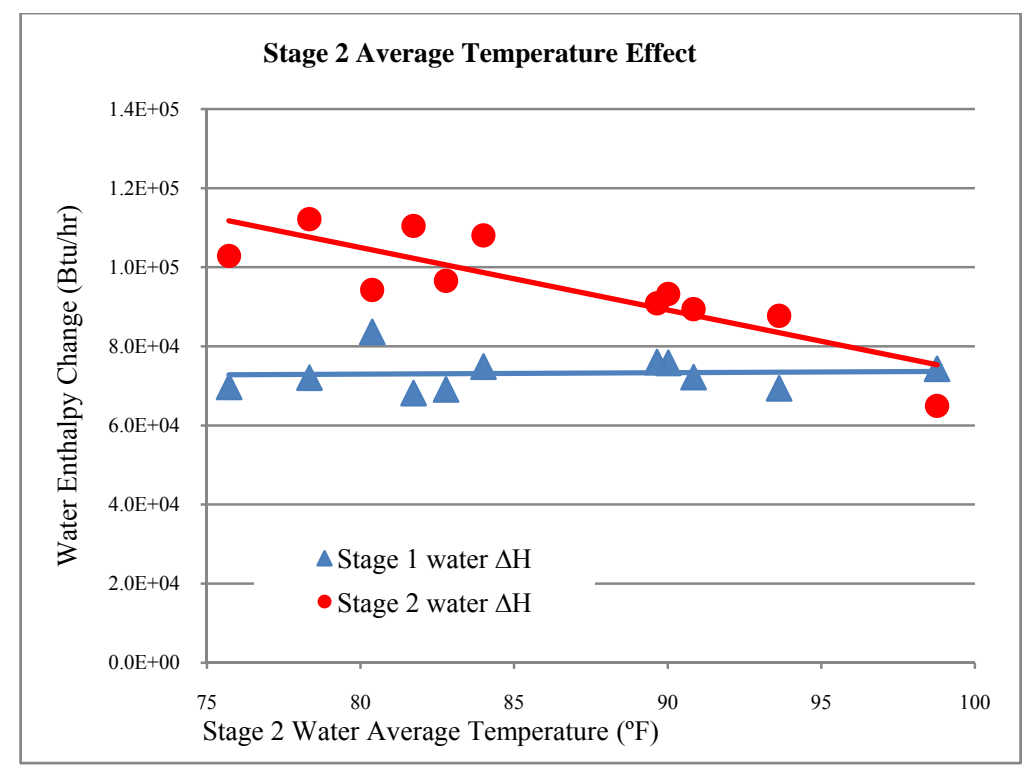

Figure 4-27: Stage 1 water average temperature effect for heat recovery

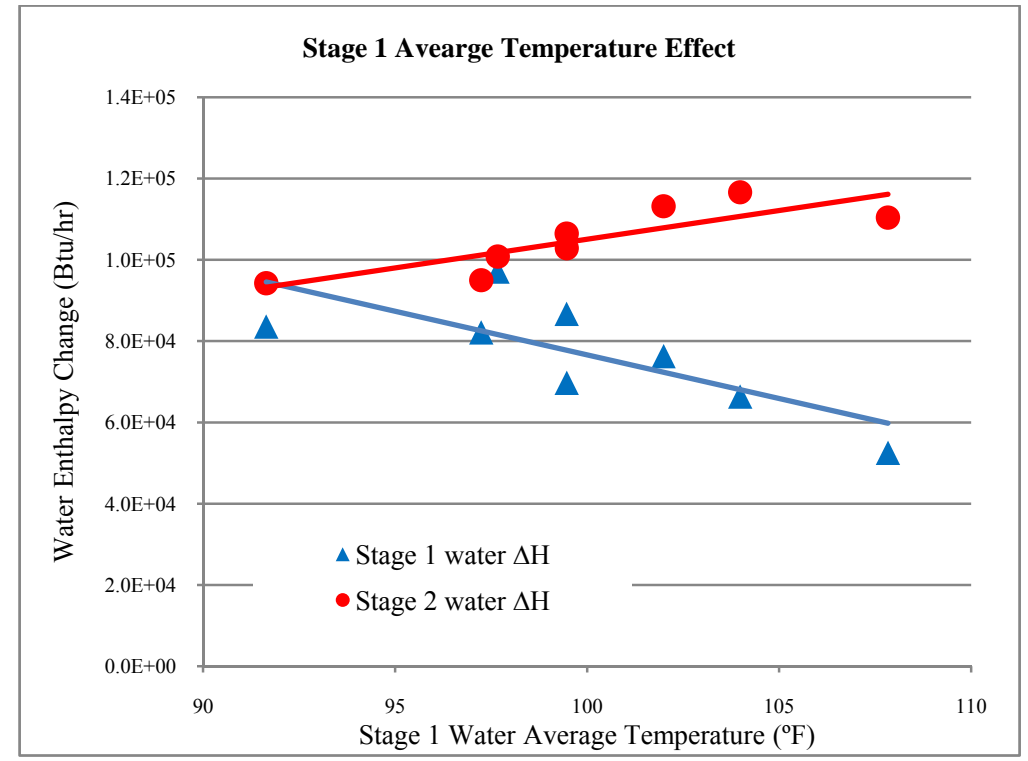

Figure 4-28: Stage 2 water average temperature effect for heat recovery

\section{$\underline{\text { Simulated coal-fired flue gas effect and water quality testing }}$}

In the TMC, water vapor from flue gas condenses inside the nano-scale TMC membrane pores, and blocks permanent gas components in flue gas to pass through. But a small amount of these permanent gases still can pass through the membrane to enter the TMC water stream. This is limited by the very short gas-membrane contact time and the membrane pore sizes, as well as the gas dissolvability into water. The following are tests we did about the water quality 
before it enters the TMC and after it coming out from the TMC, to verify how much acidic gas components may pass through the membrane, and their impact on the water quality.

The water quality was analyzed separately from the two water outlet streams of stage 1 and stage 2. For the water quality test, the stage 1 water flow rate was set to 7 GPM and its inlet temperature was $90^{\circ} \mathrm{F}$, stage 2 water flow rate was set to 10 GPM and its inlet temperature was $70^{\circ} \mathrm{F}$, and the membrane pore sizes for all the three TMC modules are $15 \mathrm{~nm}$. The measured water PH value, conductivity, and chemical analytical results are listed in Table 41 , for inlet and outlet streams of both stages. The conductivity of water is highly dependent on its concentration of dissolved salts and other ions in the solution. Pure water is typically at $0.55 \mu \mathrm{s} / \mathrm{m}$, and power plant boiler water is about $100 \mu \mathrm{s} / \mathrm{m}$. The water quality results show the $\mathrm{PH}$ value and water conductivities are almost the same for Stage 1 and Stage 2 water inlets and outlets. The decrease of $\mathrm{PH}$ values and increase of conductivities of water outlets, compared with the water inlets, are mainly due to the higher outlet water temperature. The water chemical analysis tests, including the sulfate and inorganic carbon, also show the same results for water inlet and outlet, which all proved the recovered water from TMC unit maintains almost the same quality as water inlet. Therefore, water coming out from TMC/stage 1 can meet the quality requirements of boiler makeup water, and water from TMC/stage 2 will meet the quality requirements of cooling tower makeup water.

The above tests were using flue gas from natural gas combustion, to simulate the flue gas of a coal power plant by injecting $\mathrm{SO}_{2}$ into this natural gas flue gas stream to achieve a 220250 ppm SO 2 concentration in the flue gas. The water quality was tested again for this flue gas condition, and the results, including $\mathrm{PH}$ value, solution conductivity, and water chemical analysis, are listed in Table 4-2. The results show the PH values for the outlet streams are slightly lower than the inlets, because a small amount of $\mathrm{SO}_{2}$ dissolved into the condensate and are carried into the main stream. Also the water conductivity of stage 1 outlet is slightly higher than its inlet due to $\mathrm{SO}_{2}$ in the flue increases the ions of the stage 1 water stream. The water chemical analysis, including the sulfate and inorganic carbon, show similar results for water inlet and outlet for both stages. The water quality tests with $\mathrm{SO}_{2}$ injection have showed the $\mathrm{SO}_{2}$ 250 ppm concentration in the flue gas presented minimum impact on the TMC water quality. 
Table 4-1: Water Quality Testing without SO2

\begin{tabular}{|l|c|c|c|c|}
\hline & PH & $\begin{array}{c}\text { Conductivity } \\
\mu \mathrm{s} / \mathrm{m}\end{array}$ & $\begin{array}{c}\text { Sulfate } \\
\mathrm{mg} / \mathrm{l}\end{array}$ & $\begin{array}{c}\text { Total Inorganic Carbon } \\
\mathrm{mg} / \mathrm{l}\end{array}$ \\
\hline Stage 1 IN & 7.74 & 266 & 27.2 & 23 \\
\hline Stage 1 OUT & 7.36 & 284 & 27.5 & 27 \\
\hline Stage 2 IN & 7.31 & 274 & 26.2 & 27 \\
\hline Stage 2 OUT & 7.16 & 279 & 27.3 & 27 \\
\hline
\end{tabular}

Table 4-2: Water Quality Testing with 250ppm SO2

\begin{tabular}{|l|c|c|c|c|}
\hline & PH & $\begin{array}{c}\text { Conductivity } \\
\mu \mathrm{s} / \mathrm{m}\end{array}$ & $\begin{array}{c}\text { Sulfate } \\
\mathrm{mg} / \mathrm{l}\end{array}$ & $\begin{array}{c}\text { Total Inorganic Carbon } \\
\mathrm{mg} / \mathrm{l}\end{array}$ \\
\hline Stage 1 IN & 7.72 & 218 & 26.1 & 28 \\
\hline Stage 1 OUT & 7.17 & 283 & 26.8 & 25 \\
\hline Stage 2 IN & 7.39 & 262 & 26.0 & 27 \\
\hline Stage 2 OUT & 7.03 & 280 & 28.3 & 26 \\
\hline
\end{tabular}

Besides the recovered water quality from the $\mathrm{TMC}$, we also investigated the $\mathrm{SO}_{2}$ impact on the TMC long term heat and water recovery performance. During the 50 hour continuous test with a 250 ppm SO2 concentration in flue gas, the TMC performance data was recorded and analyzed with varied flue gas and water inlet parameters, such as inlet flue moisture content, water inlet flow rates and temperatures for both stage 1 and stage 2 . Tests had been conducted to test the TMC performance before the $\mathrm{SO}_{2}$ injection, during the $\mathrm{SO}_{2}$ injection, and after the SO2 injection and purging. Figures 4-29 and 4-30 show the two-stage TMC water transfer rates for stage 1, stage 2, and overall TMC at different stage 1 and stage 2 average cooling water temperatures, before, during and after $\mathrm{SO}_{2}$ injection. The $\mathrm{TMC}$ performances are almost the same for stage 1 for different cooling water conditions, and the water transfer rates are slightly higher, during and after $\mathrm{SO}_{2}$ injection for stage 2 , at higher water temperature range.

Figures 4-31 and 4-32 show the two-stage TMC water transfer rates for stage 1, stage 2, and overall at different stage 1 and stage 2 average cooling water temperatures for higher inlet flue gas dew point at $153^{\circ} \mathrm{F}$, before and after $\mathrm{SO}_{2}$ injection. Those results show the stage 1 and stage 2 TMC performance are the same for the higher moisture flue gas before and after the $\mathrm{SO} 2$ injection. 




Figure 4-29: Stage 1 water average temperature effect before and after $\mathrm{SO}_{2}$ injection



Figure 4-30: Stage 2 water average temperature effect before and after $\mathrm{SO}_{2}$ injection 


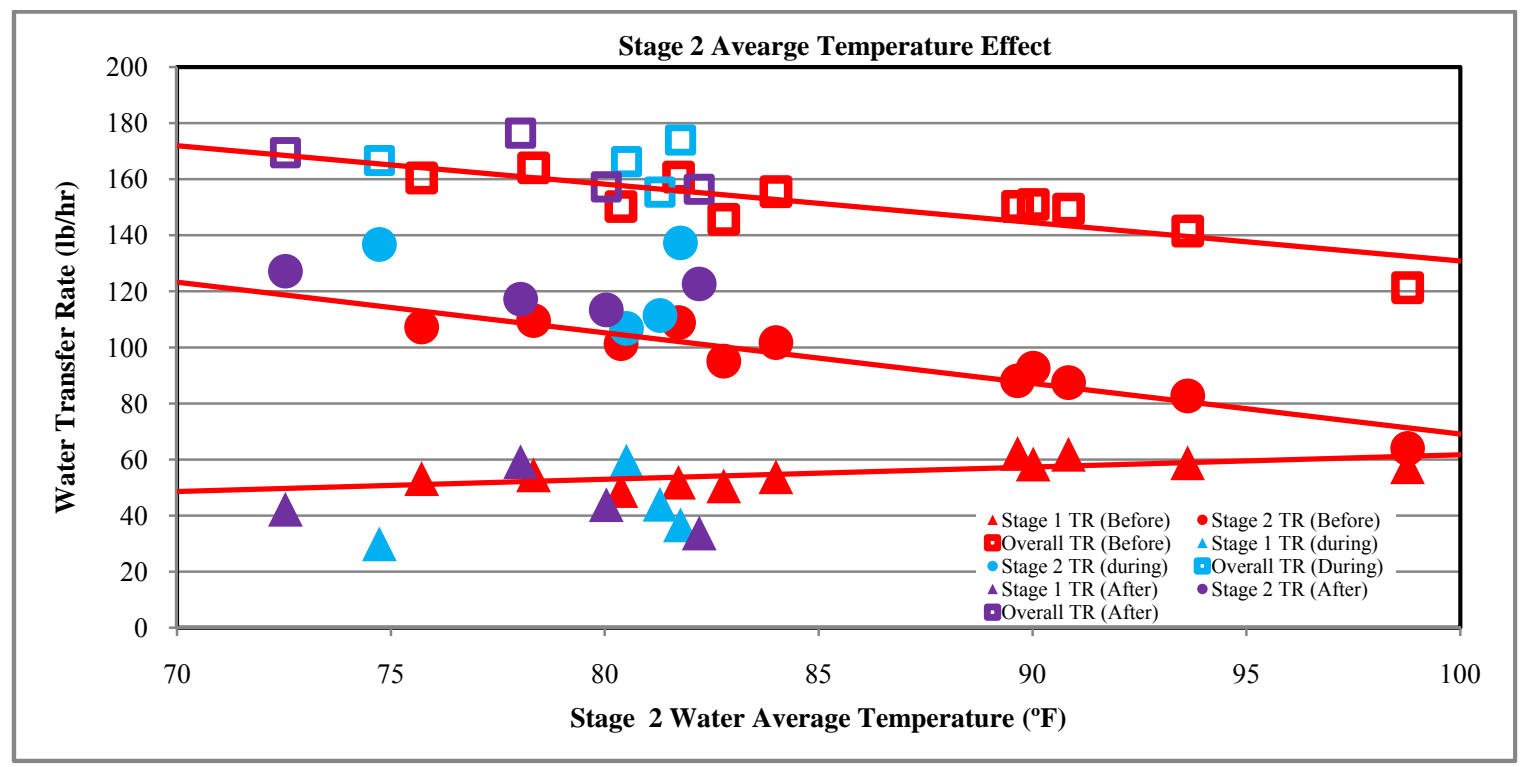

Figure 4-31: Stage 1 water average temperature effect before and after $\mathrm{SO}_{2}$ injection at high moisture content

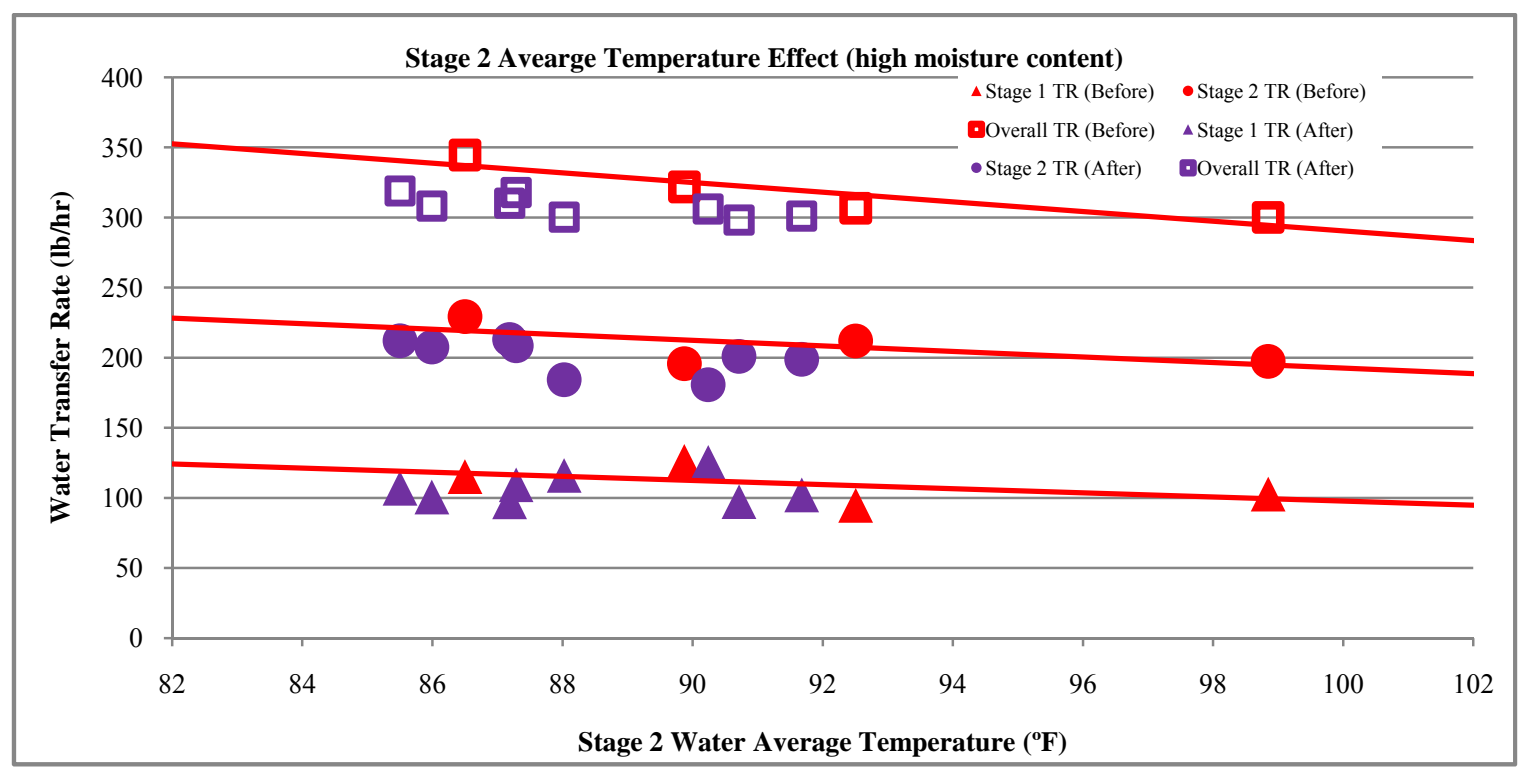

Figure 4-32: Stage 2 water average temperature effect before and after $\mathrm{SO}_{2}$ injection at high moisture content 


\section{CHAPTER 5 \\ Pilot-Scale TMC Field Testing at a Power Plant}

\section{Introduction}

The pilot-scale TMC waste heat and water recovery testing system was installed in a coal-fired power plant for real world condition testing after our laboratory investigation. A slip stream of flue gas from the plant flue gas duct was introduced into the TMC, and two separate TMC cooling streams were arranged, with their flow rates adjusted to match in proportion with the power plant boiler operating conditions, to enhance the TMC water and heat recovery performance for each stages. Recovered water quality was analyzed separately from the two water outlet streams. Energy recovery and water recovery by the TMC were analyzed.

After the initial TMC parameter performance at the host site, a five-week around-theclock TMC continuous field testing was performed to verify the TMC system longer term performance and operation reliability.

\section{TMC Field Test System Setup}

A power plant at Baltimore agreed to host the field testing, and a slip stream of flue gas from its Unit \#1 coal-fired boiler was used. Figure 5-1 shows the picture of the testing system before shipment and the schematic we envisioned about the installation. Figure 5-2 shows the location we have agreed upon to install the test unit, which is at floor level before the ID fan of the Unit \#1 flue gas ductwork. Two 10" flue gas ports with isolation valves was opened by the host, our test system was mounted on a skid for quick field installation. Figure 5-3 shows two pictures of the test system in the field. 


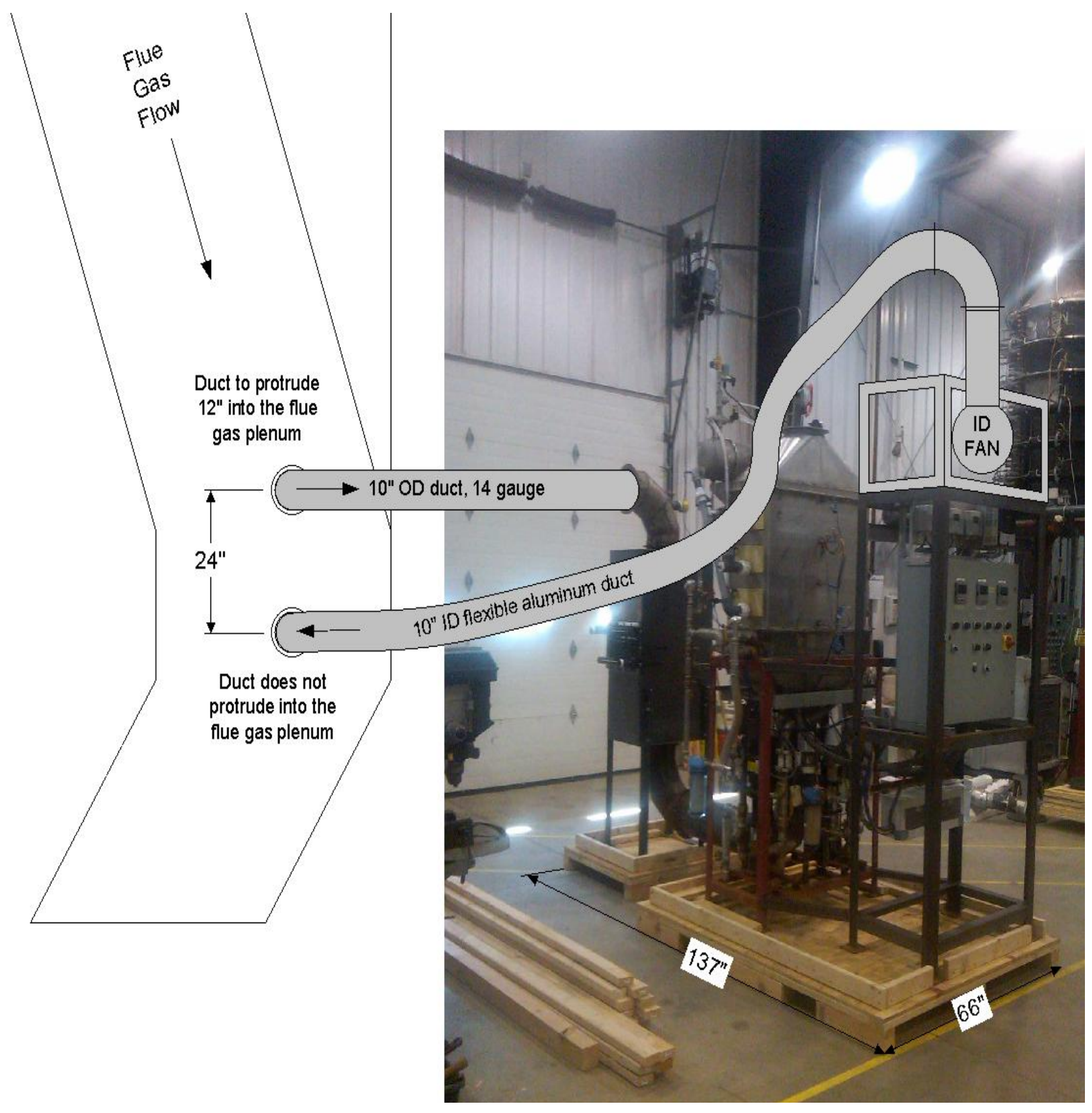

Figure 5-1: The test system with envisioned ductwork hookup to plant ductwork 




Figure 5-2: picture of the test system installation location before installation 


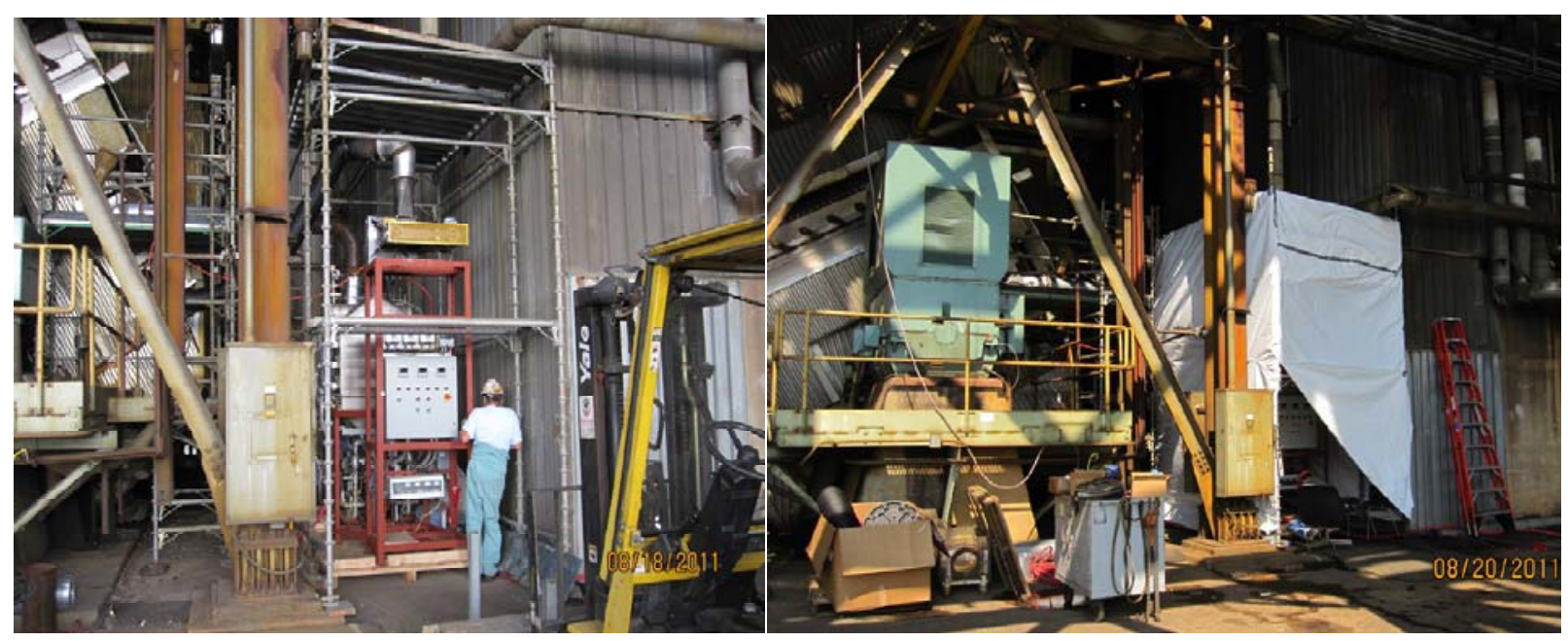

Figure 5-3: Pilot unit in the field: left shows in installation, right shows in testing with a tent

\section{Field Test Results}

1. TMC real world performance and long term operation

The long term TMC power plant flue gas slip stream test has been carried out at a host power plant in Baltimore area for 31 days around-the-clock, from Aug 172011 to Sep 16, 2011. The whole pilot test system was able to run automatically with only adjustment needs for different parameter testing.

Flue gas flow rates flowing through the pilot TMC unit was from 24,000 SCFH to 40,000 SCFH, by adjusting the TMC system ID fan speed and with varied plant boiler operation conditions. Typical flue gas component concentrations in volume are listed at Table 5-1

Table 5-1: Host site flue gas components by measurement

\begin{tabular}{|l|l|}
\hline Component & Concentration (in volume) \\
\hline $\mathrm{CO} 2$ & $12.4 \%$ \\
\hline $\mathrm{H} 2 \mathrm{O}$ & $10.7 \%$ \\
\hline $\mathrm{N} 2$ & $71.9 \%$ \\
\hline $\mathrm{SO} 2$ & $0.043 \%$ \\
\hline $\mathrm{CO} 2$ & $5.0 \%$ \\
\hline
\end{tabular}


The flue gas inlet dew point was $118^{\circ} \mathrm{F}$ based on the water vapor volume concentration, and measured flue gas inlet dew points were in the range from $118^{\circ} \mathrm{F}$ to $122^{\circ} \mathrm{F}$. The flue gas inlet temperatures were from $150^{\circ} \mathrm{F}$ to $190^{\circ} \mathrm{F}$ after passing through a flue gas heat exchanger.

For the long term field test, TMC cooling water flow rates were set at 7 GPM for TMC stage 1 and $10 \mathrm{GPM}$ for stage 2 . The stage 1 inlet water temperatures were from $80^{\circ} \mathrm{F}$ to $100^{\circ} \mathrm{F}$, and stage 2 inlet water temperatures were from $78^{\circ} \mathrm{F}$ to $85^{\circ} \mathrm{F}$.

Figures 5-4 to 5-6 show the TMC performance over the whole long term field test period. Results show the TMC pilot unit can achieve relatively stable performance for the five weeks real world field test, considering the plant boiler had to follow the load demand that caused flue gas parameter changes beyond our control.

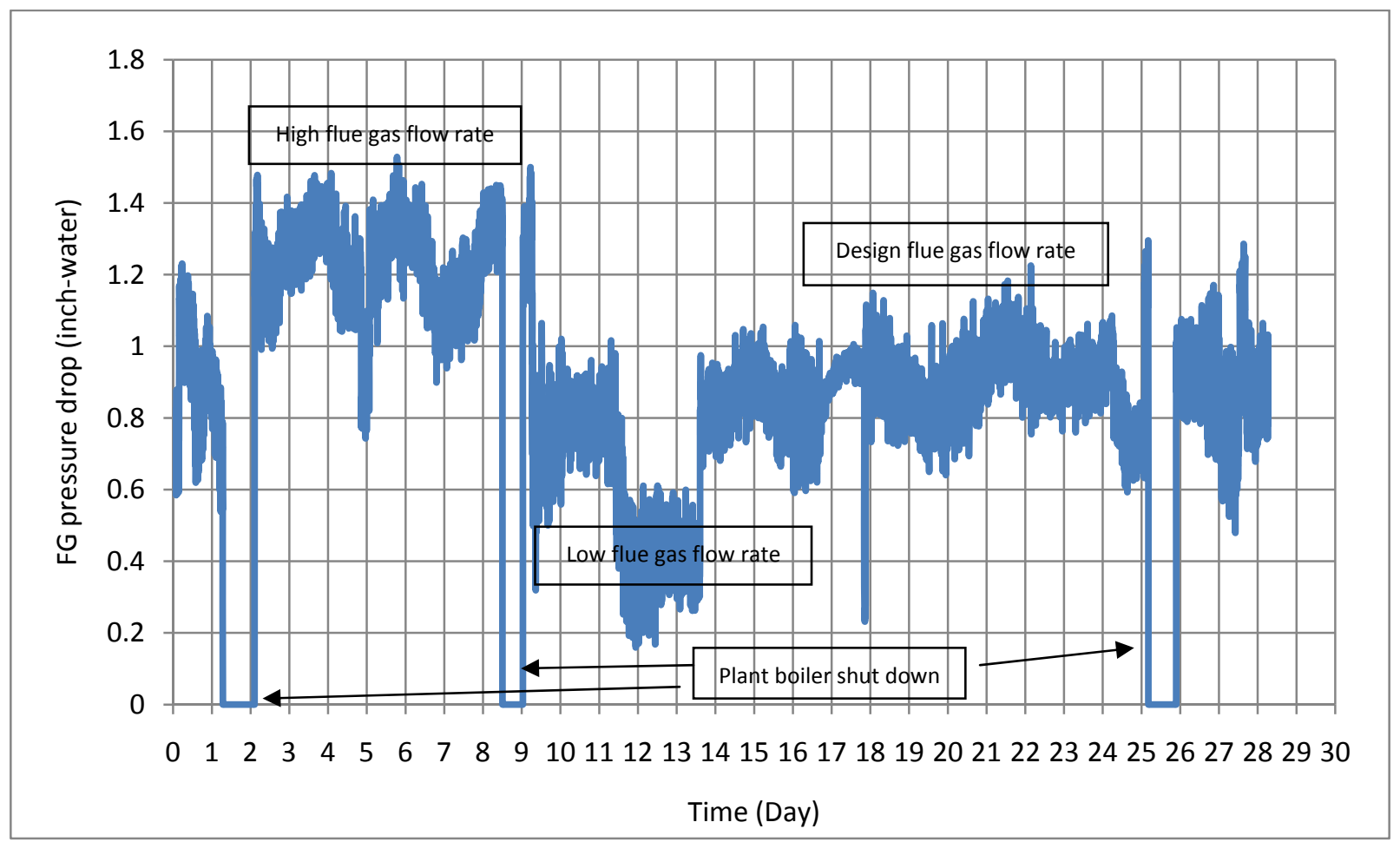

Figure 5-4: Flue gas pressure drop through the pilot unit for the whole long term test period 


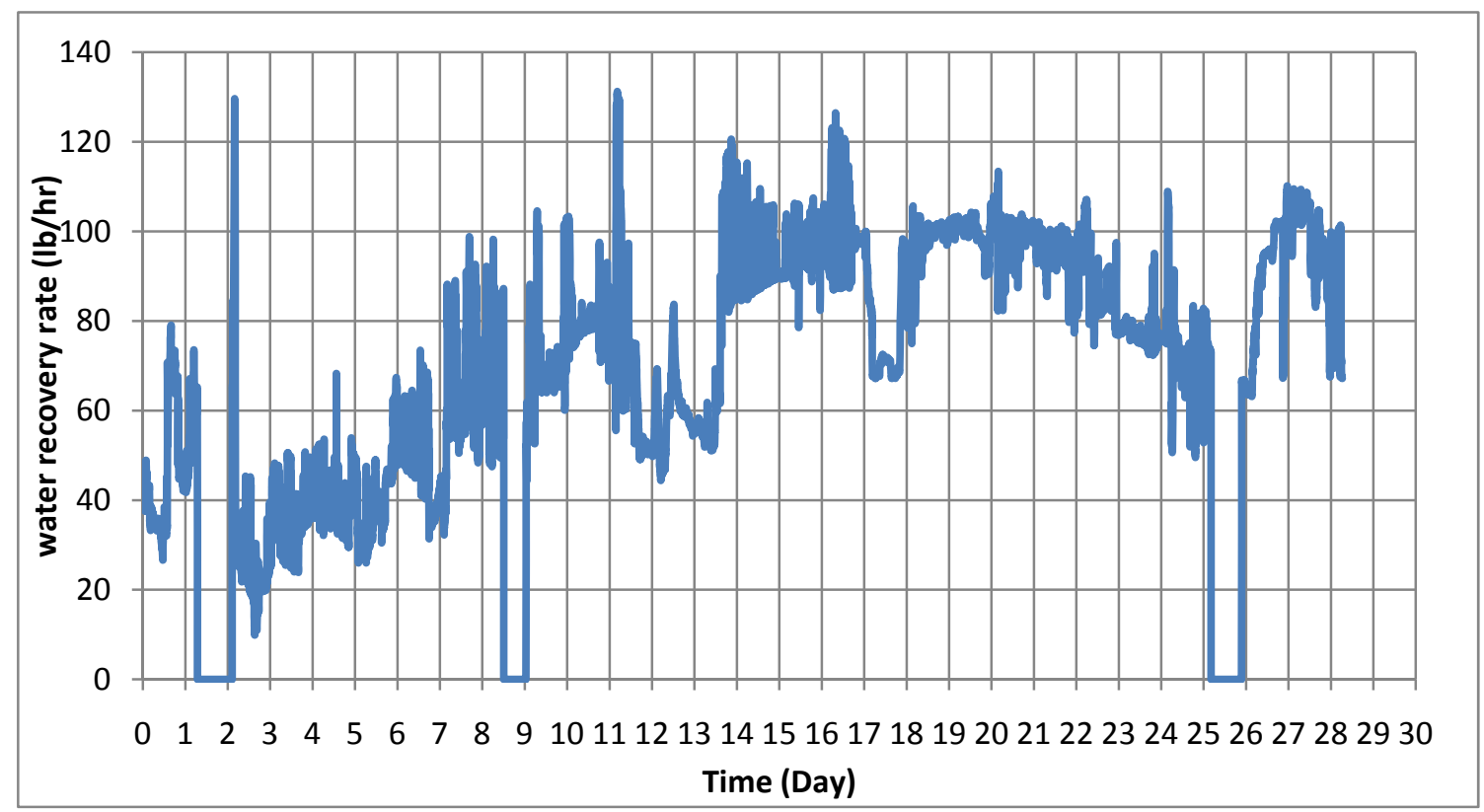

Figure 5-5: The pilot unit overall water recovery rate for the long term test period

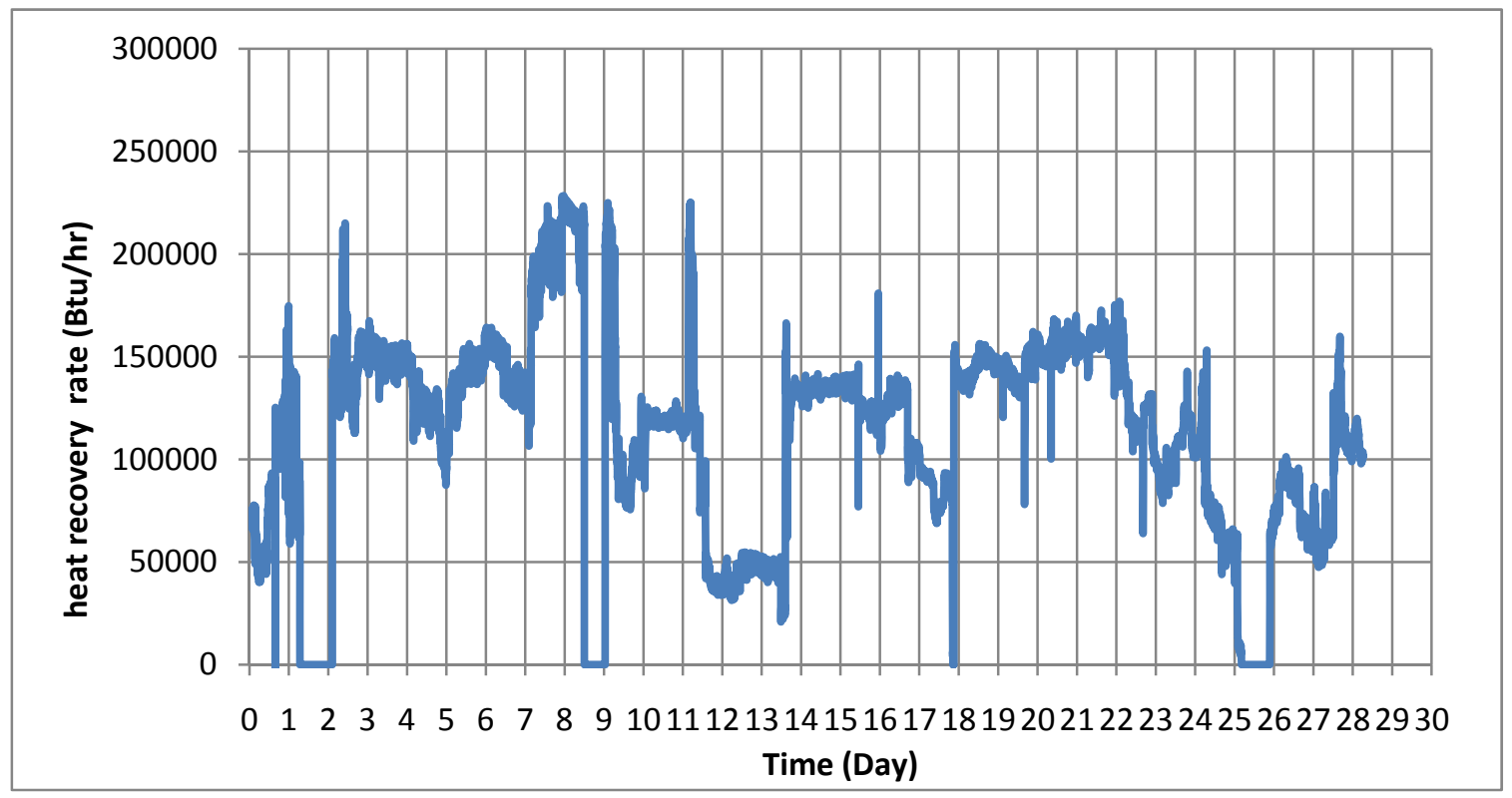

Figure 5-6: the pilot unit overall heat recovery rate for the long term test period

2. Water quality test

The water quality flowing in and out of the two-stage TMC unit were sampled and analyzed. Sulfate and inorganic carbon measurements show the actual measurable sulfur and carbon dioxide are minimum and there were not much changes before and after the TMC, 
which means minimum contamination passing through the TMC membrane. PH value stays the same for the water inlet and outlet, the water sample chemical analysis also confirmed minimum dissolved acid gases passing through, which should have affected the PH values if there were a relatively large amount passed through the membrane.

Table 5-2 Water Chemical Analysis

\begin{tabular}{|c|c|c|c|c|}
\hline $\begin{array}{c}\text { Sample } \\
\text { Number }\end{array}$ & Sample Description & $\underline{\text { Sulfate, } \mathrm{mg} / \mathrm{l}}$ & $\frac{\text { Total Inorganic }}{\text { Carbon, } \mathrm{mg} / \mathrm{l}}$ & $\underline{\mathrm{pH}}$ \\
\hline $111607-001$ & Fresh water supply & 17.8 & 24 & 6 \\
\hline $111607-002$ & Stage 1 outlet & 15.4 & 23 & 6 \\
\hline $111607-003$ & Stage 2 outlet & 50.3 & 16 & 6 \\
\hline
\end{tabular}

3. TMC membrane fouling test

During the long term field test period, the membrane transport rates at the beginning and at the end were compared to check any membrane fouling effect which can significantly reduce the membrane transport performance. Figure 5-7 shows minimum performance difference between the two results, which verified there was minimum membrane fouling during this testing period.

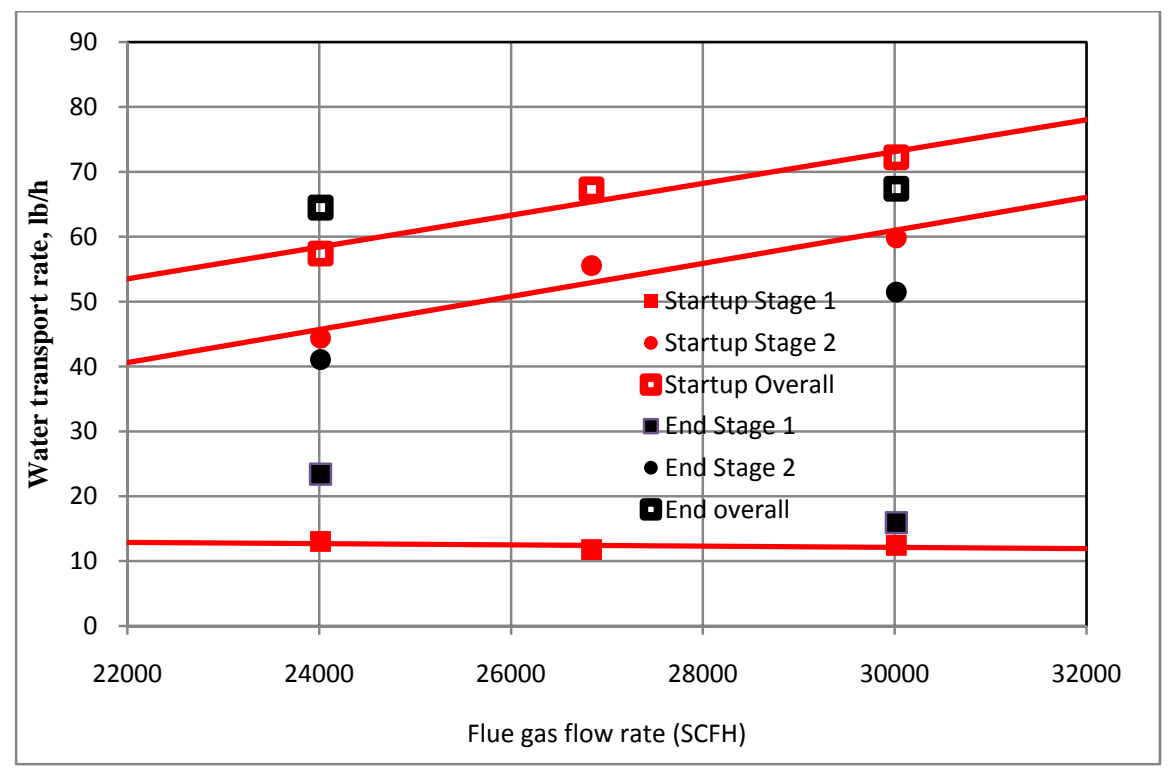

Figure 5-7: Water transport rates at the beginning and at the end of the long term field test 


\section{Comparison of TMC field test and laboratory test results}

TMC performances were compared for the pilot unit in the field test and at GTI laboratory test (3-million-Btu/h natural gas-fired boiler) at about the same flue gas flow rate, $30,000 \mathrm{SCFH}$. The flue gas inlet dew point was around $118^{\circ} \mathrm{F}$ for the field test, and $133^{\circ} \mathrm{F}$ for laboratory test. Figure 6 compares the water and heat recovery rates for lab test and field test. The lower water and heat recovery rates for field test was mainly due to lower flue gas inlet dew point and thus less vapor latent heat available for the flue gas in the field.


Figure 5-7: Laboratory test and field test TMC performance comparison

\section{Summary}

The long term field test showed that the TMC pilot unit can achieve and maintain stable performance in a real coal-fired flue gas condition, and recover significant amount of waste heat and moisture. The TMC performance was strongly dependent on moisture content in the flue gases, and better optimization of the membrane surface area and cooling water flow rate to match flue gas conditions can help the TMC achieving its best performance. 


\section{CHAPTER 6 \\ TMC Waste heat and Water Recovery System Scale-Up Design Investigation}

\section{Scale up investigation for a 550MW power plant}

1. Basic information about a $550 \mathrm{MW}$ power plant for the scale up

For one typical 550MW coal-fired power plant, we have gathered related data for the TMC scale-up investigation. The boiler flue gas duct size at the flue gas inlet to the stack is $\mathbf{1 7 . 2}$ $\mathrm{ft}$ by $23.4 \mathrm{ft}$., and there are two inlets total. The flue gas density is at $0.87 \mathrm{~kg} / \mathrm{m} 3$ with $285^{\circ} \mathrm{F}$. The calculated gas velocity is about $35.5 \mathrm{ft} / \mathrm{s}$. More detailed information is listed in the table below.

Table 6-1: A 550 MW boiler operating condition

\begin{tabular}{|c|c|c|c|c|c|}
\hline Load & $\begin{array}{c}\text { Feed water } \\
\text { Flow }\end{array}$ & Flue Gas Flow & $\begin{array}{c}\text { AH Gas Inlet } \\
\text { Temp }\end{array}$ & $\begin{array}{c}\text { AH Gas } \\
\text { Outlet Temp }\end{array}$ & Stack Temp \\
\hline MW & $\mathrm{kpph}$ & $\mathrm{kpph}$ & ${ }^{\circ} \mathrm{F}$ & ${ }^{\circ} \mathrm{F}$ & ${ }^{\circ} \mathrm{F}$ \\
\hline 550 & 3,655 & 5,608 & 721 & 285 & 287 \\
\hline
\end{tabular}

2. TMC overall dimension, membrane surface area, and arrangement

Based on our pilot-scale TMC unit power plant slip stream testing results in this project, the total membrane surface area calculated for this 550MW unit is: $2,172 \mathrm{~m}^{2}$, which will need 300 TMC modules with 500 tubes in each of it. The 500 tube TMC module outside dimension is $4^{\prime}$ long by $2^{\prime}$ wide by $1.5^{\prime}$ high.

Based on the dimensions of the plant flue gas ducts and the modules, the modules can be arranged as follow: 4 modules in the ductwork depth direction, 11 modules in the ductwork width direction, and 3 modules along the flue gas flow direction. Therefore the total TMC module numbers for the two ductworks will be: $4 \times 11 \times 3$ layers $\times 2$ ducts $=264$ modules. This is a little bit less than the $\mathbf{3 0 0}$ modules of the initial estimate, but should be enough to achieve good performance based on our past experience. Figure 6-1 shows how the modules with 
proper housing can be fitted into the power plant flue gas ductwork, only one of the ductwork is shown.



Figure 6-1: TMC module arrangement in one of the $550 \mathrm{MW}$ unit flue gas ductwork

3. Flue gas side pressure drop, temperature for water and flue gas

Considering typical pressure head available from exiting power plant draft fan, less than 1" $\mathrm{H} 2 \mathrm{O}$ additional is usually available without changing the fan impellers. Therefore, our TMC unit is designed to have less than $0.8^{\prime \prime} \mathrm{H} 2 \mathrm{O}$ flue gas side pressure drop, which is also consistence with our current pilot unit design, which has less than 1" H2O pressure drop. Flue gas temperature leaving from the TMC is designed at about $110^{\circ} \mathrm{F}$ with $105^{\circ} \mathrm{F}$ dew point. Water temperature leaving the TMC will be $155^{\circ} \mathrm{F}$ for stage 1 , and $100^{\circ} \mathrm{F}$ for stage 2 .

4. Integration with the plant loops-water and flue gas

The integration concept is similar to what we have laid out before as shown in the following schematic in Figure 6-2: 
On the water side, the first stage TMC inlet water will be obtained from steam condensate from the condenser. Its outlet water with recovered water vapor and associated latent heat from flue gas will go to the deaerator for boiler water makeup. The second stage TMC inlet water will be from part of the condenser cooling water stream. This outlet water will go back to the cooling water stream with extra recovered water from the flue gas. On the flue gas side, the TMC is situated between the FGD unit and the stack. The impact of this water on the overall plant water conditioning requirements has been studied, as have been proved our water quality testing in both laboratory and field tests. The recovered water quality is very good because of the high selectivity of the membrane under capillary condensation operation, so no additional water treatment is needed.

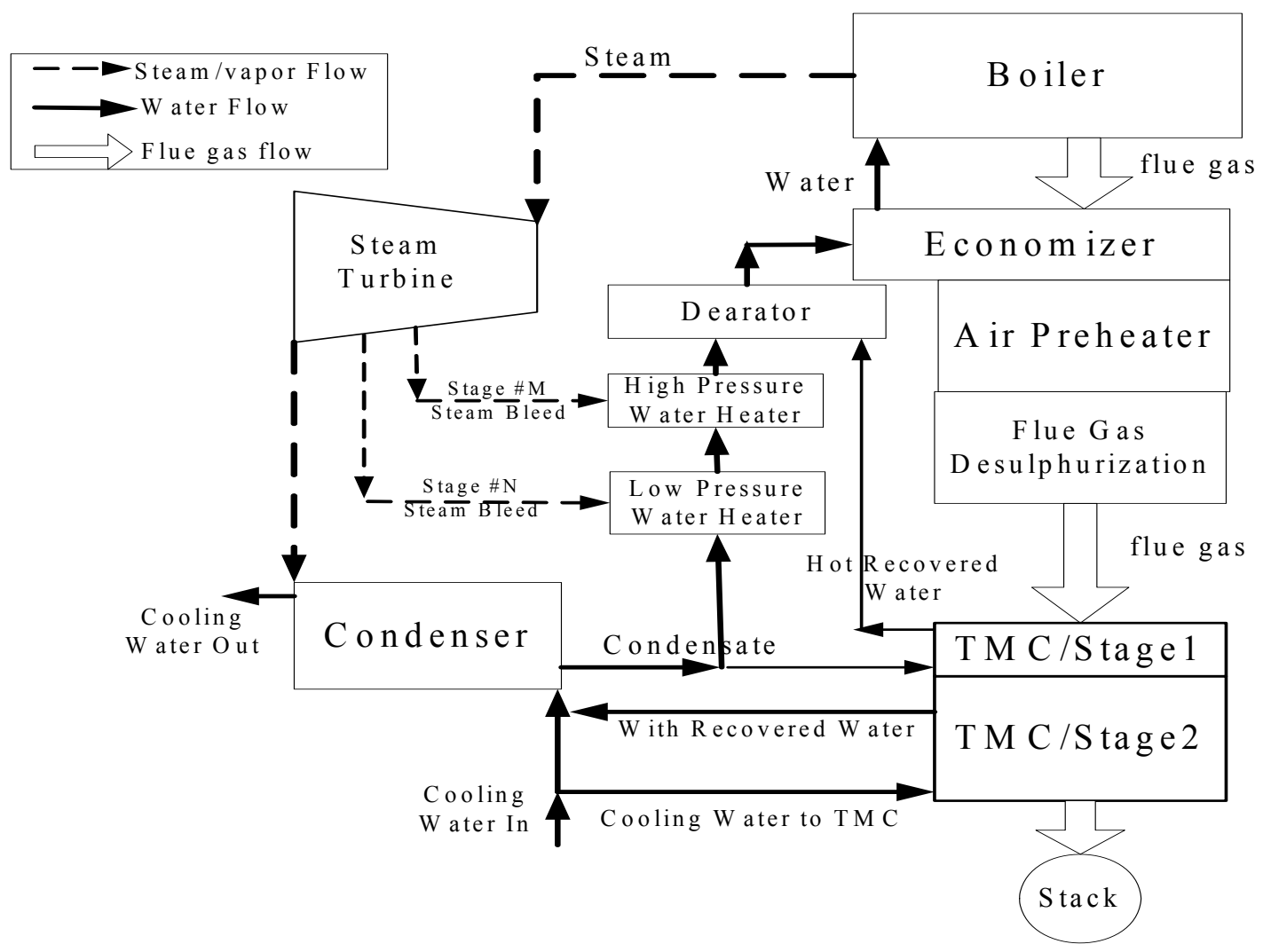

Figure 6-2: Power Plant Flue Gas Water Recovery with a Two-Stage TMC 


\section{CHAPTER 7 \\ Technology Application and Commercialization}

The TMC technology was developed initially for natural gas boiler flue gas heat and water recovery. The present project has developed a new design to expand its use for power plant flue gas applications. This technology can recover high-purity water from flue gas and reuse it as boiler feed water. It is expected that the recovered water will exceed the boiler fresh makeup water requirement, and so it can be used for other purposes such as cooling tower water makeup, FGD water makeup, and/or other plant uses. When this high-purity mineral-free water is used for cooling tower water makeup, it also reduces the water blowdown amount from the cooling water stream, which may account for up to $10 \%$ of its total makeup water. Not only does this technology save water and water treatment cost, it can also improve the energy efficiency of the power plant by replacing the cold makeup water with this preheated water. It also minimizes or even eliminates reheating the flue gas after the FGD process. The improved boiler efficiency sends less emission into the atmosphere and reduces solid waste.

The economic benefits of water vapor removal from flue gas are substantial. Typically it reduces the flue gas dew point from $140^{\circ} \mathrm{F}$ to $100^{\circ} \mathrm{F}$, which corresponds to recovering of $84 \mathrm{lb} / \mathrm{h}$ water per 1 million Btu/h firing rate. For the year 2000, the net U.S. electric power generation was 3,802 billion kWh, of which coal-fired generation was 1,966 billion kWh, and natural gasfired generation was another 613 billion $\mathrm{kWh}^{1}$. Because this water recovery technology could be used for both coal- and gas-fired power plants, up to 2,579 billion kWh of capacity could be impacted by this technology. Assuming $35 \%$ baseline fuel-to-electricity efficiency, the total firing rate is estimated at 25 trillion Btu/h. The corresponding total water saving, if this technology were applied to all U.S. power generation, would be 8.3 billion tons per year. At a typical water price of $\$ 0.52 /$ ton $^{2}$, the total annual U.S. cost saving in water alone would be $\$ 4.3$

\footnotetext{
1 Electric Power Annual 2000, Volume II.

2 http://www.watertechonline.com
} 
billion/year. In addition to the cost savings from reduced water requirement, the use of TMC can increase boiler thermal efficiency as described above by recovering the vapor latent heat.

\section{TMC technology application and economic analysis}

The following are some case analyses on how to use the recovered water from the flue gas system, and potential benefit analysis, which mainly covers three areas:

- Boiler feedwater (BFW) make up water

- FGD make up water

- Water usage for RRI/SNCR system to dilute urea solution prior to injection

Calculation for boiler feedwater (BFW) and FGD makeup water saving

Assumption:

Demineralized water price $=\$ 5.25 / 1000$-gal

Boiler feedwater (BFW) make up water usually requires $\sim 10$ gals/MWh, data from Reference $^{3}$, as shown in Figure 7-1.

3 DOE/NETL-402/080108. "Water Requirements for Existing and Emerging Thermoelectric Plant Technologies." August 2008 (April2009 Revision) 


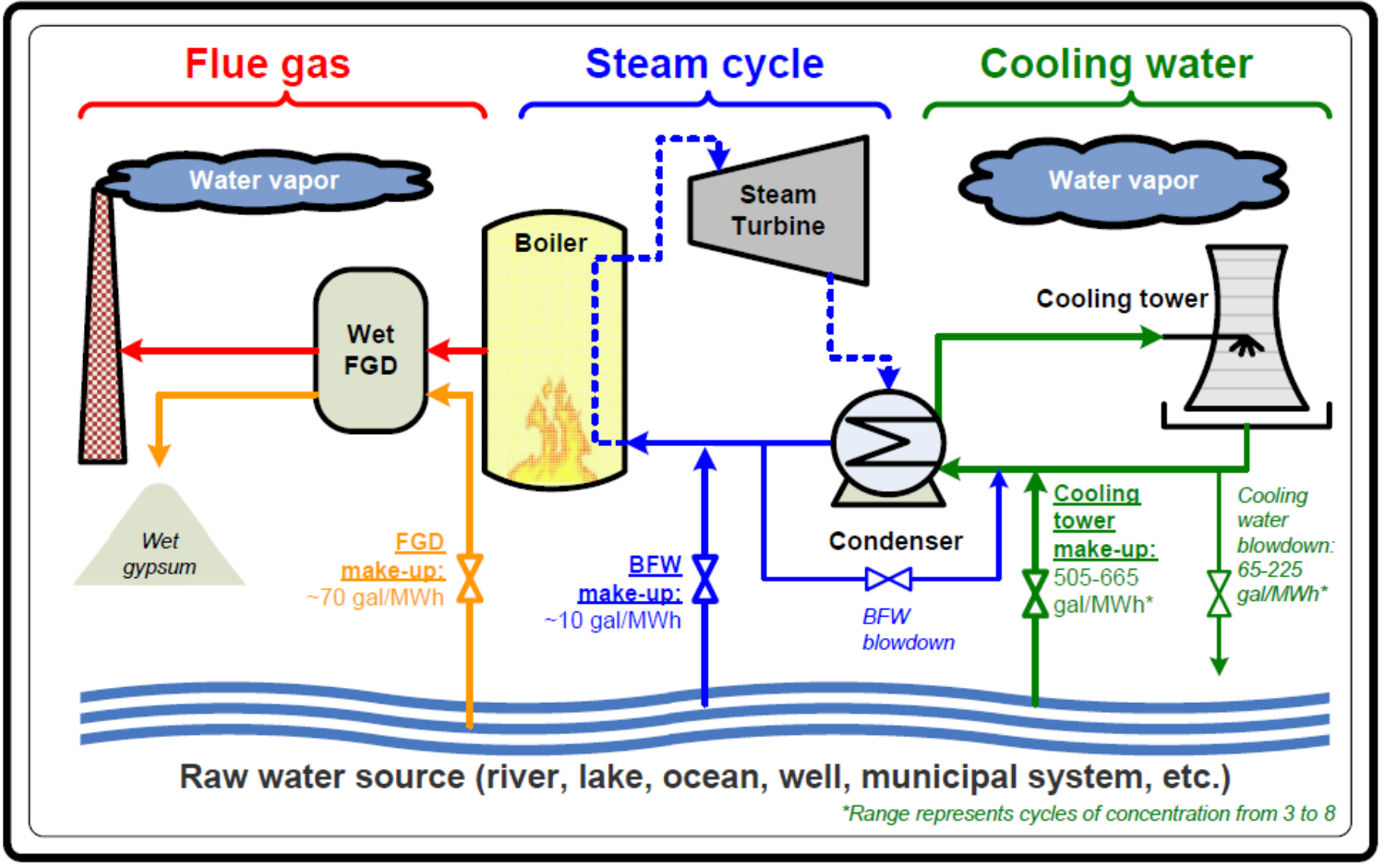

Figure 7-1: Water usage in a coal fired power plant (source: NETL)

Table 7-1 shows the calculation of FGD make up water for three different size units with bituminous and PRB coal.

Table 7-1: FGD make up water calculation

\begin{tabular}{|l|r|r|r|r|l|}
\hline FGD make up water & Case A-1 & Case A-2 & \multicolumn{1}{|l|}{ Case B } & \multicolumn{1}{l|}{ Case C } & \\
\hline Gross Generation & 550 & 550 & 200 & 50 & $\mathrm{MW}$ \\
\hline Coal Type & Bituminous & PRB & PRB & PRB & \\
\hline S content in coal & 3.20 & 0.40 & 0.40 & 0.40 & $\%$ \\
\hline $\mathrm{SO}_{2}$ moles & 0.48 & 0.08 & 0.03 & 0.01 & $\mathrm{klbmole} / \mathrm{h}$ \\
\hline Limestone & 47.63 & 8.25 & 3.00 & 0.75 & $\mathrm{klb} / \mathrm{h}$ \\
\hline \% solid for limestone spray & 15.00 & 15.0 & 15.0 & 15.0 & $\%$ \\
\hline Wet FGD make up water & 317.57 & 55.00 & 20.00 & 5.00 & $\mathrm{klb} / \mathrm{h}$ \\
\hline Water density at 100 F & 8.288 & 8.288 & 8.288 & 8.288 & $\mathrm{Lb} / \mathrm{gal}$ \\
\hline Wet FGD make up water & 38,300 & 6,600 & 2,400 & 600 & $\mathrm{gph}$ \\
\hline Wet FGD make up water & 69.6 & 12.0 & 12.0 & 12.0 & $\mathrm{gal} / \mathrm{MWh}$ \\
\hline
\end{tabular}

1. Case A-1: $550 \mathrm{MW}$ unit - bituminous coal

Annual capacity $=550 \mathrm{MW} \times 8,760$ hours $\times 80 \%=3,854,400 \mathrm{MW} /$ year 
FGD makeup water for bituminous $=70 \mathrm{gal} / \mathrm{MWh}$

Total make up water $=(69+10) \times 3,854,400=304,848,000$ gals $/$ year

$90 \%$ water recovery from flue gas $=274,900,000$ gals $/$ year

Total make water saving $=\$ 5.25 \times 274,900,000 / 1,000=\$ 1,443,200 /$ year

2. Case A-2: $550 \mathrm{MW}$ unit - PRB coal

FGD makeup water for $\mathrm{PRB}=12 \mathrm{gal} / \mathrm{MWh}$

Total make up water $=(12+10) \times 3,854,400=84,797,000$ gals $/$ year

Total make water saving $=\$ 5.25 \times 84,797,000 / 1,000=\$ 445,200 /$ year

3. Case B: $200 \mathrm{MW}$ unit - PRB coal with RRI/SNCR system

Annual capacity $=200 \mathrm{MWh} \times 8,760$ hours $\times 75 \%=1,314,000 \mathrm{MWh} /$ year

Total make up water $=(12+10)$ gals $\times 1,314,000=28,918,000$ gals $/$ year

Total makeup water saving $=\$ 5.25 \times 28,908,000 / 1,000=\$ 151,800 /$ year

4. Case C: $50 \mathrm{MW}$ unit - PRB coal

Annual capacity $=50 \mathrm{MW} \times 8,760 \mathrm{hrs} \times 75 \%=328,500 \mathrm{MW} / \mathrm{year}$

Total make up water $=(12+10)$ gals $\times 328,500=7,227,000$ gals $/$ year

Total makeup water saving $=\$ 5.25 \times 7,227,000 / 1,000=\$ 37,900 /$ year

Calculation for dilution water for RRI/SNCR system

Case B: 200 MW Unit - PRB coal with RRI/SNCR system

Water usage for RRI/SNCR system to dilute urea from $50 \%$ to $5 \%$ urea solution.

Table 7-2: Dilution water calculation

\begin{tabular}{|l|r|l|}
\hline Baseline NOx & 0.35 & $\mathrm{Ib} / \mathrm{MMBtu}$ \\
\hline Baseline Heat Input & $13,797,000$ & $\mathrm{MMBtu} / \mathrm{yr}$ \\
\hline Baseline NOx & $4,829,000$ & $\mathrm{Ib} / \mathrm{yr}$ \\
\hline NSR & 2.50 & \\
\hline Urea 50\% & $15,747,000$ & $\mathrm{Ib} / \mathrm{yr}$ \\
\hline Water needed to dilute to 5\% & $149,597,000$ & $\mathrm{Ib} / \mathrm{yr}$ \\
\hline Water needed to dilute to 5\% & $18,050,000$ & gals/year \\
\hline Water needed to dilute to 5\% & 13.7 & gals/MWh \\
\hline
\end{tabular}

Dilution water for RRI/SNCR saving $=\$ 5.25 \times 18,050,000 / 1,000=\$ 94,000 /$ year 
TMC system may also be used to capture the moisture (fine droplets) in flue gas after the wet scrubber to resolve stack opacity issue for the power plants using wet scrubber to control particulate emission. For example, a $50 \mathrm{MW}$ boiler sometimes have seasonal derates to maintain opacity under control. Avoiding derates provides additional capacity for the plant to generate power. Opacity improvement can recover $\sim 7 \mathrm{MW}$ during seasonal derates from June to September each year.

Calculation for generation recovery of seasonal derates saving:

Case D - 50 MW unit - PRB coal

Number of hours of peak load during the day $=12-16$ hours/day

Generation recovery saving = $7 \mathrm{MW} \times 122$ days $\times 12 \mathrm{hrs}=10,248 \mathrm{MWh}$ saving/year

Power plant price during the day ranges from $\$ 40-200 / M W h$

Assume average power price during the day $=\$ 80 / \mathrm{MWh}$

Generation recovery saving $=\$ 80 \times 10,248 \mathrm{MWh}=\$ 818,900 /$ year

Table 7-3 shows the system cost benefit for three different size units with bituminous and PRB coal.

Table 7-3: TMC system cost benefit analysis

\begin{tabular}{|c|c|c|c|c|c|}
\hline & Case A-1 & Case $A-2$ & Case B & Case C & \\
\hline Gross Generation & 550 & 550 & 200 & 50 & MW \\
\hline Capacity Factor & $80 \%$ & $80 \%$ & $75 \%$ & $75 \%$ & \\
\hline Annual Capacity & $3,854,400$ & $3,854,400$ & $1,314,000$ & 328,500 & MWh/year \\
\hline Coal Type & Bituminous & PRB & PRB & PRB & \\
\hline Moisture in flue gas & $6.36 \%$ & $8.60 \%$ & $8.60 \%$ & $8.60 \%$ & wt \\
\hline Wet FGD make up water & 69.3 & 12.0 & 12.0 & 12.0 & gals/MWh \\
\hline BFW make up water & 10.0 & 10.0 & 10.0 & 10.0 & gals/MWh \\
\hline 90\% TMC water recovery & $274,900,000$ & $367,000,000$ & $121,400,000$ & $30,800,000$ & gals/year \\
\hline FGD make up water & $266,304,000$ & $46,253,000$ & $15,768,000$ & $3,942,000$ & gals/year \\
\hline BFW make up water & $38,544,000$ & $38,544,000$ & $13,140,000$ & $3,285,000$ & gals/year \\
\hline RRI/SNCR dilution water & & & $18,050,000$ & & gals/year \\
\hline Total water saving & $274,900,000$ & $84,797,000$ & $46,958,000$ & $7,227,000$ & gals/year \\
\hline$\%$ flue gas water recovery & $90 \%$ & $21 \%$ & $35 \%$ & $29 \%$ & \\
\hline Saving of water recovery & $\$ 1,443,200$ & $\$ 445,200$ & $\$ 246,500$ & $\$ 37,900$ & $\$ /$ year \\
\hline Generation recovery saving & & & & $\$ 819,800$ & $\$ /$ year \\
\hline Cost of TMC system & $\$ 1,570,000$ & $\$ 1,570,000$ & $\$ 770,000$ & $\$ 260,000$ & $\$$ \\
\hline Payback & 1.09 & 3.53 & 3.12 & 3.30 & years \\
\hline
\end{tabular}


Payback $=$ Total System Cost $/$ Annual benefit saving cost

Installing wet FGD system for bituminous coal provides the fastest payback for 1 year for the TMC system. For PRB coal applications, the payback duration increases to 3.5 year.

\section{TMC technology commercialization path}

The TMC technology has been licensed to Cannon Boiler Works, Inc. (CBW) for industrial boiler application, with the trade name Ultramizer. Media \& Process Technology Inc. (MPT) has provided the key material-ceramic membrane tubes. CBW has established the capability to assemble TMC modules, fabricate the TMC housing, and configure the control system independently. CBW is a well known, trusted supplier of boiler heat recovery devices including economizers, vent condensers, air coolers, after coolers, and other energy efficiency devices. They also have a non-exclusive license from GTI to apply to the market sector beyond boiler applications. For the TMC technology commercial application in power generation market, the following is a path we plan to go:

First, a larger size field demonstration is needed to demonstrate the technology with water integration to the plant. We are in negotiation with South California Gas Company for potential field demonstration for larger size full integration with the plant flue gas and water loops. They have a 50MW power generation unit for testing purpose in California and have shown interest to host the TMC technology demonstration. Second, an equipment supplier, preferably a FGD equipment manufacturer can build the TMC as an add-on for its FGD unit to remove moisture from its flue gas outlet, which is currently the pathway that we think can quickly commercialize the TMC technology for power generation industry. We are actively working with our power generation partners to discuss with potential FGD equipment suppliers. MPT at this stage is still our membrane supplier, and CBW can fabricate the TMC modules for the FGD supplier. Next step will be negotiating a license agreement with the FGD supplier to supply the TMC system to power generation industry. 